University of Redlands

\title{
Evaluating the Presence of the Endocrine Disruptor 4-Nonylphenol in California Glaciers
}

A Major Individual Project submitted in partial satisfaction of the requirements

for the degree of Master of Science in Geographic Information Systems

by

Jonah Lay

Ruijin Ma, Ph.D., Committee Chair

Mark Kumler, Ph.D.

August 2019 

Evaluating the Presence of the Endocrine Disruptor 4-Nonylphenol in California Glaciers

Copyright @ 2019

by

Jonah Lay 

The report of Jonah Lay is approved.

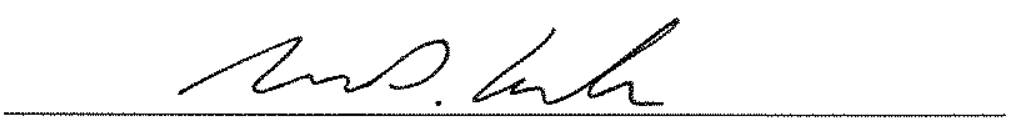

Mark Kumler, Ph.D.

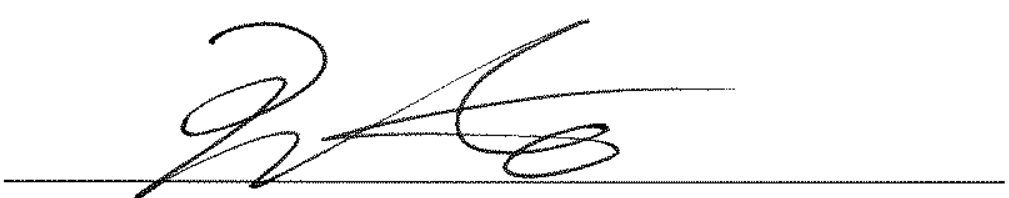

Ruijin Ma, Ph.D., Committee Chair

August 2019 



\section{Acknowledgements}

While the "I" in MIP stands for Individual, the completion of this work would not have been possible without the support of many. I would like to thank Dr. Ruijin Ma for his counsel and critiques throughout this entire process. Because of Dr. Mark Kumler and his expertise, I discovered a love for design and will always remember his guidance. Special thanks to Dr. Douglas Flewelling for constantly challenging me to think outside the box and for providing refreshing humor throughout the program. Sincere appreciation for Dr. Fang Ren's care and work as Department Chair. Special thanks to Andrea Alvarado who labored tirelessly, often behind the scenes. The contributions of Lisa Benvenuti, Nate Strout, and Nicole Kanahele-Stutz were invaluable in providing guidance, technical advice, and editorial feedback.

To my colleagues in Cohort 33.5 through 35.5 and especially 34 - I will always remember our time and treasure the memories we made in Lewis Hall, AKA (Affectionately Known As) The Bunker. We shared many sweat, sweets, and victories.

Working with and for Dr. Rebecca Lyons was a blessing unlooked for but an experience I will always be thankful for. Her energy for discovery was inspiring. I could not have wished for a more challenging, engaging, or rewarding research project - I enjoyed every moment.

I would like to thank Dr. Anthony Corso who introduced GIS at California Baptist University during my final year. His commitment to address the educational need there has brought me where I am today.

The members of Sovereign Grace Orthodox Presbyterian Church were a source of great refreshment and joy. I will always be grateful.

My studies would not have been possible without the support of my family. To my parents and siblings - thank you for all you have been for me.

Most importantly and though done imperfectly, I strove to honor the One who sustained and upheld me in every moment. He who gave me life and the ability to live it was and is the source of my strength. Isaiah 41:10 was a source of great comfort and encouragement amidst the many challenges. The Creator's handiwork will always inspire awe.

Out of whose womb came the ice?

And the hoary frost of heaven, Who hath gendered it?

The waters are hid as with a stone, And the face of the deep is frozen.

Job 38:29-30

Soli Deo Gloria 



\begin{abstract}
Evaluating the Presence of the Endocrine Disruptor 4-Nonylphenol in California Glaciers

by

Jonah Lay

The use of GIS in addressing environmental problems is evident in its application to the Sierra Nevada mountain range glaciers in California. The presence of 4-nonylphenol (4NP) in pesticides used in agriculture has led to its accumulation in California glaciers through onshore wind deposition. As an endocrine disruptor, 4NP poses a threat to human health because it can interrupt and alter physiological processes such as human development and metabolism, and lead to ovarian and prostate cancer at higher concentrations. To evaluate the mass of 4NP in the glacier, GIS analysis is conducted with considerations of wind direction, topographic features, and 4NP concentrations throughout the glacial space. This study investigates the transport, deposition, and presence of 4NP. LiDAR is used to calculate snow depth and glacier volume, and ice core sample data provided 4NP concentrations. The goal of this study is to determine the total mass concentration of 4NP by investigating the influence topographic shielding has on $4 \mathrm{NP}$ concentration gradients in glaciers.
\end{abstract}





\section{Table of Contents}

Chapter 1 - Introduction ................................................................................................ 1

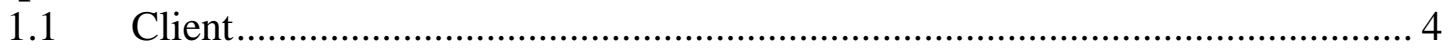

$1.2 \quad$ Problem Statement ............................................................................ 4

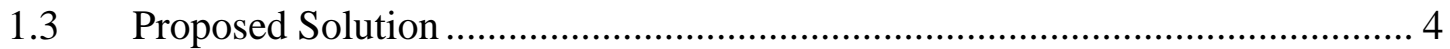

1.3.1 Goals and Objectives .......................................................................... 5

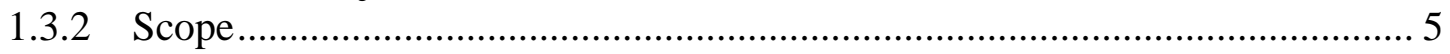

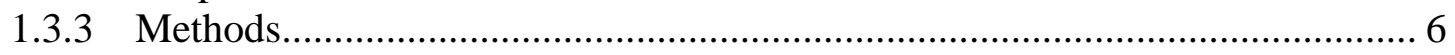

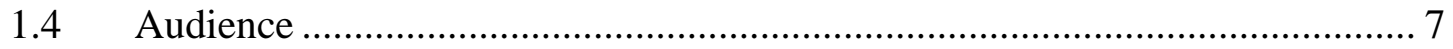

1.5 Overview of the Rest of this Report ......................................................... 7

Chapter 2 - Background and Literature Review ........................................................... 9

$2.14 \mathrm{NP}$ as an Endocrine Disruptor..............................................................

2.2 4NP Transport and Storage .................................................................. 11

2.2.1 4NP's Transport Potential......................................................................... 11

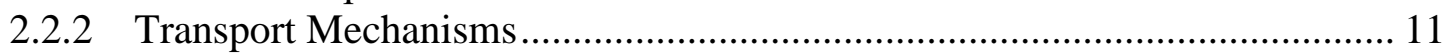

2.2.3 Topographic Shielding .................................................................... 12

2.2.4 Storage and Release ................................................................................ 13

2.3 LiDAR for Snow Depth Measurement …………………………............. 14

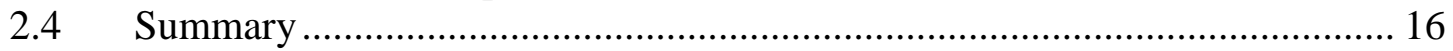

Chapter 3 - Systems Analysis and Design........................................................................ 17

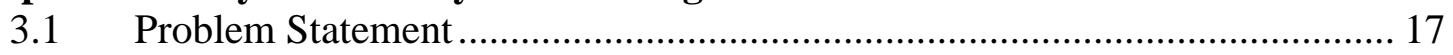

3.2 Requirements Analysis ............................................................................ 17

3.2.1 Functional Requirements ....................................................................... 17

3.2.2 Non-Functional Requirements ............................................................... 19

$3.3 \quad$ System Design ..................................................................................... 19

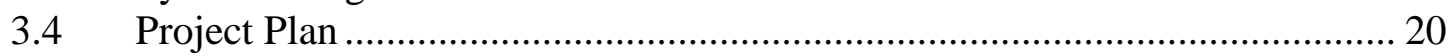

3.4.1 Original Project Plan................................................................................... 20

3.4.2 Project Plan Outcomes ......................................................................... 21

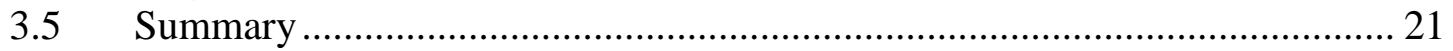

Chapter 4 - Database Design.................................................................................................... 23

4.1 Conceptual Data Model .......................................................................... 23

4.2 Logical Data Model …………………………................................ 24

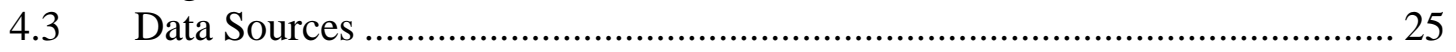

4.4 Data Scrubbing and Loading ……………………................................. 26

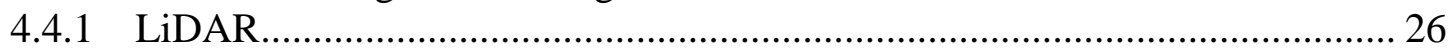

4.4.2 4NP Concentration Sampling Data ............................................................ 26

4.4.3 Topographic Shielding Model Inputs ........................................................... 27

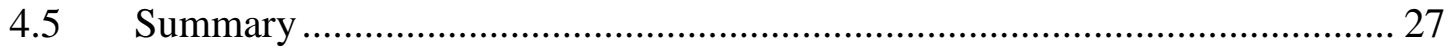

Chapter 5 - Implementation............................................................................................. 29

$5.1 \quad$ Calculating Snow Volume ...................................................................... 29

5.1.1 LiDAR Data Preparation............................................................................ 30

5.1.2 Snow Volume Calculation ......................................................................... 30

5.2 4NP Concentration Estimation ……………………................................. 31 
5.2.1 Prevailing Wind Direction ...................................................................... 31

5.2.2 Topographic Shielding Index................................................................. 32

5.3 Shielding-based Concentration .................................................................... 33

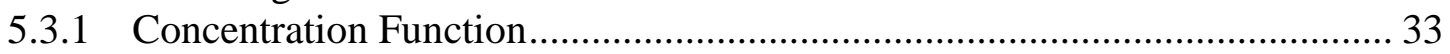

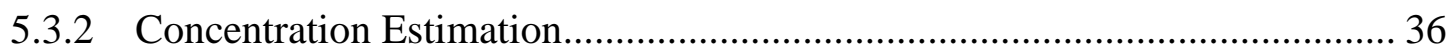

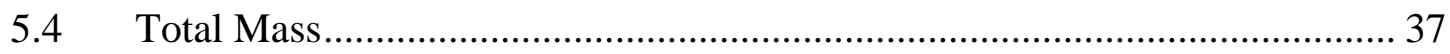

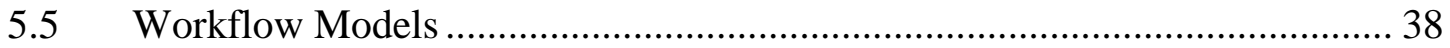

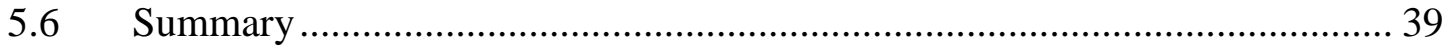

Chapter 6 - Results and Analysis........................................................................................ 41

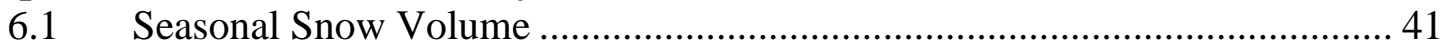

6.1.1 Research and Data Assumptions................................................................. 41

6.1.2 Volume Measurement Results ................................................................... 42

6.2 Calculating Topographic Shielding ………………................................... 44

6.3 Concentration and Shielding Regression Analysis ........................................ 45

6.4 4-Nonylphenol Mass Estimation..................................................................... 47

6.5 Discussion on Study Challenges .................................................................. 48

6.5.1 Unexpected Snow Elevation ......................................................................... 49

6.5.2 Variations in Snow Coverage and Glacial Boundaries .................................... 51

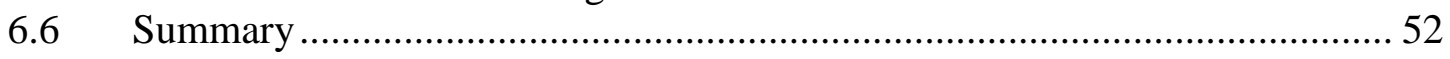

Chapter 7 - Conclusions and Future Work .......................................................... 53

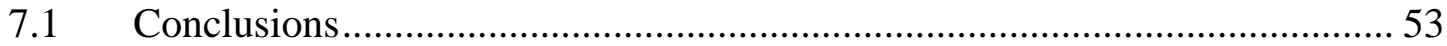

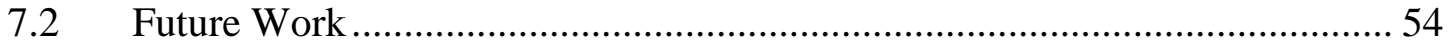

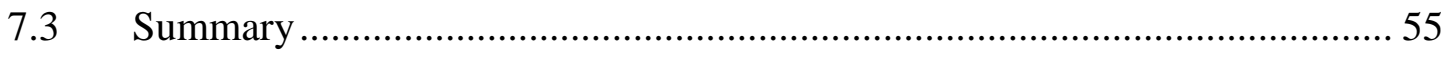

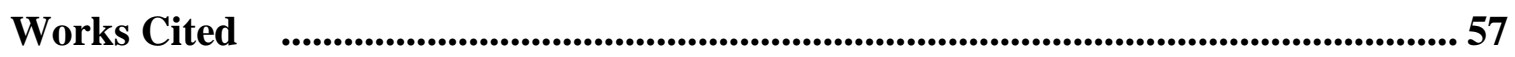

Appendix A. Topographic Shielding Calculator ............................................................ 59

Appendix B. Models and Scripts .......................................................................................... 60 


\section{Table of Figures}

Figure 1-1: NASA satellite image of California (2018) .............................................. 1

Figure 1-2: Middle Palisade Glacier in September 2015. Image: Scott Weavil.............. 2

Figure 1-3: Palisade Glacier and Middle Palisade Glacier locations............................... 3

Figure 1-4: Palisade Glacier in July 2018. Image: Jesse Felten .................................... 3

Figure 2-1: Endocrines mimic natural hormones by binding to cell receptor sites. Image

Copyright: European Parliamentary Research Service ..................................................... 10

Figure 2-2: A comparison between 17-ß-estradiol and bioactive isomer of 4-

nonylphenol (Lyons, et al. 2014)............................................................................ 10

Figure 2-3: Topography shielding influences wind-borne mass deposition................... 12 Figure 2-4: Topographic shielding equation developed by Dr. Rebecca Lyons. Graphic

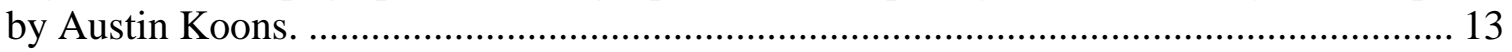

Figure 2-5: Airborne LiDAR. Image: Wayne Wright ................................................... 14

Figure 2-6: NASA Airborne Snow Observatory Snow Measurement Method .............. 15

Figure 3-1: General Schema …………………………...................................... 20

Figure 4-1: Conceptual model of project components and relationships ...................... 24

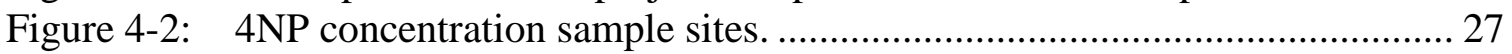

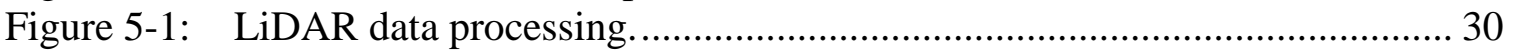

Figure 5-2: Snow volume raster analysis workflow. .................................................. 30

Figure 5-3: Prevailing wind direction in the Middle Palisade Glacier. ......................... 32

Figure 5-4: Topographic Shielding Custom Tool Prompt ............................................... 33

Figure 5-5: Workflow for determining 4NP concentration function............................. 34

Figure 5-6: Concentration sample points in Middle Palisade Glacier ............................ 34

Figure 5-7: Attribute table of Middle Palisade Glacier 4NP concentration samples..... 35

Figure 5-8: Graph of shielding values (x-axis) and concentration (y-axis) of samples. 35

Figure 5-9: Concentration estimation raster workflow................................................. 36

Figure 5-10: Palisade Glacier interpolated concentration estimations............................ 37

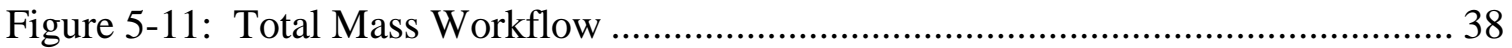

Figure 5-12: 4NP Mass Calculator tool prompt. ……………………………........... 39

Figure 6-1: Surface Difference calculations for areas above (blue), below, (green), and

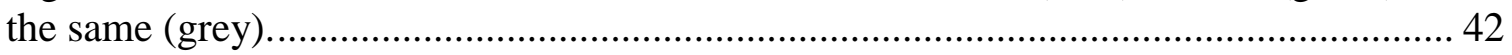

Figure 6-2: Middle Palisade Glacier with topographic shielding points. ...................... 45

Figure 6-3: Middle Palisade 4NP concentration estimations.......................................... 46

Figure 6-4: V-notch in Palisade Glacier ridge ............................................................. 47

Figure 6-5: Middle Palisade Mass Raster ................................................................ 48

Figure 6-6: Palisade Glacier snow-off (yellow) above snow-on (blue)......................... 49

Figure 6-7: Middle Palisade Glacier snow-off (yellow) above snow-on (blue) ............ 50

Figure 6-8: Palisade Glacier terminus point clouds: Snow-Off (left) and Snow-On

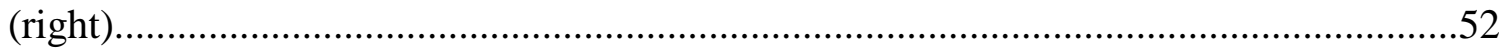

Figure 6-9: Palisade Glacier in October 2018 (left) and LiDAR point cloud datasets 2014 (brown) and 2018 (blue). Image reproduced with permission, Dale Matson.......... 52

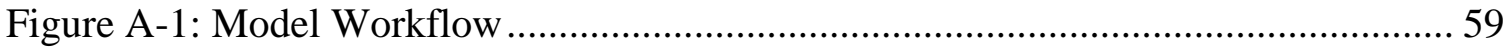





\section{List of Tables}

Table 1. Project Functional Requirements....................................................... 18

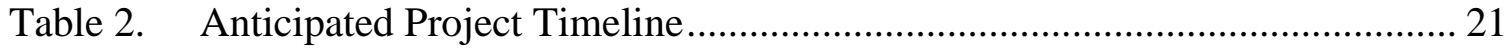

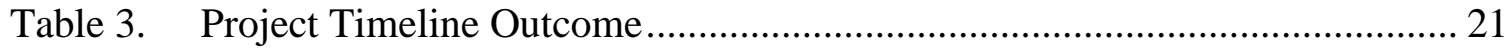

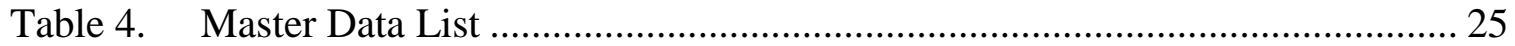

Table 5. Comparison of DHM and Surface Difference Results ............................... 43

Table 6. Total Seasonal Snow Volume Results ........................................................... 43

Table 7. Adjusted Total Seasonal Snow Volume Results ....................................... 44

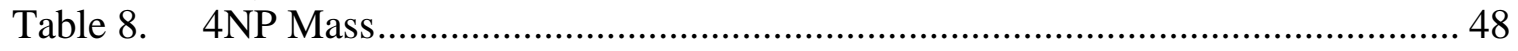

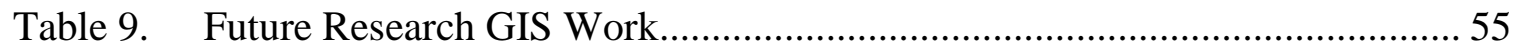





\section{List of Acronyms and Definitions}

$\begin{array}{ll}\text { ASO } & \text { Airborne Snow Observatory } \\ \text { CSV } & \text { Comma Separated Values } \\ \text { DEM } & \text { Digital Elevation Model } \\ \text { DHM } & \text { Digital Height Model } \\ \text { DSM } & \text { Digital Surface Model } \\ \text { DTM } & \text { Digital Terrain Model } \\ \text { EDC } & \text { Endocrine Disrupting Chemicals } \\ \text { GIS } & \text { Geographic Information System } \\ \text { IDW } & \text { Inverse Distance Weighting } \\ \text { JPL } & \text { Jet Propulsion Laboratory } \\ \text { LiDAR } & \text { Light Detection and Ranging } \\ \text { LRT } & \text { Long-range transport } \\ \text { NASA } & \text { National Aeronautics and Space Administration } \\ \text { POP } & \text { Persistent Organic Pollutants } \\ \text { PPM } & \text { parts per million } \\ \text { TIN } & \text { Triangulated Irregular Network } \\ \text { UML } & \text { Unified Modeling Language } \\ \text { USGS } & \text { United States Geological Survey } \\ \text { UTM } & \text { Universal Transverse Mercator } \\ \text { WGS } & \text { World Geodetic System } \\ \text { 4NP } & \text { 4-nonylphenol }\end{array}$





\section{Chapter 1 - Introduction}

California's unique geological features makes its landscapes rich for research. Its topography, which includes glaciers surrounded by formidable physical barriers, presents an intriguing case study for the long-range transport (LRT) of the endocrine disruptor, 4nonylphenol (4NP). Endocrine disruptors present a problem to human health because they interrupt and alter human development, metabolism, and other physiological processes. The widespread use of $4 \mathrm{NP}$, a persistent organic pollutant (POP) in pesticides, makes it a focus endocrine disruptor in this study. Fresno County, the center of the Central Valley's agriculture industry, has been ranked as California's frontrunner pesticide user. Onshore wind generated in the Pacific Ocean transports the POP in aerosols inland from the Central Valley and deposits them in the Sierra Nevada where they are accumulated and stored in glaciers (Figure 1-1).

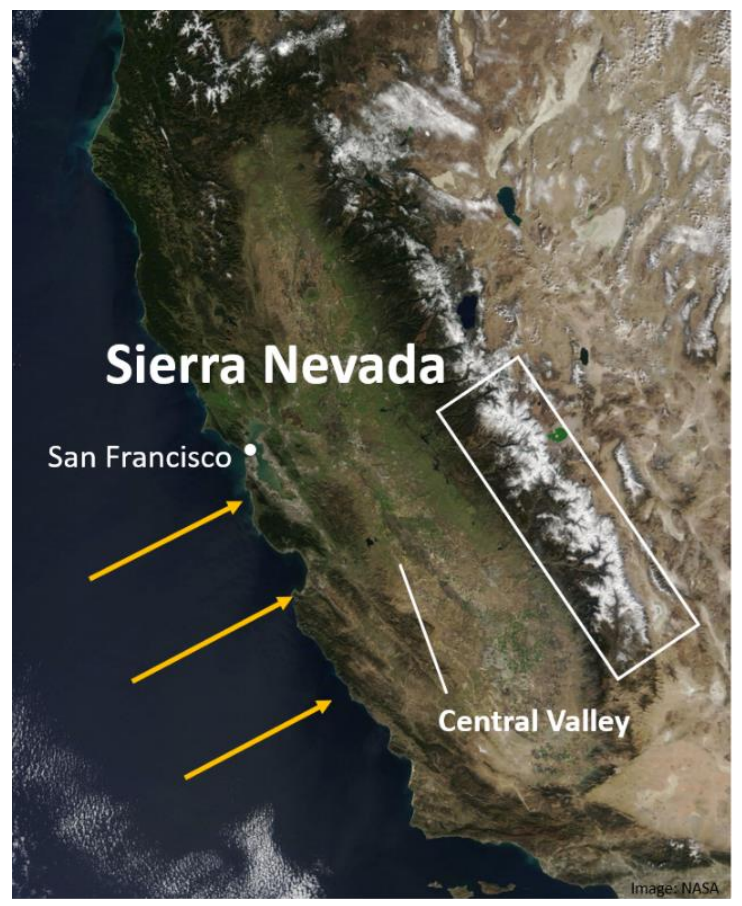

Figure 1-1: NASA satellite image of California (2018)

The Sierra Nevada, Spanish for "snowy mountain range", is the site of 497 USGS documented glaciers (Raub, Brown, \& Post, 2006). Glaciers located in the Sierra Nevada mountain range present an intriguing space that is witness to dynamic interactions between meteorological factors and topographical features. 4NP movement serves as the link and observable phenomenon of these interactions.

Glaciers are of specific interest to this research because of their ability to serve as a long-term reservoir for 4NP and other POPs. A glacier is a land mass of accumulated and compacted snow-formed ice that has sufficient thickness and weight to act like a slowmoving river over time (Guyton, 1998). Glaciers can be classified in three different ways. 
First, glaciers are described according to their temperatures based on their location. Glaciers situated in high latitudes or at high elevations are known as polar glaciers where temperatures are below melting point. On the contrary, temperate glaciers are in moderate latitudes where glacial ice exists at melting point all throughout the year. Second, glaciers can be classified as confined or unconfined depending on whether they are constrained by mountains or valleys. Third, glaciers can be classified based on their size and shape. Confined glaciers (also known as a mountain glaciers) are categorized as two types: valley glaciers or cirque glaciers. A valley glacier forms in a valley usually carved out by a former river. On the other hand, a cirque glacier is a glacier that is situated in a bowl-like area carved from the mountainside from constant eroding of the glacier (Guyton, 1998).

Because of their location, size, and shape, most glaciers in the Sierra Nevada are temperate, confined cirque glaciers. One such glacier, the Palisade Glacier seen in Figure $1-2$, is found in Inyo National Forest and is the largest glacier in the Sierra Nevada situated at 3870 meters (12,697 feet) (USGS Feature Detailed Report, 1981). Middle Palisade Glacier, the primary site of the project's work, is located three miles southeast of Palisade Glacier and is the southernmost glacier in the Sierra Nevada (Figure 1-3) (Guyton, 1998). At 3890 meters (12,762 feet), Middle Palisade Glacier seen in Figure 1-4 consists of two glaciers separated by a moraine, an accumulated mass of unconsolidated glacial deposit (USGS Feature Detailed Report, 1981). Due to seasonal melts of these temperate glaciers, snow runoff can act as an effective medium for the movement of trace organic pollutants, thus transporting and re-releasing 4NP into water bodies that provide drinking water and irrigation. At the time of this study, most of the 4NP samples were collected from Middle Palisade Glacier with plans to expand work to the Palisade Glacier.

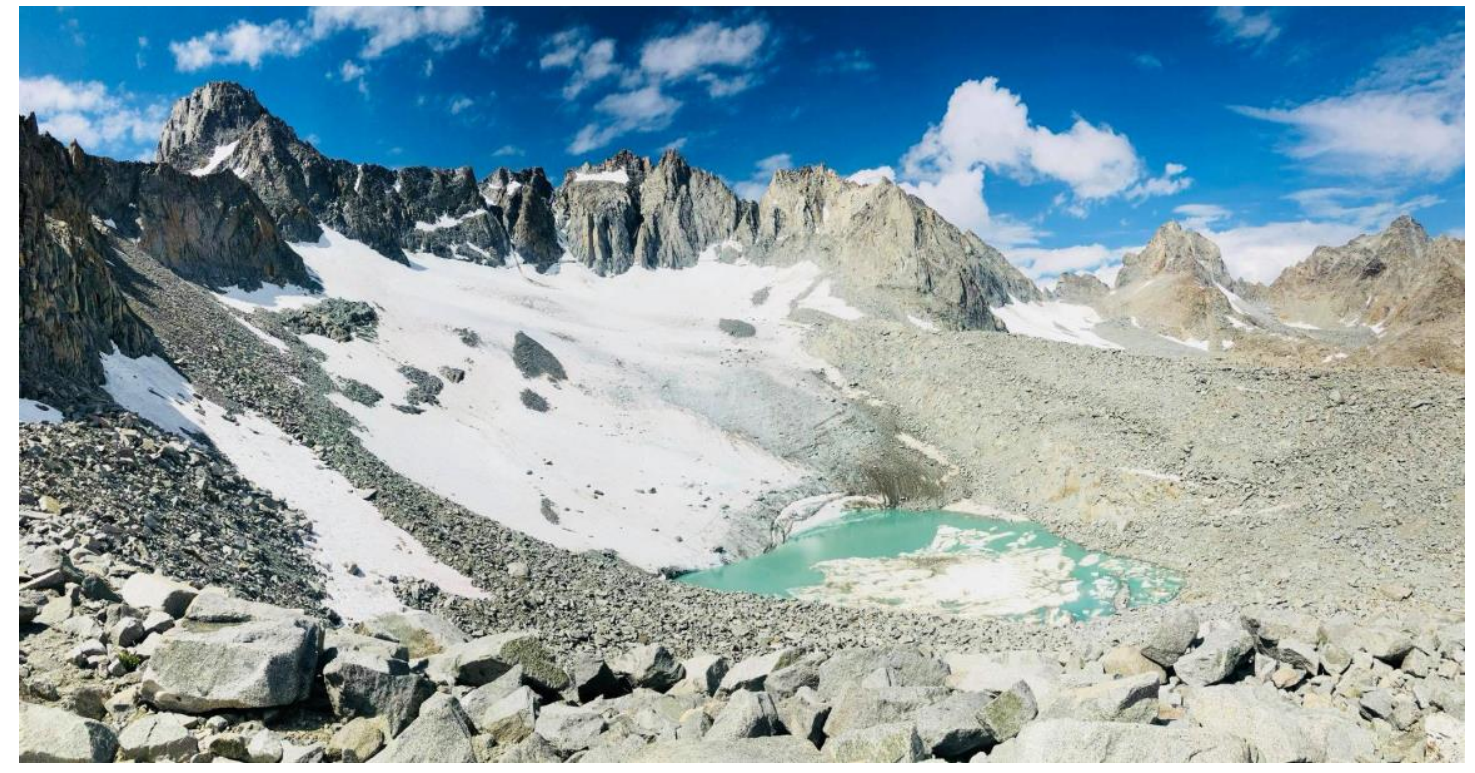

Figure 1-2: Middle Palisade Glacier in September 2015. Image: Scott Weavil 


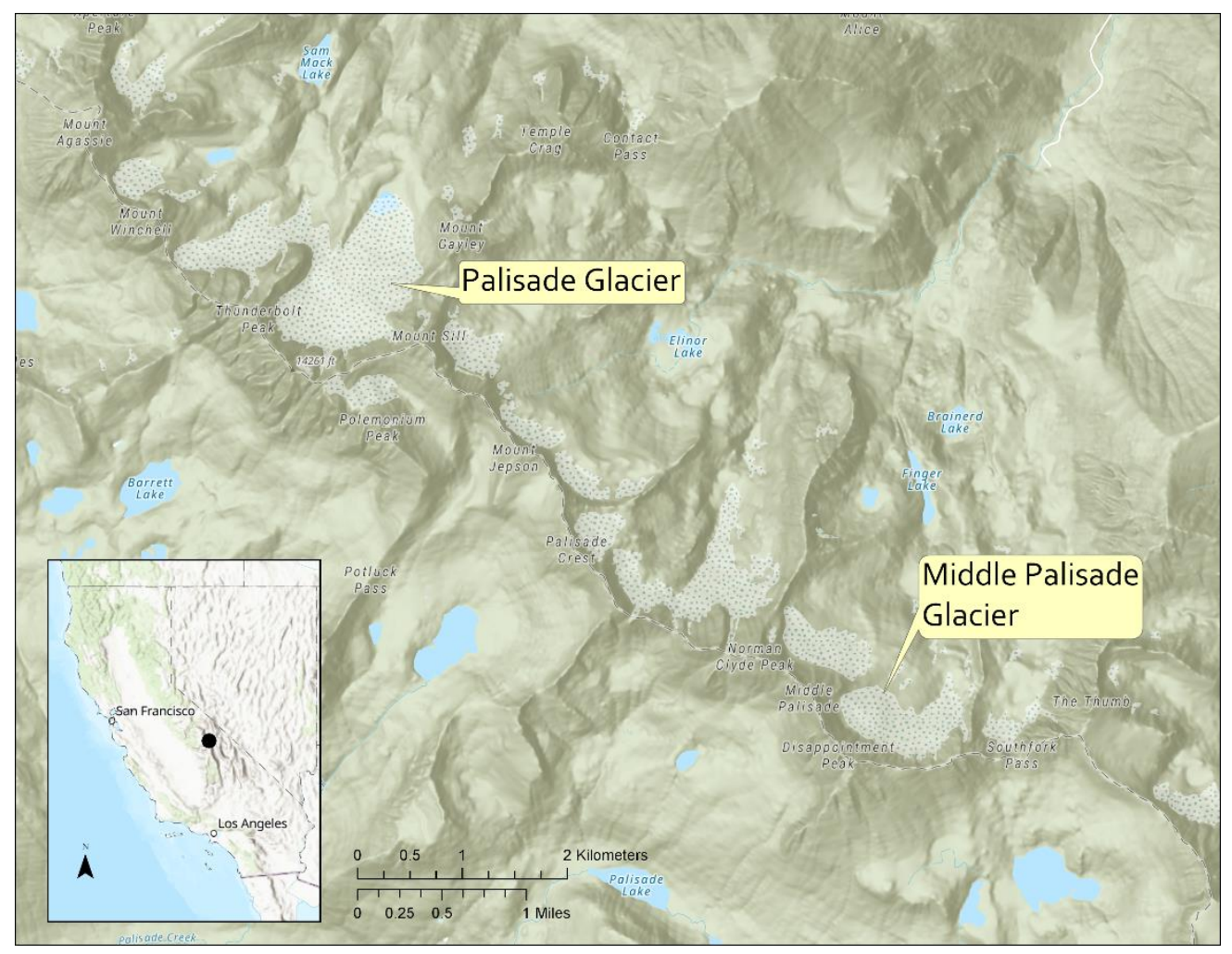

Figure 1-3: Palisade Glacier and Middle Palisade Glacier locations.

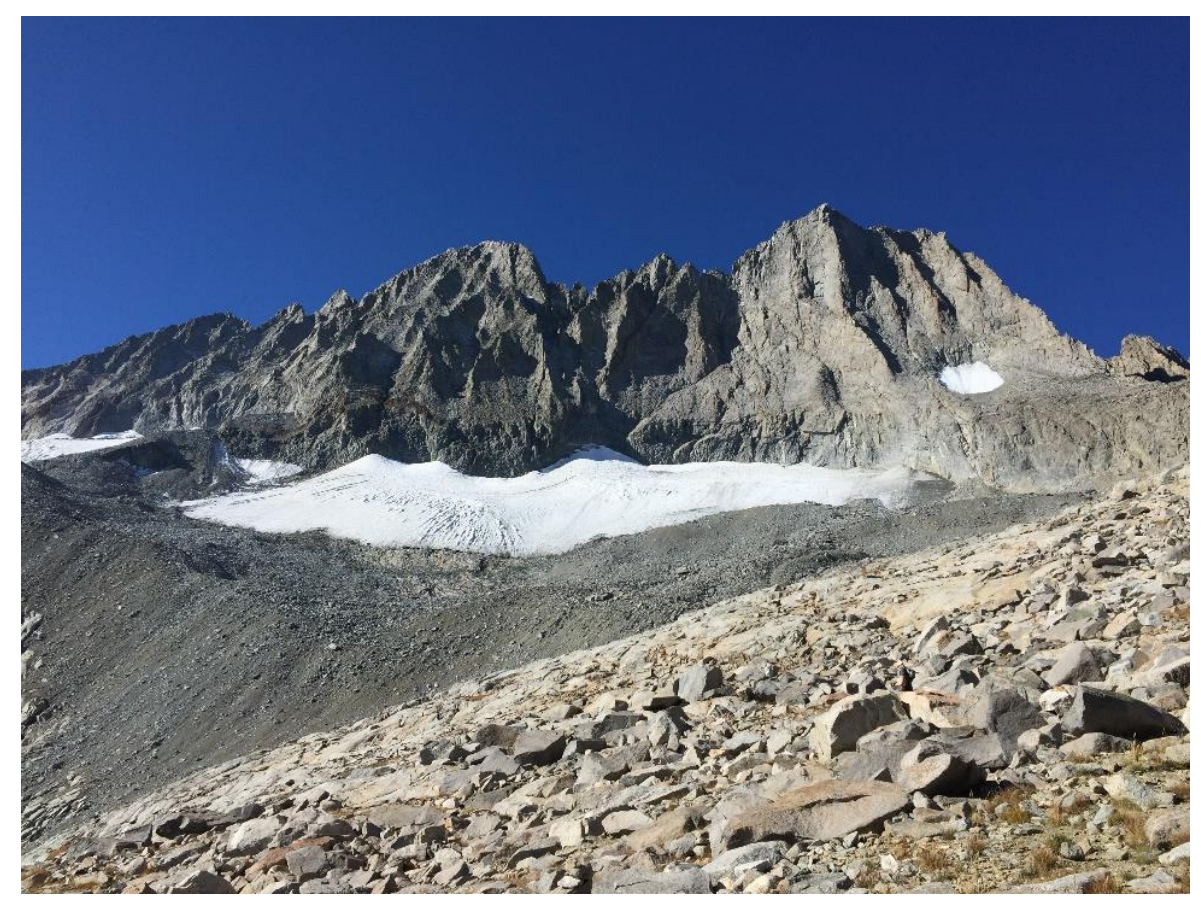

Figure 1-4: Palisade Glacier in July 2018. Image: Jesse Felten 
This report contains a demonstration of the capability of GIS in answering important spatial questions in an environmental science project and furthering scientific research. The use of GIS technology in the integration of topography, hydrology, and meteorology will be beneficial to the GIS and environmental science communities in illustrating its application to glacier studies and chemical mass transport qualitative analyses.

\subsection{Client}

The client of this project was Dr. Rebecca Lyons, Associate Professor of Chemistry at the University of Redlands. Her area of expertise is in environmental chemistry, specifically ecotoxicology. Dr. Lyon's primary research involved investigating the movement mechanisms and accumulation behavior of trace organic pollutants across topographic boundaries. After first noting 4NP concentrations in various creeks and lakes downstream from glaciers, Dr. Lyons expanded her work to glaciers and has accumulated data from ice core samples from different glaciers. She served as the main point of contact for the project and facilitated communication among the team of researchers. The client had a team of undergraduate research students responsible for the bulk of the data collection. Dr. Lyons supported the project and insured that the requirements were appropriately specified so that the research needs were met.

\subsection{Problem Statement}

The client needed to determine the presence of 4-nonylphenol released from glacial melt in the Sierra Nevada mountain range of California. To illustrate the accumulation and spread of 4NP in the glaciers, GIS work needed to be completed to describe snow volume and 4NP concentration to ultimately estimate the total mass of endocrine disruptor in glaciers. The presence of 4NP in the glaciers needed to be quantitatively described given the factor of prevailing wind direction as determined by topographic shielding. Dr. Lyons was ultimately interested in quantitatively describing the presence of 4-nonylphenol in a California glacier, based on the influence of topographic shielding.

\subsection{Proposed Solution}

The solution to the problem consisted of a series of raster analyses that determined an estimate of the total mass of 4NP per glacier. Methods applied to Middle Palisade Glacier served as a model for other at-risk glaciers. Given that manual surveying in glaciers is costly, time-consuming, and potentially dangerous, Light Detection and Ranging (LiDAR) mapping is becoming a more prominent method in obtaining high-resolution terrain data. Snow volume was determined from data provided by the NASA Airborne Snow Observatory, an imaging spectrometer and scanning LiDAR system. Calculating snow depth required at least two separate data collections, snow-free and snow-covered. Subtracting the two surface datasets yielded snow depth with an anticipated accuracy of $10 \mathrm{~cm}$ RMSE (Deems \& Painter, 2006). The total volume was calculated in ArcGIS Pro. The process involved interpolating the point clouds of both snow-free and snow-covered datasets as digital elevation models (DEMs) before subtracting their cell values.

A topographic shielding model was previously created that would calculate a shielding value based on slope, and horizontal and vertical distances from the sample site 
to the ridge. Upon completion of the topographic shielding model, which illustrated the role topographic features have on 4NP deposition, the model's shielding calculations were plotted with 4NP concentration from sampling points. A regression analysis was conducted to describe the relationship between shielding and concentrations. The graph would assist the interpretation of the impact of topographic shielding on 4NP presence in the glaciers. Using the logarithmic regression equation, an interpolated raster layer was produced that contained anticipated concentration throughout the glacier based on topographic shielding calculations. The interpolated raster also served as a concentration gradient that visually illustrates and supports the logarithmic equation describing an increase in concentration as the distance from the ridge decreases. The quantitative results supported the client's research work on the role topographic shielding has on influencing 4NP deposition.

\subsubsection{Goals and Objectives}

The goal of this project was to quantitatively estimate the mass of 4NP in California glaciers. Methods had to be devised to calculate snow volume and estimate 4NP concentrations based on the influence of the surrounding area's topographical features. Topographic shielding is a determining factor for 4NP presence and could be used to estimate concentrations in the glacier. Insuring that the existing topographic shielding model was complete and functional was necessary to begin its application on the study glacier. Once LiDAR data had been acquired, analyses were conducted to determine the total snow volume of each glacier. This component was important to quantitatively describe the extent of 4NP presence in the glacier.

There were three strategic objectives for embarking on this project. First, the objective of this project was to produce results that would lead to publishable materials that would benefit the scientific and public health community and further related research. Secondly, the completion of this project would demonstrate the capabilities of GIS in creating a comprehensive solution to a large-scale environmental problem by incorporating various factors and parameters. Thirdly, the completion of the project exemplified the functionality of GIS as an all-encompassing science that crosses barriers between different disciplines while simultaneously furthering study in each. The result was a system of better understanding how the different fields of biology, chemistry, environmental science and engineering interact with one another. Within environmental science, GIS integrated the branches of meteorology, hydrology, and topography to illustrate a phenomenon that interacts with components in each discipline.

\subsubsection{Scope}

Since the project's initiation occurred within a subset of a research continuum, a clearly defined scope was necessary to drive the development of methodologies to reach the study's needs and objectives. The scope of the project was oriented around the research objective of determining the total mass of 4NP in the Palisade Glacier and Middle Palisade Glacier based on the influence of topographic shielding in determining concentration estimations.

The research-oriented nature of the project allowed for the segmentation of goals and requirements. Methodologies and analyses were developed to determine total snow 
volume and 4NP concentration. The scope of the project was constructed in specific stages, some of which acted independently from each other, but could be integrated to further research. The first phase of the project was dedicated to research and acquiring the data for measuring snow volume in the Palisade and Middle Palisade glaciers. The snow coverage and glacier mapping depended on LiDAR data provided by the NASA Airborne Snow Observatory (ASO). The second phase of the project was focused on using a regression analysis to determine the relationship between calculated shielding values and 4NP sample concentrations. The final phase consisted of the fundamental research objective of determining the total 4NP mass stored in a glacial space. The integration of 4NP concentration and topographic shielding conveyed an understanding about how deposition transport factors influence 4NP accumulation and storage. The project results include a map of 4NP sample sites, maps containing estimated concentration rasters, and a series of analyses that calculated total 4NP mass in a glacier and the role of topographic shielding in concentration gradients.

\subsubsection{Methods}

This project consisted of four stages: research, data acquirement, design, and implementation. Literature review began in the early stages of project initiation to gain an understanding of the field of study, the natural processes involved, and other topics pertinent to the research. Significant background research work was conducted throughout the project to derive and build on methods that would integrate each project component. The investigation of previous work done was essential in building analyses appropriate to the project's scope. Consulting others who contributed to the ongoing research was helpful in drawing from the resources of previous GIS work. This was necessary in addressing the challenge of managing a project-encompassing but restrained scope that integrates previous work without repeating it. Due to the investigative nature of the project, research was conducted throughout the project timeline to support each stage.

Following the development of strategies extracted from client research work and other authoritative sources, data needs were identified. Connections were established with the NASA ASO team, and the LiDAR data measuring snow volume was obtained from Kathryn Bormann, a Jet Propulsion Laboratory (JPL) scientist and member of the observatory team. The project utilized the existing client's concentration samples at the time of the study and the input data in the model used for calculating topographic shielding values.

The successful completion of the project depended on the systematic design of methodologies and workflows that would meet specific research objectives. A Unified Modeling Language (UML) relational model was created to comprehensively illustrate the components of the project by integrating data with study objectives. This translated natural processes into concrete project requirements that, once identified, were set as objectives to be achieved. Additionally, the equation for calculating total mass served as the framework and a formal mathematical guide for determining total 4NP mass. This and the conceptual model served as the basis for the creation of implementation strategies and methods.

The implementation of the project began with executing strategies and methods to accomplish the client's requirements. Technical workflows were created to process data 
from preparation to analyses. Results were described with discussion on relevance to the client's research goals.

\subsection{Audience}

This report was compiled to assist GIS professionals, environmental scientists, and public health professionals in a combined effort to reduce exposure risks caused by hazardous organic compounds by evaluating the quantitative presence of 4NP stored in glaciers. This document was structured to further research in the areas of glacier snow mapping by demonstrating the capabilities of LiDAR as a highly accurate cost-effective method of surveying. Additionally, the information contained in this report will provide the basis for continual study in environmental toxicology specifically in the release, movement, and deposition factors of organic compounds in the natural environment.

\subsection{Overview of the Rest of this Report}

This document consists of 7 chapters that will delve into each section of the project from its design and planning to its execution and completion. A discussion of the client's previous research work and the literature review required for this report is found in Chapter 2. Chapter 3 covers an outline of the major requirements structured around the central problem statement and project timelines. In Chapter 4, conceptual and logical models designed for the achievement of project objectives are discussed with emphasis on data usage and functionality. Implementation is recorded in Chapter 5 with the analysis results and commentary appearing in Chapter 6. Lastly, project conclusion, application, and future work is addressed in Chapter 7. 



\section{Chapter 2 - Background and Literature Review}

The interdisciplinary nature of this project necessitates an overarching field that serves as a framework for the development of methods, applications, and the analyses that are implemented into the project. Environmental science serves as the domain whereby all other related studies and interacting systems are addressed. The field of environmental science encompasses the study of the natural world and its interactions with the living organisms that rely on its resources and services. The problem addressed in this project requires understanding the environmental challenge arising from the interactions between humans and the natural world. While environmental science serves as the foundation for approaching the problems to be solved, the fields of biology, chemistry, and environmental engineering are likewise involved. The breadth of this study necessitates an exploration into the appropriate topics in these fields. Thus, this chapter contains a fundamental concepts discussion on biology, chemistry, environmental toxicology, and environmental engineering as it relates to mass balance and transport of chemicals.

Literature reviews were directed to investigate methods to support Dr. Lyons' research work. Research was conducted in the planning stages of the project to devise methods and workflows to quantitatively describe the presence of 4-nonylphenol in glaciers. A discussion in this chapter on the chemical structure and behavior of 4NP in Section 2.1 is followed by an explanation of the transportation of 4NP in Section 2.2. Lastly, Section 2.3 includes a discussion on Light Detection and Ranging (LiDAR) as a surveying method to determine snow volume.

\subsection{NP as an Endocrine Disruptor}

The biological and chemical aspects to this study surrounding the endocrine disruptor, 4nonylphenol (4NP), are important because of its direct implications on humans and other living organisms. Endocrine disrupting chemicals (EDCs) are a class of chemicals that interfere and affect the physiological function of the endocrine system (Davis \& Masten, 2016). Because of EDCs' ability to directly affect the synthesis and behavior of natural hormones (Figure 2-1), they are of interest to the scientific and public health communities. After first entering the environment as nonylphenol polyethoxylates before being anaerobically digested, 4NP is one endocrine disruptor compound that has significant impact because of the nature of the compound and its use in pesticides. 


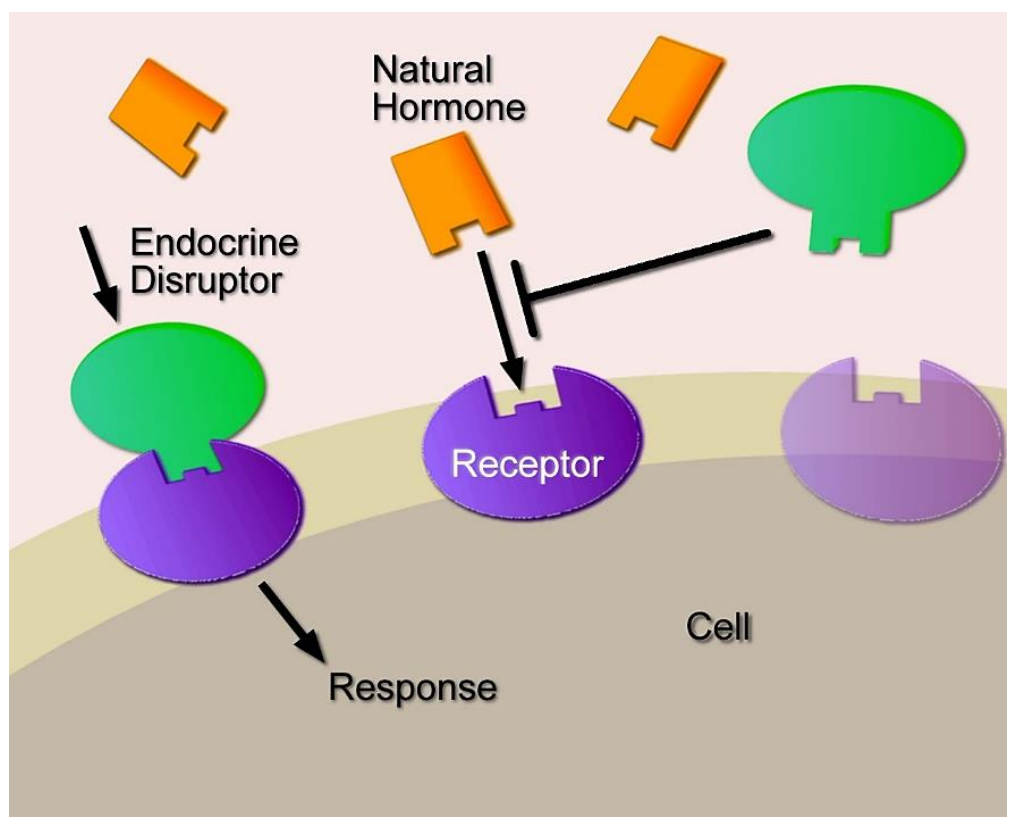

Figure 2-1: Endocrines mimic natural hormones by binding to cell receptor sites. Image Copyright: European Parliamentary Research Service

4NP acts as an endocrine disruptor by mimicking 17-3-estradiol, the female sex hormone. Due to its similar structure to the natural hormone seen in Figure 2-2, 4NP can fit into hormone receptor sites and prevent or change hormonal responses (Lyons \& Benvenuti, 2016).<smiles>CCC(C)CC(C)C(C)c1ccc(O)cc1</smiles>

Figure 2-2: A comparison between 17-B-estradiol and bioactive isomer of 4nonylphenol (Lyons, et al. 2014).

As an environmental contaminant, 4NP's widespread presence in the application of pesticides brings concerning risks associated with its ingestion and dispersal throughout the food chain. Studies have shown that 4NP makes up $10 \%$ or more of the total volume of many pesticides (Lyons \& Benvenuti, 2016). Because of its status as an endocrine disruptor, the implications of 4NP bioaccumulation in organisms are significant. Nonylphenol is considered toxic to fish at concentrations as low as $17 \mu \mathrm{g} / \mathrm{L}$ (Vazquez- 
Duhalt, et al., 2005). In humans, 4NP can have significant consequences on reproductive health. The stimulation of ovarian cancer cell migration has been linked to nonylphenol (Kim, et al., 2015). Studies have shown that nonylphenol can also affect the kidney and liver in addition to reproductive organs and induce the apoptosis of gastric epithelial cells (Manente, et al., 2011). Nonylphenol may even deregulate cell cycles which can increase the risk of cancer by proliferating prostate epithelial cells (Forte, et al., 2016).

\subsection{NP Transport and Storage}

Deposition determining factors such as landscape features, wind direction, and topographical shielding have complicated the task of determining the quantitative presence of 4NP, a necessary step towards future application of local exposure risk prediction. Topographical shielding plays a role in the deposition of wind-borne compounds. It is correlated with 4NP concentrations and depends on factors such as the slope, and the horizontal and vertical distance from the sample site to the natural barrier (Lyons \& Benvenuti, 2016). In this project, GIS was instrumental in analyzing the spread of $4 \mathrm{NP}$ by organizing, interpreting, and visualizing the determining factors of the deposition and release of the endocrine disruptor. An understanding of 4NP's transport potential, its transport mechanisms, and glaciers as storage reservoirs provided a foundation for GIS to be integrated into the study. The following subsections discuss 4NP's chemical characteristics, transport factors, the concept of topographic shielding, and the storage and release of $4 \mathrm{NP}$ in glaciers.

\subsubsection{NP's Transport Potential}

The chemical properties of 4NP makes it an effective candidate for long range transportation and deposition. The calculated octanol-air partition coefficient $\left(\mathrm{K}_{O A}\right)$ of 4NP is 7.9, which falls between 6.5 and 10, the $\mathrm{K}_{O A}$ range for POPs with significant longrange transport (LRT) potential. Additionally, 4NP has a vapor pressure of $0.02 \mathrm{~Pa}$ and will condense at approximately $-15^{\circ} \mathrm{C}$ (Lyons \& Benvenuti, 2016). The high altitudes of the Sierra Nevada mountains combined with the 4NP's low vapor pressure provides suitable conditions for condensation and deposition.

\subsubsection{Transport Mechanisms}

Tracing the mass flow of 4NP through environmental systems presents a challenge because it involves understanding its cyclic movement through the atmosphere and in the hydrologic cycle. The difficulties of analyzing the mass transport of $4 \mathrm{NP}$ can be addressed by utilizing GIS as a system to visualize and conduct spatial data analyses. Technical work has been developed to quantify pollutant deposition from the atmosphere as well as particulate matter flux calculations (Brooks, 2012). A topographical shielding model was previously created and provided a basis for furthering analyses on topographical and meteorological parameters in chemical transportation and deposition.

The research work of the client, Dr. Lyons, provided the background and context for this project. Much of her research had been to draw attention to the spread of 4NP, a known endocrine disruptor. Understanding the mass transport of 4NP through the atmosphere by wind and its subsequent deposition, storage, and re-release from glaciers 
was a challenging task. Dr. Lyons' investigation of mass transfer mechanisms and patterns of deposition has brought to light the presence of 4NP in the Sierra Nevada Mountains. Sediment samples indicated that 4NP concentrations were highest in lakes at close proximity to glaciers upstream (Lyons, et al. 2019). Studies have indicated that mass transfer and deposition of 4NP are likely more dependent on the influence of other air particulates than on wet precipitation (Lyons et al., 2014). Topographical features like headwalls and ridges played roles in interrupting wind currents and influencing deposition sites.

Other studies on the transport of persistent organic pollutants (POPs) have indicated the difficulties of quantifying long-range transport due to inconsistent regional data. Historical and present pesticide usage rates, emission estimations, and chemical concentrations vary in spatial and temporal resolution. Previous studies have implemented investigations on sediment cores to analyze the likelihood of long-range transport (LRT) (U.S. Environmental Protection Agency, 2002). Thus, this study was built on this approach by using data collected from snow core samples to support transportation evidence and investigate deposition of 4NP. Data on wind direction was critical for determining transport patterns, possible deposition regions, and the significance of topographic shielding on chemical presence in glaciers.

\subsubsection{Topographic Shielding}

The localized topography, a major determining factor for the deposition of atmospheric compounds like 4-nonylphenol, was of significant interest to this study. Topographic shielding is an effect caused by a landscape's natural barriers in providing a resistance to wind-borne mass flow. The concept of topographic shielding is visualized in Figure 2-3.

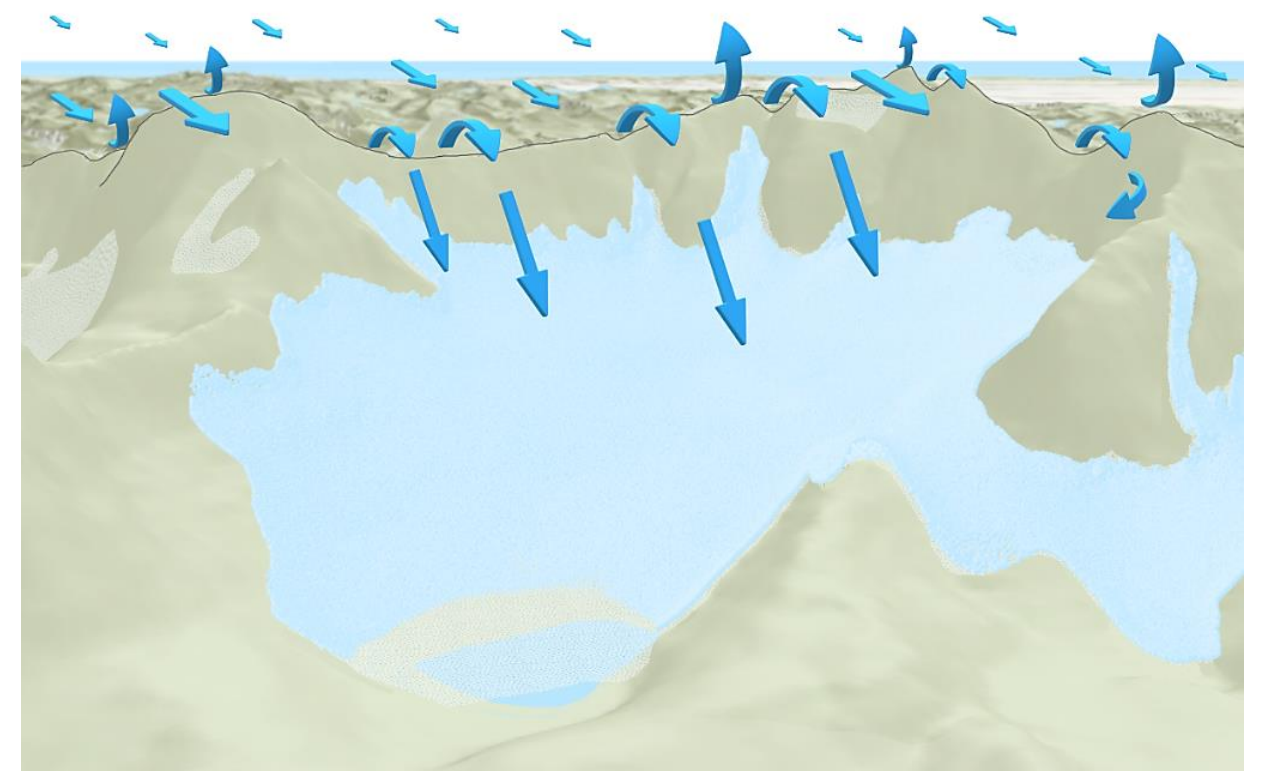

Figure 2-3: Topography shielding influences wind-borne mass deposition. 
The concept of topographic shielding or "sheltering" was described by Davidson and Knapp in a 2007 study on amphibian declines as a result of an increase in pesticide applications. They suggested that topographic shielding, described in the article as "topographic sheltering", was a significant influencer on the presence or absence of frogs sensitive to the effects of pesticides. This shielding effect caused by localized topographic barriers reduced the amount of windborne contaminates that negatively affected amphibian populations (Davidson \& Knapp, 2007). This concept was further developed mathematically by Dr. Rebecca Lyons and implemented in her research. Topographic shielding was explored in this study as an important factor in influencing the deposition and concentration of 4NP. While physical barriers serve as a resistance to air-borne deposition, it does not prevent POP long-range transportation. Thus, it remained worthwhile to investigate the effects of topographic barriers on deposition factors.

Topographic shielding is calculated by dividing the product of the headwall slope and the vertical distance of the ridge to the sample site by the horizontal distance of the ridge to the sample site (Figure 2-4).

\title{
DEPOSITION DETERMINING FACTORS
}

\author{
CORRELATION BETWEEN SIZE OF CANYON HEADWALLS AND THE AMOUNT
} OF NP FOUND IN THEM

TOPOGRAPHICAL SHIELDING (T)

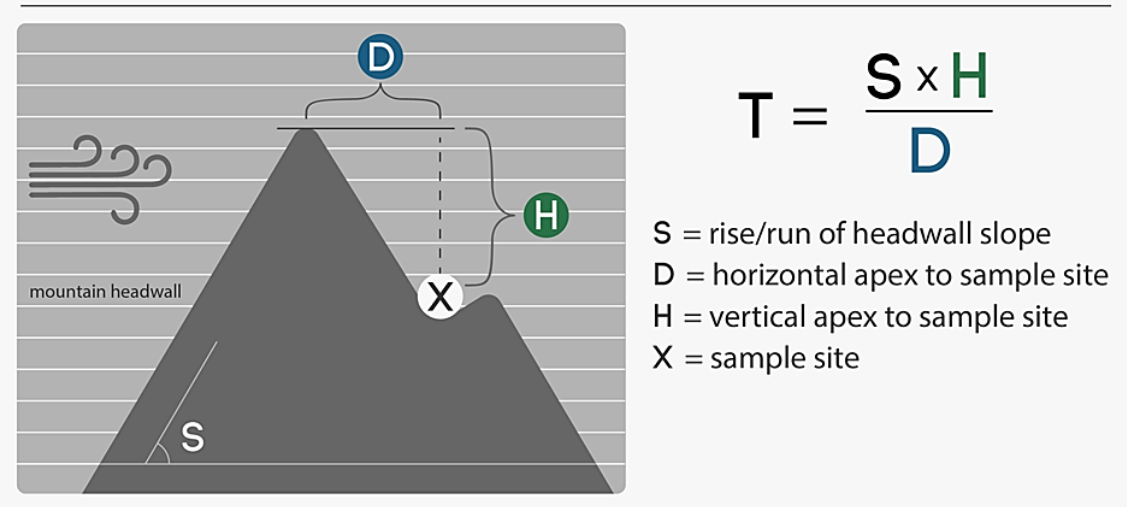

Figure 2-4: Topographic shielding equation developed by Dr. Rebecca Lyons. Graphic by Austin Koons.

\subsubsection{Storage and Release}

As a POP, $4 \mathrm{NP}$ can bioaccumulate in glaciers since snow serves as a major source of storage for 4NP. Sierra Nevada's gentle western slopes have the appropriate space for snow accumulation (Guyton, 1998). Seasonal glacial warmings release 4NP, thus increasing concentrations in nearby lakes and water bodies. The melting of winter snow 
during spring months may release high concentrations at critical periods of important organismal development (Lyons \& Benvenuti, 2016). Studies have shown that glacial streams contain unusually high concentrations of POPs. This is likely because glacial contents are low in organic matter required for chemical breakdown. Transport mechanisms also minimize contact between snow melt runoff and catchment soils (Blais, et al., 2001).

\subsection{LiDAR for Snow Depth Measurement}

With the continual expansion of remote sensing, LiDAR has been explored as a surveying method to measure snow depth (Deems et al., 2013). LiDAR systems are composed of active sensors that transmit light pulses to produce highly accurate measurements of the earth's surface (Figure 2-5).

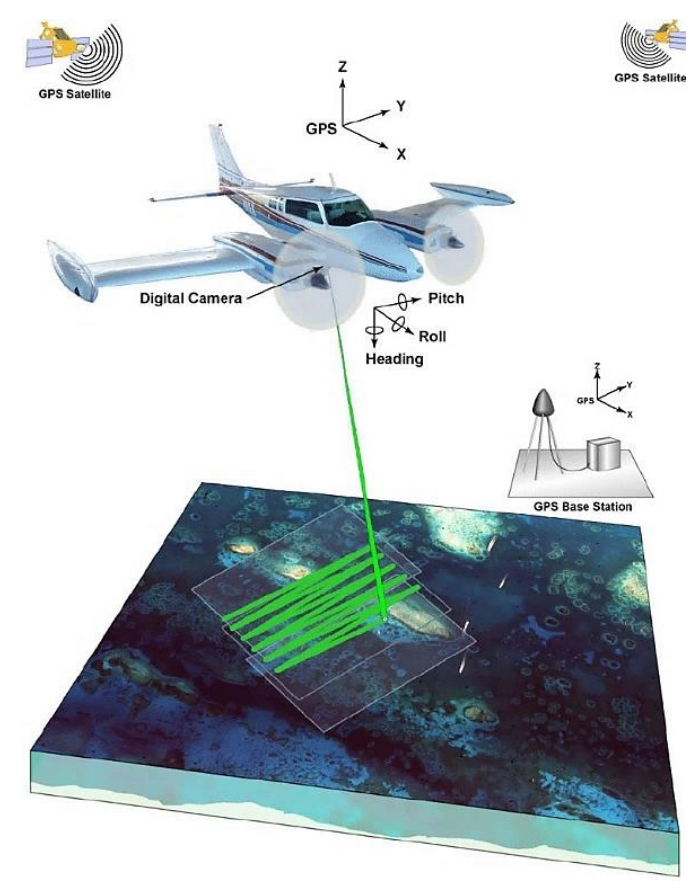

Figure 2-5: Airborne LiDAR. Image: Wayne Wright

LiDAR systems integrate three technologies: laser ranging for distance measurement, Global Positioning System (GPS) to determine the sensor's geographic position and height, and an inertial measurement unit (IMU) to record the precise orientation of the sensor on the aircraft (Aronoff, 2005). A LiDAR system can record thousands of returns per second (Campbell, 2002). The range to the target feature $(R)$ is computed as

$$
R=c \frac{t}{2}
$$

where $t$ is the time-of-flight and $c$ is the speed of light. 
Emitted laser pulses are reflected off surface features such as bare earth, vegetation, or snowpack (Tedesco, 2015). LiDAR laser returns are categorized as first, intermediate, and last. First or primary returns are derived from the first objects a LiDAR pulse encounters. It is usually associated with a landscape's highest feature, often a tree canopy or building. The intermediate or secondary return occurs when portions of the pulse pass through gaps in the canopy onto interior branches or leaves, or even the ground surface itself. The last return is usually the ground return but may not always represent the ground surface in the case of pulses that encounter a branch.

In the past, sampling snow to determine depth was done manually. This work is often dangerous, expensive, and time-consuming. Recent studies have proposed LiDAR as a safe, cost-effective, and efficient method of mapping snow depth (Deems et al., 2013). NASA's Airborne Snow Observatory (ASO) collects data during two periods, snow-covered and snow-free, to analyze seasonal snow changes (Figure 2-6). The pulsed lasers capture surface elevations in remote areas to yield snow depth measurements used to quantify snow water equivalent (SWE) and snow albedo for mountain watersheds.

SWE, the product of snow depth and density, is the amount of water stored in snowpack. SWE is a critical factor for applications in climatology and hydrology (Tedesco, 2015). To calculate snow depth, two LiDAR data collections representing snow-free and snowcovered dates are required (Deems et al., 2013). The generation of digital elevation models (DEM) from the LiDAR point cloud captures of surfaces allow for the examination of snow depths. Subtracting the difference between the two datasets would provide snow depth for the area of interest, an important first step in determining snow volume. Additionally, SWE is determined by calculating the product of snow depth and snow density (Tedesco, 2015).

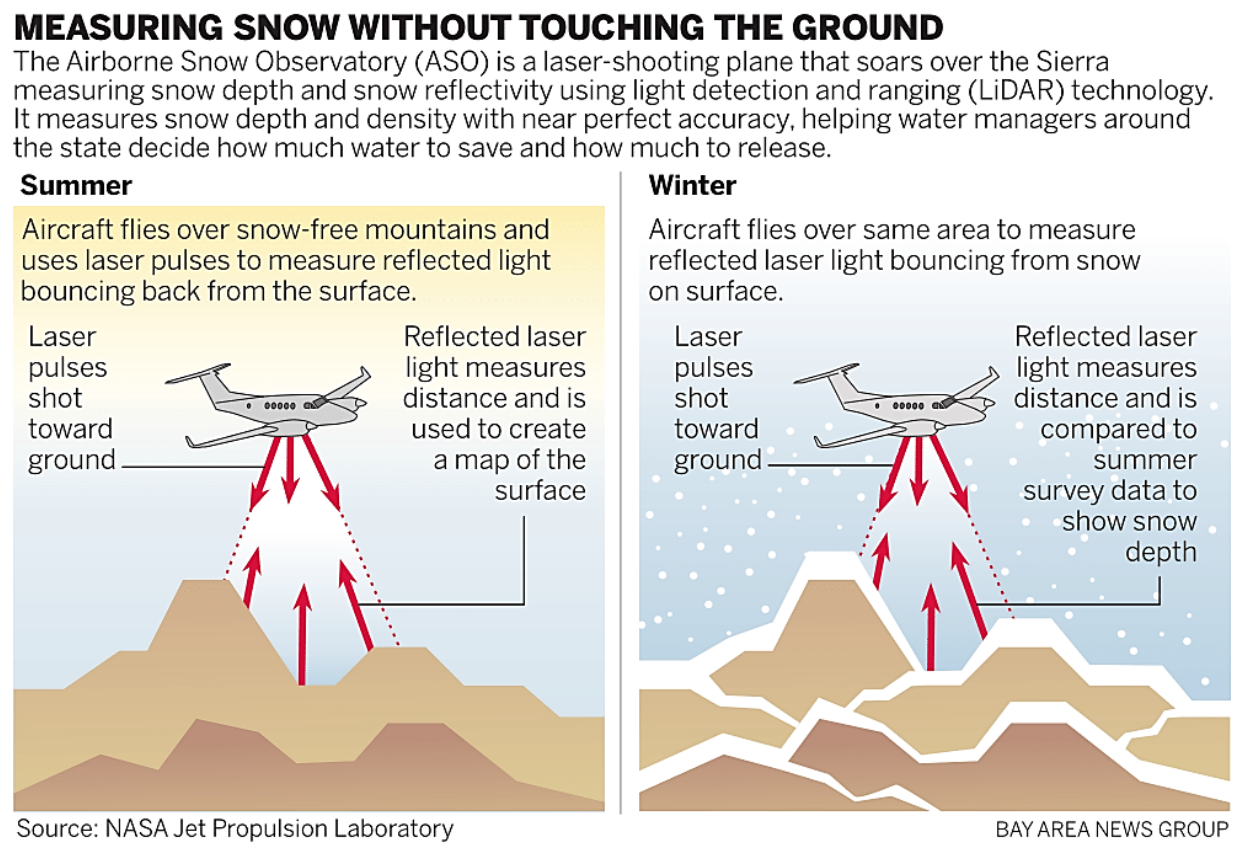

Figure 2-6: NASA Airborne Snow Observatory Snow Measurement Method 


\subsection{Summary}

GIS work addresses the spatial components of the factors that influence the spread of 4nonylphenol (4NP). The change of chemical concentration over time combined with glacier melt and hydrological modeling are important mechanisms that should be investigated. The implementation of satellite imagery to assist in answering spatial questions such as the locations of topographic barriers, control glaciers, and deposition areas has not been previously fully explored in the research. Additionally, there is a lack of information about snow depth and coverage in Sierra Nevada glaciers. The advent of NASA ASO's work has provided data and methods for snow volume calculations. Having a fundamental understanding of the biological and chemical roots of the problem associated with 4NP is necessary in comprehending the significance and implications of subsequent environmental issues. Understanding topics such as mass transport and environmental systems in environmental engineering accompanied with spatial studies assist GIS concepts and implementations. Much of the previous work associated with this topic has allowed GIS to serve as the crucial link in combining research components so that steps can be taken to move towards a better understanding of the environmental challenges caused by $4 \mathrm{NP}$. 


\section{Chapter 3 - Systems Analysis and Design}

The breadth of the research necessitated a thorough understanding of the problem before the analysis and design could be systematically planned and monitored. This chapter contains an introduction to the central problem the project addressed in Section 3.1, followed by an examination of the client requirements extracted from the problem's proposed solutions in Section 3.2. The client requested a series of GIS analyses that integrates the components of her research work to create comprehensive results. Research was done to devise methods and formulate workflows that would be needed for project execution. The system design described in Section 3.3 was critical in determining the data that needed to be retrieved for the rest of the project. The analyses needed to produce quantitative results that would further her studies and support her research conclusions. The remaining section, Section 3.4, contains a description of the original project plan and a discussion of the revised plan.

\subsection{Problem Statement}

The client, Dr. Rebecca Lyons, needed a series of analyses that would determine the mass of 4-nonylphenol (4NP) stored in a glacier in the Sierra Nevada mountain range of California. To illustrate the accumulation and spread of 4NP in the glaciers, GIS work needed to be completed to describe snow volume and 4NP concentration to ultimately determine the total mass of endocrine disruptor per glacier and deposition behavior of 4NP. The presence of 4NP in the glaciers needed to be quantitatively described given the factor of prevailing wind direction as determined by topographic shielding. The resulting analyses would lead to a logarithmic equation that would predict concentrations on the glacial surface for potential sampling sites.

\subsection{Requirements Analysis}

As a result of the client's ongoing research work, the project's core functional requirements were structured in a way that would answer key questions surrounding the client's current studies. The complex and dynamic nature of the project necessitated early and regular meetings to outline the specific requirements. Significant work was conducted to review similar research procedures and documents of other studies to formulate methodologies that were within the expected scope of the project and appropriate to the fulfillment of research objectives.

\subsubsection{Functional Requirements}

Given a fundamental understanding of the client's requests, the requirements were compiled as a series of components (Table 1). 
Table 1. Project Functional Requirements

\begin{tabular}{|l|l|}
\hline \multicolumn{1}{|c|}{ Requirement } & \multicolumn{1}{c|}{ Description } \\
\hline Glacier snow volume & $\begin{array}{l}\text { Using LiDAR to generate snow } \\
\text { minimum and snow maximum } \\
\text { surfaces, find depth based on } \\
\text { difference, then volume }\end{array}$ \\
\hline $\begin{array}{l}\text { Logarithmic function of 4NP } \\
\text { concentration }\end{array}$ & $\begin{array}{l}\text { Mathematically describe } \\
\text { concentration trends based on } \\
\text { concentration samples and } \\
\text { topographic shielding }\end{array}$ \\
\hline 4NP concentration layer & $\begin{array}{l}\text { Generate raster from logarithmic } \\
\text { equation }\end{array}$ \\
\hline Total 4NP mass per glacier & $\begin{array}{l}\text { Determine total mass by multiplying } \\
\text { concentration with glacier volume }\end{array}$ \\
\hline Predict 4NP concentrations & $\begin{array}{l}\text { Use topographic shielding as a } \\
\text { concentration predictor of } \\
\text { unsampled sites }\end{array}$ \\
\hline
\end{tabular}

While total 4NP mass was the overarching research objective, determining glacial snow volume was the first fundamental problem that had to be addressed. The first primary focus was calculating the snow volume of the Middle Palisade Glacier. The glacier volume provided the basis for the rest of the research analyses. Once the samples were collected and processed, the values were interpolated to create a map layer that illustrated 4NP concentration in the glacier. The previous two requirements needed to be accomplished before the central requirement of determining total 4NP mass in the glacier could be achieved. The total mass was determined by multiplying snow volume $(V)$ and $4 \mathrm{NP}$ concentration or density $(D)$ as seen in Equation 3.1.

$$
M=V * D
$$

Topographic shielding plays an important role in influencing the deposition of windborne compounds. A topographic shielding model was previously created to provide estimations of the influences of terrain barriers on chemical deposition. The model was used to calculate topographic shielding values used in the Middle Palisade Glacier 4NP mass analysis. Topographic shielding values of the concentration points had to be determined to create a concentration raster that demonstrated how wind direction combined with topographic features influences 4NP concentration. This concentration raster would serve as a prediction of $4 \mathrm{NP}$ concentrations for future glacial sampling 
expeditions. Providing the client with 4NP estimations at unknown locations would minimize guesswork for strategic sampling plans.

\subsubsection{Non-Functional Requirements}

Due to the structure of studies centered around furthering scientific knowledge, the nonfunctional requirements were not an essential part of the deliverables and were not specified by the client. The expectation was that the appropriate software, analyses, and methodologies were appropriately utilized or designed to produce the desired objectives of the study.

\subsection{System Design}

A system design embodies methodologies and procedures to address the requirements. The purpose of the system design was to devise the methods necessary to ultimately answer the specific research questions posed by the client. After acquiring sufficient literature, methodologies were devised to approach the project's requirements systematically. The primary intention to determine the total mass of 4-nonylphenol (4NP) in the Middle Palisade Glacier was contingent on first determining snow volume and 4NP concentration. These two components necessitated separate analyses before total mass could be calculated.

A general workflow schema was created during the project's beginning stages to devise an initial method for understanding and addressing the spatial challenges of the research work (Figure 3-1). The system design describes the overall schema of the work and identifies the major components of the analyses. Snow volume was measured utilizing LiDAR as a remote sensing surveying technique. The processing of 4NP concentration was accomplished with the client's snow sampling data. The main tasks surrounding the topographic shielding model involved applying it to the inputs and locations that served as the focus for the project. Model procedures were incorporated into the analyses to illustrate their influences on 4NP concentration gradients. Though a basic design, the general schema provided the foundation for the further development of conceptual and logical designs. 


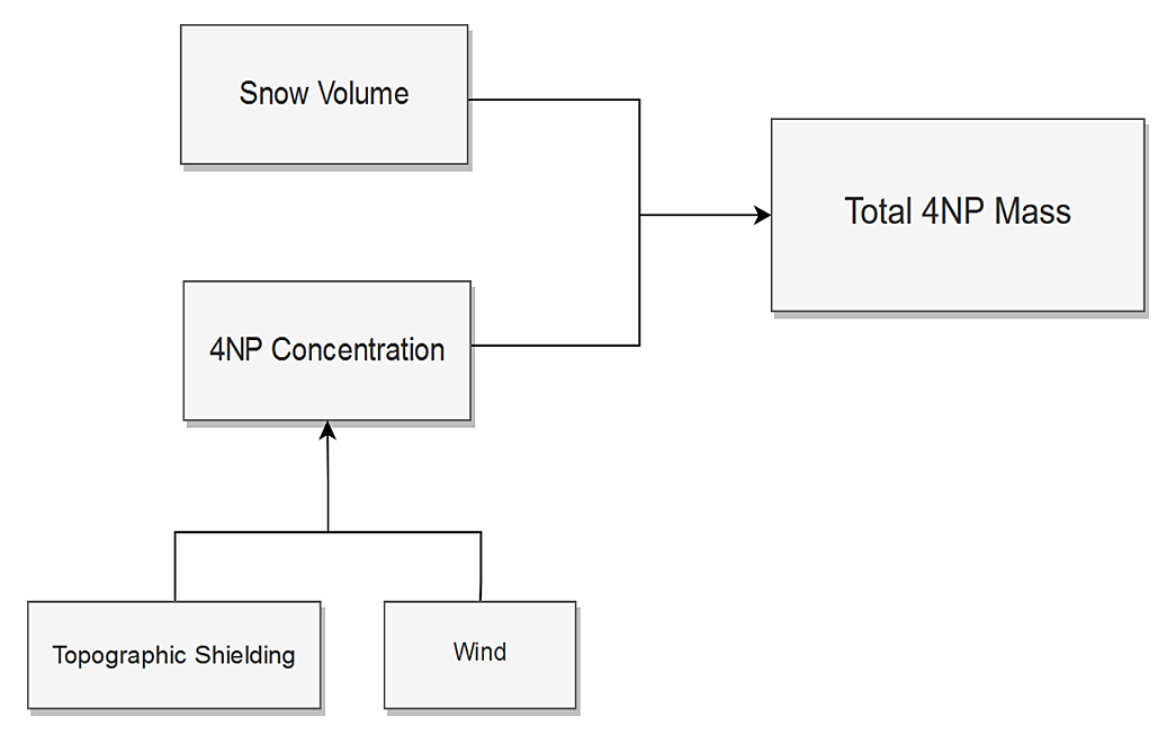

Figure 3-1: General Schema

\subsection{Project Plan}

Throughout the course of the project's lifespan, the project plan was constructed, adjusted, and maintained in adherence to the scope which was determined by time, the availability of data, and research process. The project plan was adapted from the waterfall method. Specific project tasks were organized in phases and were chronologically dependent on one another. The initiation of one stage could not begin until the previous stage's objectives had been sufficiently met. The actual completion of phases of the project was highly dependent on the availability of data. Thus, the completion of milestones was first dependent on data availability and second, deadlines. Lastly, the scope was determined by the progress of research and constrained by study objectives.

\subsubsection{Original Project Plan}

The anticipated project timeline (Table 2) consisted of four primary phases: planning, research, data acquirement, and implementation. The planning phase began with client discussions during which the project was proposed, and the scope was defined. Individual research was essential to understand the breadth of the study and to devise strategies and methodologies to accomplish the study's objectives. Data acquirement and preparation followed the methodology designs. Once the appropriate and necessary data was obtained, analysis began, thus initiating the implementation phase. 
Table 2. Anticipated Project Timeline

\begin{tabular}{|c|c|c|c|c|c|c|c|c|c|c|c|c|c|}
\hline Major Task & Milestone & Sep & Oct & Nov & Dec & Jan & Feb & Mar & Apr & May & Jun & Jul & Aug \\
\hline Client Discussions & & $\checkmark$ & $\checkmark$ & $\checkmark$ & $\checkmark$ & $\checkmark$ & $\checkmark$ & $\checkmark$ & & & & & \\
\hline \multirow{6}{*}{ Project Proposal } & Initiation & & $\checkmark$ & & & & & & & & & & \\
\hline & Define Scope & & $\checkmark$ & $\checkmark$ & $\checkmark$ & & & & & & & & \\
\hline & Literature Review & & $\checkmark$ & $\checkmark$ & $\checkmark$ & $\checkmark$ & & & & & & & \\
\hline & Method Development & & $\checkmark$ & $\checkmark$ & $\checkmark$ & $\checkmark$ & & & & & & & \\
\hline & Proposal Refinement & & & & $\checkmark$ & & & & & & & & \\
\hline & Execution & & & & & & $\checkmark$ & & & & & & \\
\hline Research & & $\checkmark$ & $\checkmark$ & $\checkmark$ & $\checkmark$ & $\checkmark$ & $\checkmark$ & & & & & & \\
\hline Data Acquirement & & & & & & $\checkmark$ & $\checkmark$ & & & & & & \\
\hline \begin{tabular}{|l|} 
Data Design \\
\end{tabular} & & & & & & $\checkmark$ & $\checkmark$ & $\checkmark$ & & & & & \\
\hline Data Preparation & & & & & & & $\checkmark$ & $\checkmark$ & & & & & \\
\hline \multirow[t]{2}{*}{ Analysis } & Snow volume & & & & & & & & $\checkmark$ & & & & \\
\hline & $\begin{array}{l}\text { Interpolated 4NP } \\
\text { concentration }\end{array}$ & & & & & & & & & $\checkmark$ & & & \\
\hline \multirow[t]{2}{*}{ Modeling } & $\begin{array}{l}\text { Total 4NP per mass } \\
\text { glacier }\end{array}$ & & & & & & & & & $\checkmark$ & & & \\
\hline & $\begin{array}{l}\text { Topographic shielding } \\
\& \text { concentration } \\
\text { correlation }\end{array}$ & & & & & & & & & $\checkmark$ & & & \\
\hline
\end{tabular}

\subsubsection{Project Plan Outcomes}

Upon examination of the project's major objectives and the original project plan, it became apparent that the research nature of the project implied an unusually adaptable plan that was unconventional to traditional projects. This resulted in a somewhat altered timeline (Table 3) that differed in time allotted to specific tasks and milestones to meet research needs as they arose. The client's own work and needs were determined by a series of trial and error throughout the project's timeline. Thus, the availability of data rather than deadlines was more influential in the outcome of the project.

Table 3. Project Timeline Outcome

\begin{tabular}{|c|c|c|c|c|c|c|c|c|c|c|c|c|c|}
\hline Major Task & Milestone & Sep & Oct & Nov & Dec & Jan & Feb & Mar & Apr & May & Jun & Jul & Aug \\
\hline Client Discussions & & $\checkmark$ & $\checkmark$ & $\checkmark$ & $\checkmark$ & 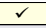 & $\checkmark$ & $\checkmark$ & & & & & \\
\hline \multirow[t]{6}{*}{ Project Proposal } & Initiation & & $\checkmark$ & & & & & & & & & & \\
\hline & Define Scope & & $\checkmark$ & $\checkmark$ & $\checkmark$ & & & & & & & & \\
\hline & \begin{tabular}{|l|} 
Literature Review \\
\end{tabular} & & $\checkmark$ & $\checkmark$ & $\checkmark$ & $\checkmark$ & & & & & & & \\
\hline & Method Development & & $\checkmark$ & 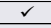 & $\checkmark$ & $\checkmark$ & & & & & & & \\
\hline & \begin{tabular}{|l|} 
Proposal Refinement \\
\end{tabular} & & & & $\checkmark$ & & & & & & & & \\
\hline & Execution & & & & & & $\checkmark$ & & & & & & \\
\hline Research & & $\checkmark$ & $\checkmark$ & 2 & $\checkmark$ & $\checkmark$ & $\checkmark$ & & & & & & \\
\hline Data Acquirement & & & & & & $\checkmark$ & $\checkmark$ & & & $\checkmark$ & & & \\
\hline \begin{tabular}{|l|} 
Data Design \\
\end{tabular} & & & & & & $\checkmark$ & $\checkmark$ & $\checkmark$ & & $\checkmark$ & & & \\
\hline Data Preparation & & & & & & & $\checkmark$ & $\checkmark$ & & $\checkmark$ & & & \\
\hline \multirow[t]{2}{*}{ Analysis } & Snow volume & & & & & & & & & $\checkmark$ & $\checkmark$ & & \\
\hline & \begin{tabular}{|l|}
$\begin{array}{l}\text { Interpolated 4NP } \\
\text { concentration }\end{array}$ \\
\end{tabular} & & & & & & & & & $\checkmark$ & & & \\
\hline \multirow[t]{2}{*}{ Modeling } & Total 4NP mass & & & & & & & & & $\checkmark$ & $\checkmark$ & & \\
\hline & $\begin{array}{l}\text { Topographic shielding } \\
\text { \& concentration } \\
\text { correlation }\end{array}$ & & & & & & & & & & $\checkmark$ & & \\
\hline
\end{tabular}

The planning stages of the project were accomplished as scheduled. Research, as anticipated, extended throughout the study lifespan to meet specific questions that arose. Data acquirement, design, and preparation took significantly longer than anticipated. The analyses and incorporated models began as scheduled, but revisions and finalizations extended into the following month.

\subsection{Summary}

The project's system design consisted of analyses that were oriented to reach the research requirements defined by the client. The functional requirements were intended to address 
the research challenges. The design was essential in providing a framework for constructing methodologies and strategies for implementation. Following the system design, the various components of the research were organized into a database design. Conceptual and logical models were the next step in preparing the system for implementation. 


\section{Chapter 4 - Database Design}

Prior to the implementation of GIS work, it was critical that extensive work was accomplished to identify the necessary methods for accomplishing the research objectives. Upon the acceptance of the various methodologies, a conceptual model needed to be designed to accurately represent real world elements. The design had to be based on the data so that GIS analyses would correspond and be relevant to the natural phenomenon occurring in the systems. Following the creation of the models, data fitting the structure of the model design had to be retrieved and processed.

\subsection{Conceptual Data Model}

A conceptual model organizes real world elements to visualize and examine their interacting parts in an abstract form. For a data model to be an accurate representation of the client's research questions, the challenges needed to be understood in context of all its interacting components. This was invaluable for understanding the scope of the project as well as the data that will be required as inputs for the analyses. The creation of a Unified Modeling Language (UML) class diagram (Figure 4-1) effectively illustrated these components and how their respective data related with each other, thereby conceptually modeling analysis structures. 


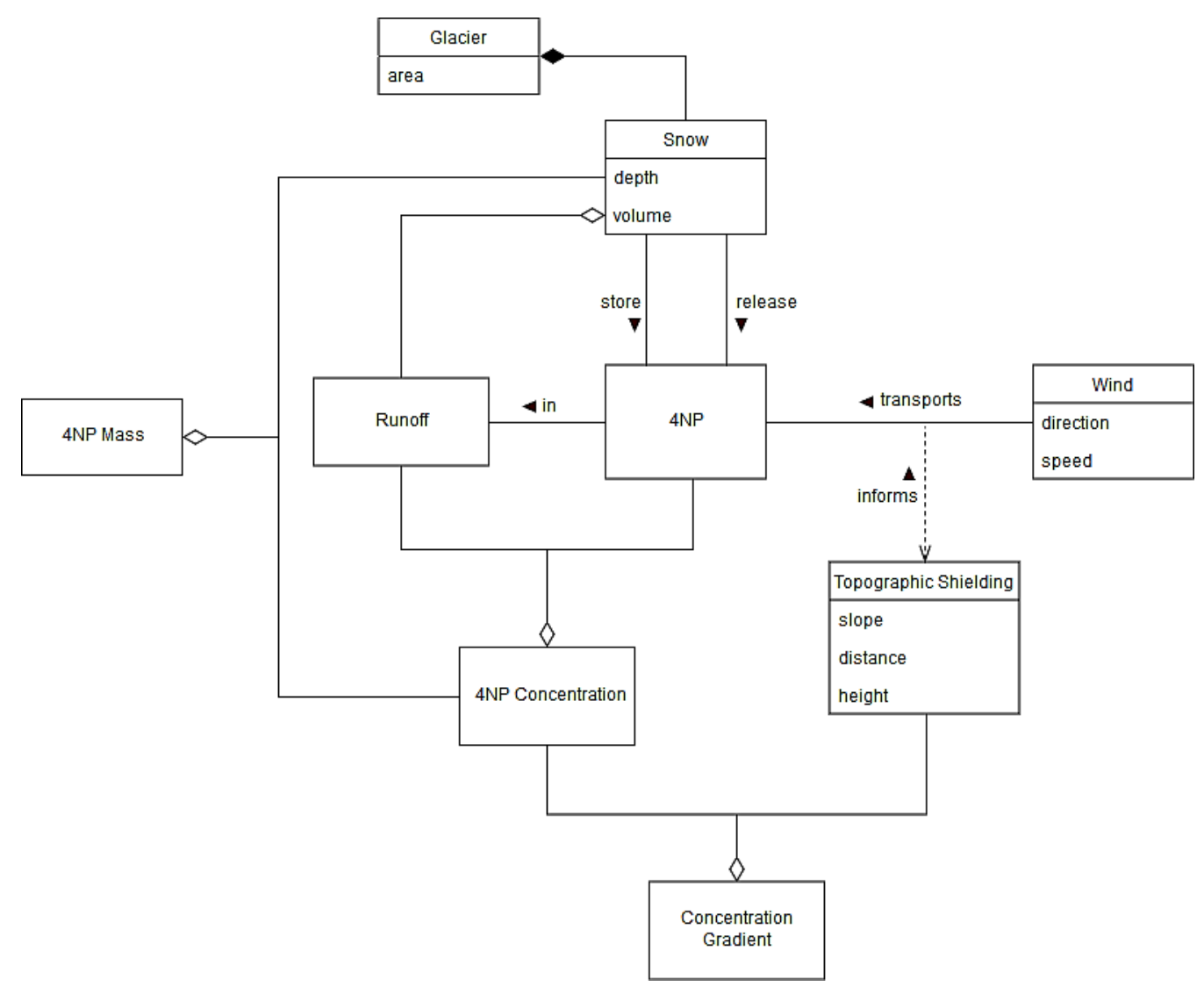

Figure 4-1: Conceptual model of project components and relationships

While the UML class diagram had not been historically used to model environmental processes, it proved effective in cohesively encapsulating complex systems without disregarding seemingly simple real-world elements. The conceptual model served as a translation of an environmental narrative broken down into its interacting components. The diagram is valuable in both modeling established relationships while simultaneously allowing further research assumptions and hypotheses to be tested. After the narrative was described in a conceptual model, the interacting and parts were implemented in a logical data model to translate data into objective functionality. The components' interconnecting associations formed the basis of workflow constructions. Lastly, the UML class diagram aids in the exploration and expansion of future research and GIS work.

\subsection{Logical Data Model}

Before implementation could begin, data needed to be converted into meaningful information by following the logic and structure behind the conceptual model. A logical model describes the relationship between data and the methodologies designed to reach project objectives. Each component of the conceptual data model was implemented in the form of rasters and feature classes from tables in ArcGIS Pro. Topographic shielding was integrated with wind direction and speed and resulted in a point feature class. Snow 
volume was determined by using two LiDAR LAS datasets. After 4NP concentration points were converted to a point feature class, a total 4NP mass was determined by multiplying an interpolated 4NP concentration raster with the snow volume raster. Spatially joining the concentration points with topographic shielding point feature class resulted in shielding values for sample locations. This led to a concentration gradient that quantitatively described logarithmic trends related to topographic shielding.

\subsection{Data Sources}

Data used throughout the project was compiled and organized in a list (Table 4).

Table 4. Master Data List

\begin{tabular}{|l|l|l|l|}
\hline \multicolumn{1}{|c|}{ Name } & \multicolumn{1}{|c|}{ Source } & \multicolumn{1}{c|}{ File Type } & \multicolumn{1}{c|}{$\begin{array}{c}\text { Processing } \\
\text { Required }\end{array}$} \\
\hline $\begin{array}{l}\text { Snow Coverage } \\
\text { LiDAR data }\end{array}$ & $\begin{array}{l}\text { NASA Airborne Snow } \\
\text { Observatory }\end{array}$ & .las files & Yes \\
\hline $\begin{array}{l}\text { 4NP } \\
\text { Concentration }\end{array}$ & Client data & csv & Yes \\
\hline $\begin{array}{l}\text { Wind Speed \& } \\
\text { Direction }\end{array}$ & $\begin{array}{l}\text { National Renewable Energy } \\
\text { Laboratory (NREL) } \\
\text { https://maps.nrel.gov/wind- } \\
\text { prospector }\end{array}$ & json & Yes \\
\hline Ridgeline & $\begin{array}{l}\text { USGS National Hydrography } \\
\text { Dataset } \\
\text { https://viewer.nationalmap.gov }\end{array}$ & shapefile & Yes \\
\hline DEM & $\begin{array}{l}\text { USGS } \\
\text { https://viewer.nationalmap.gov }\end{array}$ & raster & Yes \\
\hline
\end{tabular}

After conducting a literature review, it was decided that the project would employ a method which utilized LiDAR for determining glacier volume. Following the method's procedures, it was understood that there were specific data that had to be obtained for the method to be successfully implemented in the project. The primary data required for the first stage of the project was surface elevation data. Once the method was proposed and accepted, it required one dataset to serve as maximum snow, or snow-on coverage and a second dataset to serve as minimum snow, or snow-off coverage. Both datasets had to include point cloud data that covered the research study area. The client had expressed interest in data from the NASA Airborne Snow Observatory data. Two sets of LiDAR point cloud data were retrieved from NASA via email correspondence with Kathryn Bormann, a NASA Jet Propulsion Laboratory (JPL) project scientist with the ASO. The first set of point cloud data was collected on August 30, 2014 and served as the snow-off layer. A second set of point cloud data collected on April 28, 2018 served as the snow-on layer. The second data requirement was met by the client when she and her team of researchers provided the 4-nonylphenol concentrations. The sampling data was collected in July 2018 and processed in the laboratory in the following months. The data was delivered as a CSV file with X and Y coordinates representing sampling sites and 4NP 
concentrations. Lastly, a ridgeline shapefile was obtained from the Watershed Boundary Dataset provided by the USDA-NRCS, USGS and EPA. The USGS National Hydrography Dataset can be retrieved at https://viewer.nationalmap.gov.

\subsection{Data Scrubbing and Loading}

Three sets of data were acquired for the implementation of the project analyses. They consisted of LiDAR point cloud data from the NASA ASO, the client's research teams, and the inputs for the topographic shielding model. Each set of data provided the foundation for the file processing necessary for vector and raster-based analyses.

\subsubsection{LiDAR}

To verify that the LiDAR data from the NASA Airborne Snow Observatory (ASO) were contained in the study area, the las files were loaded with the appropriate coordinate systems. A LAS dataset was created for both sets of las files to confirm that the datasets contained point cloud data covering the project's location of interest. Unlike raster datasets, a LAS dataset could not be stored in a geodatabase. It exists as a binary file which is generated and stored in a file system (U.S. Fish \& Wildlife Service, 2016). The LAS dataset included the projected coordinate system specified by the project scientist in charge of the data. The Create LAS Dataset tool was used to create two LAS datasets representing "snow-on" and "snow-off." Specifying WGS 1984 UTM Zone 11N as the horizontal coordinate system and WGS 1984 as the vertical coordinate system verified that there was point cloud data in the glaciers of interest. A polygon feature class of the target area was created, and the point cloud data of the glacier area of both datasets was isolated using the Extract LAS tool.

A basic but fundamental assumption regarding the LiDAR data was that any registered ground returns in the glacier area represented snow returns. The two LiDAR data sets from the NASA ASO consisted of a large amount of points classified as medium vegetation with far fewer classified as ground points. Historical studies observed that the Palisade Glacier consisted of "strictly ice, snow, and rock; no vegetation, not even lichen can be found adjacent to the glacier" (Trent, 1983 as cited in Guyton, 1998). Following client confirmation and satellite and digital imagery investigation confirming the lack of vegetation in Middle Palisade Glacier, it was decided that most of the returns were misclassified. The points were reclassified from "medium vegetation" to "ground" using the Change LAS Class Codes tool in ArcGIS Pro.

\subsubsection{NP Concentration Sampling Data}

The concentration data delivered in a CSV file had some errors in coordinate entries and had to be corrected before processing. The CSV file was added to the table of contents. The XY Table to Point tool was then used to create a point layer that located the sample sites in the glacier (Figure 4-2). 


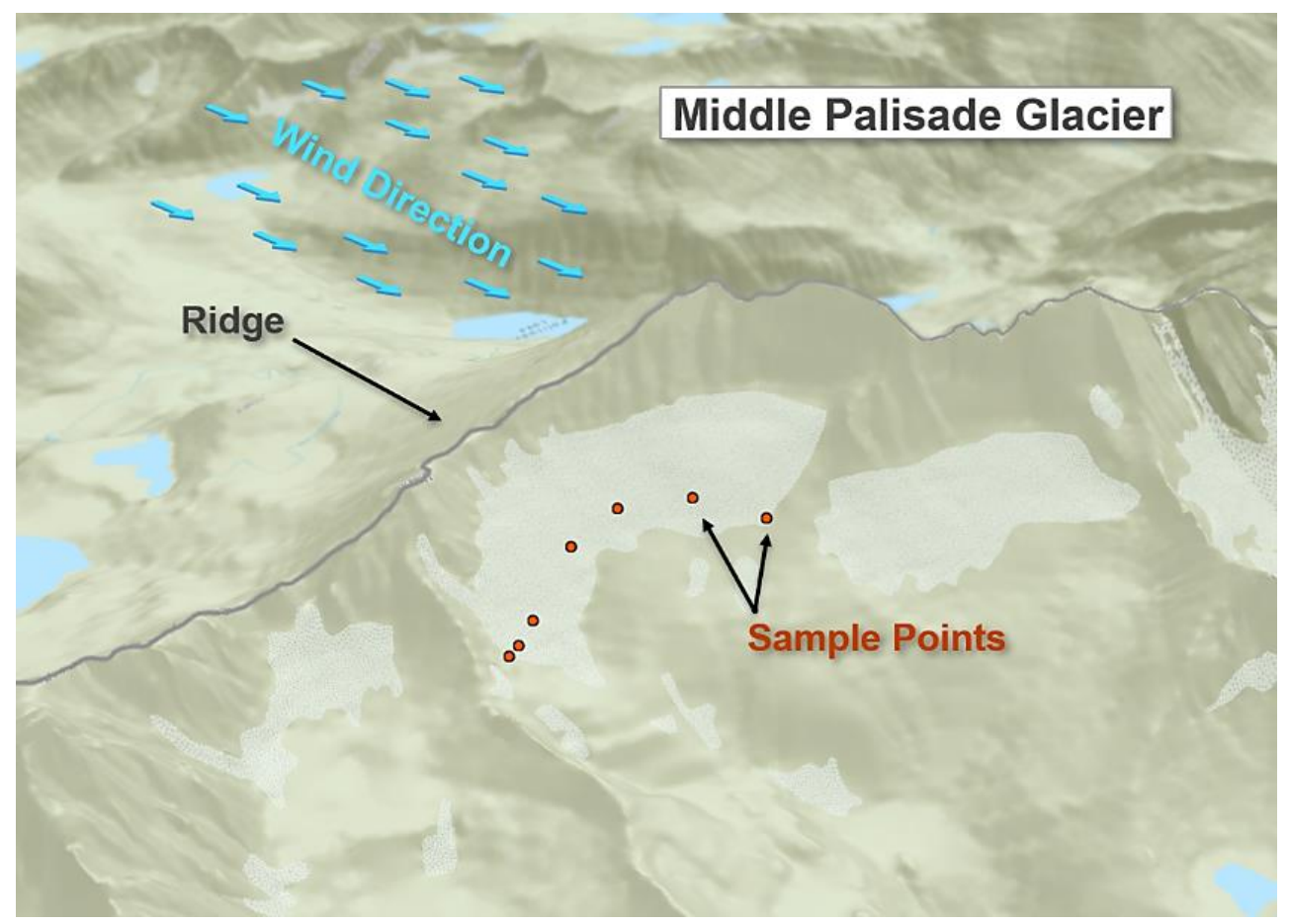

Figure 4-2: 4NP concentration sample sites.

\subsubsection{Topographic Shielding Model Inputs}

The topographic shielding model that was refined and integrated into the project was built on wind, ridgeline boundaries, and elevation data. Average wind direction and speed from 2013 was retrieved as 40-meter GeoJSON files from the Wind Prospector maintained by the National Renewable Energy Laboratory (NREL). Ridgelines were extracted from the USGS National Hydrography Dataset High Resolution provided by The National Map. 90-meter DEMs were retrieved from USGS and used to generate elevation values as inputs for the topographic shielding model. The input data were processed and existed as feature classes that were copied off a server and implemented in an individual ArcGIS Pro Project.

\subsection{Summary}

The project's data design phase consisted of procedures that would deliver a comprehensive understanding of the data needs, the datasets' interactions with one another, and their specific functions in the analyses. Designing a conceptual model and a subsequent logical model provided a framework that ensured that the project would move towards its intended objectives. Systematic design occurred before the implementation phase of the project was initiated. A conceptual model provided a way of translating a natural phenomenon and research narrative into a system that could later be used to extract workflows. This required that the next process, the creation of the components of the logical model, be actualized in the form of functional data. Data processing and loading was essential before the implementation of analyses could begin. This design 
process consisted of the major decisions of methodologies and their associated data, addressing errors, and preparing the data for project implementation. 


\section{Chapter 5 - Implementation}

The implementation phase was structured to produce results that would meet the project's objectives. This chapter describes the bulk of the primary work done to achieve the research requirements. The methodologies, both researched and created, were designed to determine the presence of 4-nonylphenol (4NP) in glaciers. Implementation was intended to build on, refine, and integrate the client and other research contributors' accomplishments at the time of the study.

Each component of the project was structured to support the hypothesis of local shielding phenomenon for concentration presence and provide an analysis for total 4NP mass. The calculation of 4NP mass $(M)$, given volume $(V)$ and concentration or density (D) is provided in Equation 3-1.

$$
M=V * D
$$

However, before implementing the analyses, the general mass equation was further expounded to develop the details of the volume and density variables. This was necessary to account for the raster analysis method designed to determine the total mass of 4NP. This new equation was specifically developed so that the mass could be calculated on an individual unit or cell basis. The mass of $4 \mathrm{NP}$ in the glacier $(M)$ for each raster cell can be estimated as

$$
M=\frac{V * \rho_{g} *[4 \mathrm{NP}]}{\rho_{w}}
$$

where $V$ is the glacial volume within a raster cell, $\rho_{g}$ is the density of the glacier, [4NP] is the density of 4-nonylphenol in snow water, and $\rho_{w}$ is the density of water.

This chapter examines the procedures to derive glacial volume and the 4NP concentration necessary to find total 4NP mass. Sections 5.1 through 5.3 address glacial snow mass measurements using LiDAR and 4NP concentration glacial estimations based on regression analysis. Section 5.4 discusses the incorporation of volume and density to derive a total 4NP mass.

All workflow and analyses work were conducted in ArcGIS Pro 2.3 and specifically based on the sampling data from the southern glacier of Middle Palisade Glacier as determined by the availability of client data at the time of the study. The project objective was to create and establish testable practices and workflows. The series of analytical steps described were intended to advance and expand the client's research work to other glaciers.

\subsection{Calculating Snow Volume}

The calculation of snow volume consisted of a set of raster analyses. The use of digital elevation models (DEMs) generated from LiDAR methods was an essential part of obtaining snow depth and volume measurements. 


\subsubsection{LiDAR Data Preparation}

Before raster analysis could begin, LiDAR data had to be first loaded, examined, and processed in ArcGIS Pro. Figure 5-1 shows the four-step process of loading and processing the basic LiDAR las files for use. Once LAS Datasets were created to host the snow-on and snow-off files in the appropriate coordinate systems, the points that existed within the glacial area polygon were extracted using the Extract LAS tool in ArcGIS Pro. Lastly, the LAS class codes of the points in the glacier, originally misclassified as "medium vegetation", were changed to "ground" to represent snow surfaces captured by the airborne sensors.

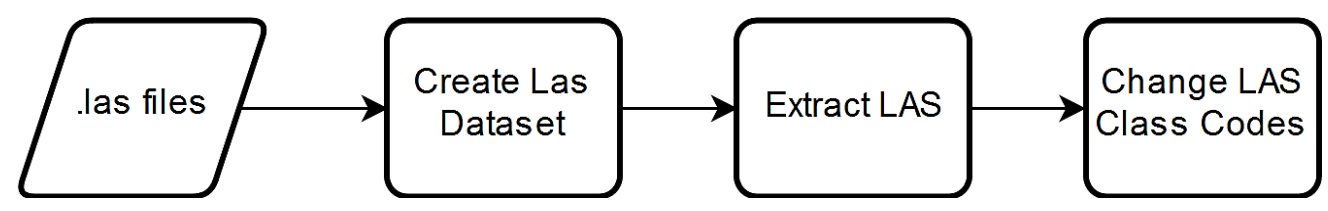

Figure 5-1: LiDAR data processing.

\subsubsection{Snow Volume Calculation}

Raster analysis began following the completion of LiDAR data preparation. First, the point cloud las files were converted to DEMs using the LAS Dataset to Raster tool in ArcGIS Pro. The two DEMs, one for snow-on and the other for snow-off, were needed to determine the elevation difference between the snow-on and snow-off seasons. The procedures for generating the snow volume are outlined in Figure 5-2.

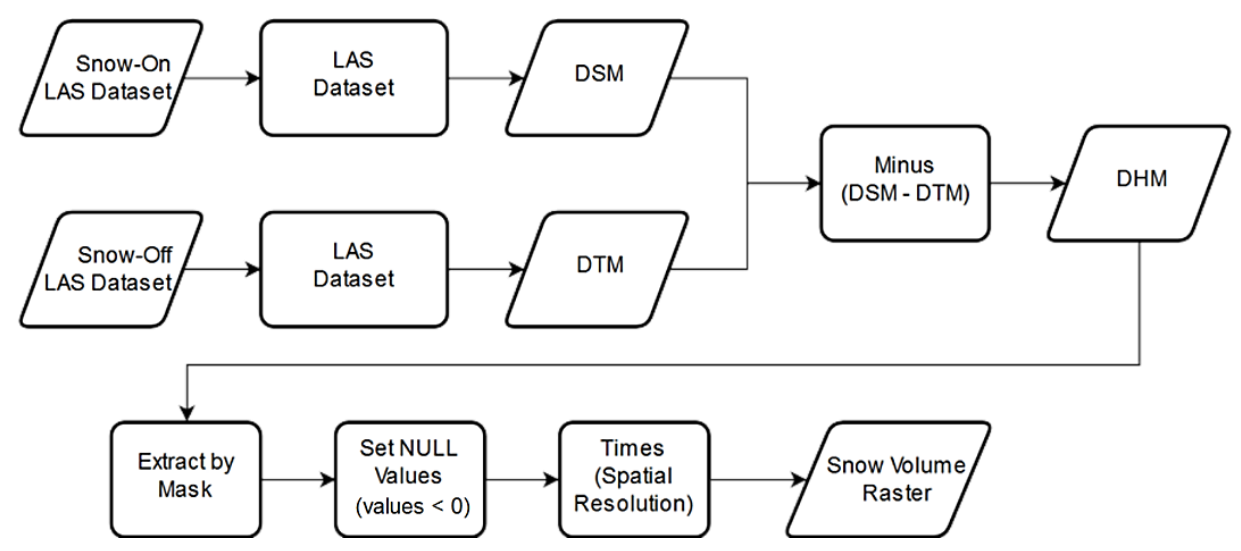

Figure 5-2: Snow volume raster analysis workflow.

For the purpose of understanding the analysis process, the snow-covered surface served as the digital surface model (DSM), while the snow-free surface was represented as the digital terrain model (DTM). The digital height model (DHM) is the result of the difference between the surface model and terrain model (Equation 5-2).

$$
D H M=D S M-D T M
$$


The DHM was generated using the Minus geoprocessing tool to subtract cell values of the two corresponding rasters. This stores the snow elevation difference of the two snow coverage periods as the height (z) value of each cell in the DHM. The DHM was then clipped to the glacial snow area using the Extract by Mask tool so that cells contained in the area were included in the raster. After the DHM was generated, any negative values were set as NULL and removed from future calculations. It is worth noting that while this process of setting negative values as NULL was implemented, other approaches should be considered. The replacement of negative cells with a constant value or the absolute value of the elevation difference is an approach worth considering for future analyses. The raster's values were then multiplied by the raster's spatial resolution. This resulting raster contained the components of a cuboid in each cell necessary for volume measurements: the height $(\mathrm{z})$, width $(\mathrm{x})$, and length $(\mathrm{y})$ of the cell. This transformed the DHM into a raster that contained a snow volume value for each cell.

Additionally, total seasonal snow volume could be quantitively described by using the Zonal Statistics as Table tool to find the sum of all cell values. This final additional step reported an estimation of the total accumulation of snow between two time periods. This estimation served as the total quantitative seasonal snow volume in glacial areas.

\subsection{NP Concentration Estimation}

The effect of topographic shielding was hypothesized to be a contributing indicator of the presence of 4NP in glaciers. To address the challenge of estimating the 4NP concentration throughout a glacial space, topographic shielding had to be first determined for any given location in the glacier. The determining factors for topographic shielding include prevailing wind direction and the headwall or ridge's slope, height, and distance to the sample site.

\subsubsection{Prevailing Wind Direction}

Prior to calculating the topographic shielding index of a location in space, wind direction was an important contributing factor in the investigation. The previous research indicating that topographic shielding directly influences 4NP glacial deposition and therefore concentration is based on the behavior of prevailing wind movement towards the glacier. Prevailing wind direction was a necessary component in deriving topographic shielding values at specific locations in the glacier by providing the bearing distance necessary for the calculations. To illustrate this and provide inputs into the model, a wind map (Figure 5-3) was created from 40-meter 2013 average annual wind direction and speed GeoJSON files. The files were converted to polygons using the "JSON to Features" conversion tool. The polygons were then clipped to the ridgeline. Wind speed and direction were spatially joined and symbolized. Since wind direction is reported as the degree of origin, symbols were rotated $180^{\circ}$ to display arrows in the direction the wind was moving. The annual average north-easterly direction of the wind movement supported the concept of prevailing winds in modeling 4NP presence and topographic shielding influences. 


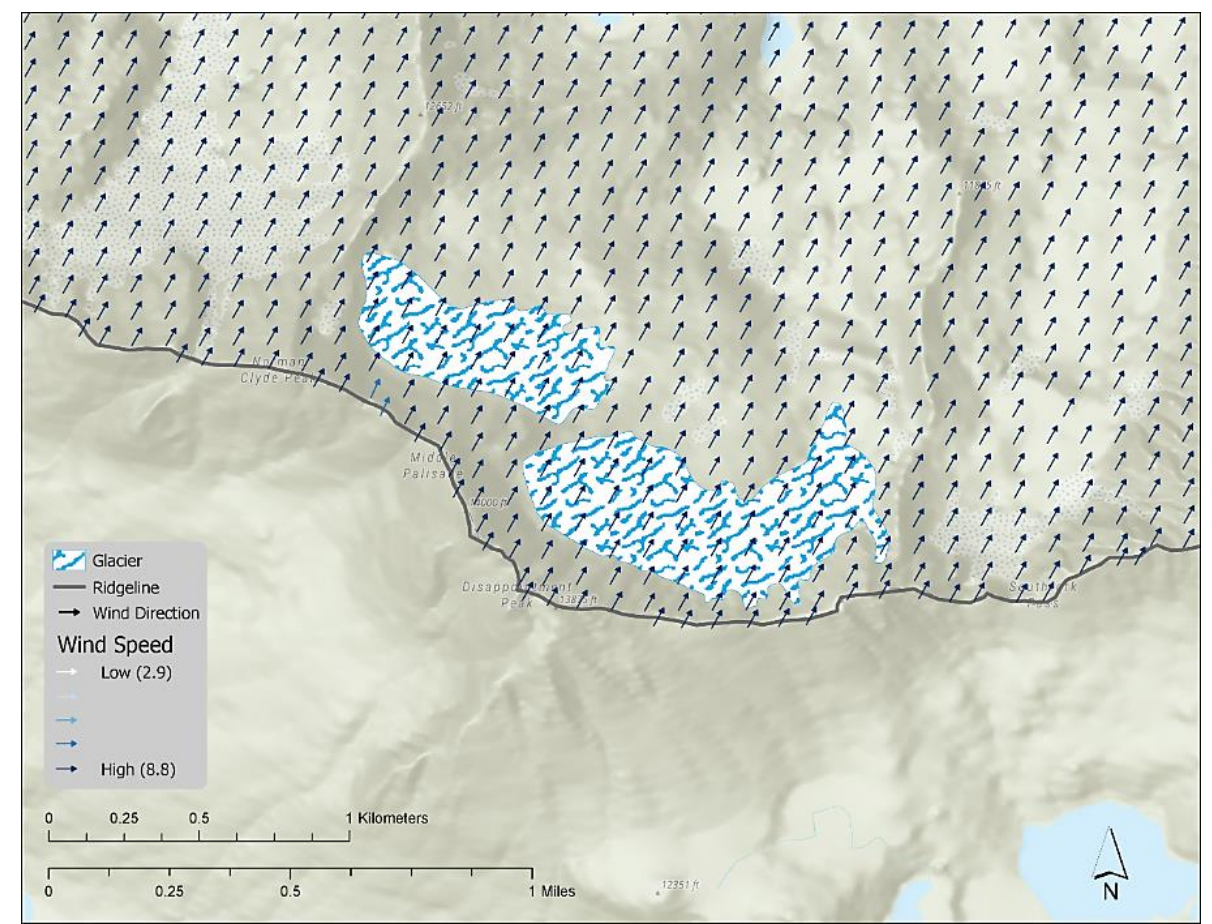

Figure 5-3: Prevailing wind direction in the Middle Palisade Glacier.

\subsubsection{Topographic Shielding Index}

The topographic shielding index denoted as $T$, an indicator of the shielding effect of a ridgeline or physical barrier, is calculated as

$$
T=\frac{S * H}{D}
$$

where $S$ is the slope of the ridge, $H$ is the height of the ridge from the sample site, and $D$ is the horizontal distance from the same sample site.

A model developed by the University of Redlands' Center for Spatial Studies was used to automate and simplify the topographic shielding calculation workflow. The model incorporates wind direction, distance to the ridge along the wind direction, elevation, and slope values in the calculation. It is important to note that the model requires file inputs that exist on the Spatial Studies server. Running the model will require a connection to the server. The custom tool prompts the user for parameter inputs for the model execution (Figure 5-4). 


\begin{tabular}{l} 
Geoprocessing \\
Topographic Shielding Generator \\
Parameters Environments \\
Input Points \\
\hline Palisades_ShieldinglnputPoints \\
Wind Direction Field \\
\hline winddirection \\
Ridgeline Segments \\
\hline PalisadesRidgeline_Intersect \\
Ridgeline Clip Polygon \\
\hline Palisades_AOl \\
Output Shielding Points \\
\hline Palisades_Shielding \\
\hline
\end{tabular}

\section{Figure 5-4: Topographic Shielding Custom Tool Prompt}

The inputs include a point feature class containing elevation and wind direction fields, a ridgeline segment with elevation and slope, and a polygon used to clip geodetic lines to measure distances to the ridge. The model was designed to integrate input points containing elevation and wind direction values with a ridgeline feature class that contained ridge slope and elevation values extracted from a USGS 90-meter DEM. A detailed description of the model is available in Appendix A.

\subsection{Shielding-based Concentration}

The hypothesis that topographic shielding influences concentration implied an association between the shielding and concentration values. The objective was to use topographic shielding as an indicator of 4-nonylphenol (4NP) presence by predicting its concentration at a location based on the shielding effect of the local topography. This was accomplished by determining a logarithmic equation from the reported 4NP sample concentrations of Middle Palisade Glacier's southern glacier to estimate concentration values for the Palisade and Middle Palisade Glacier.

\subsubsection{Concentration Function}

Establishing a relationship between shielding and concentration was central to the study. A workflow (Figure 5-5) was devised that would integrate topographic shielding values 
with the concentration samples to create a regression analysis for a 4NP concentration function.

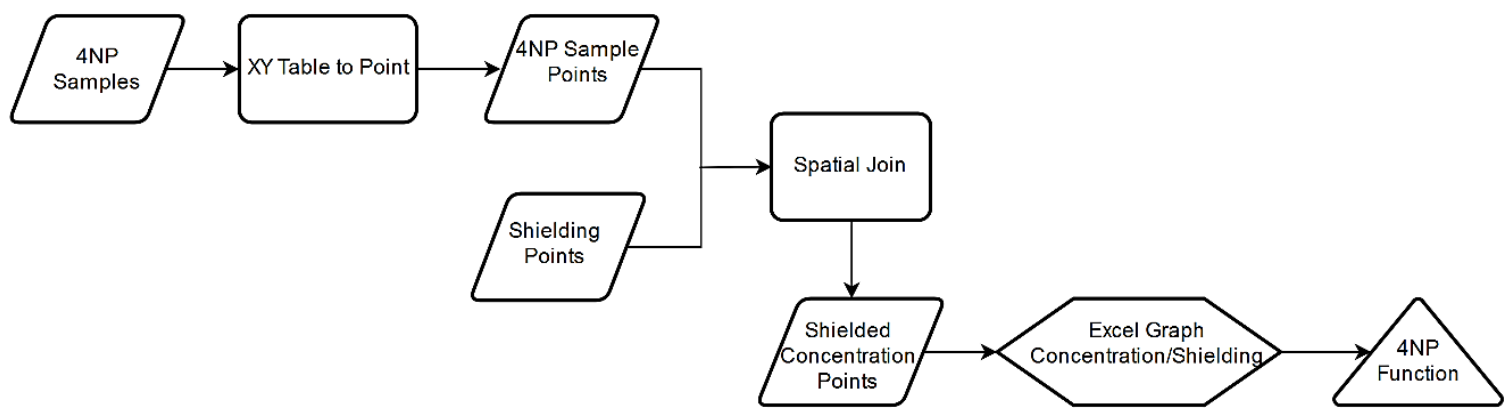

Figure 5-5: Workflow for determining 4NP concentration function.

The 4NP sampling point coordinates in Middle Palisade Glacier's southern glacier and their associated concentrations in parts per million (ppm), equivalent to $\mathrm{mg} / \mathrm{L}$, were provided by the client as a CSV file. Inputting the file into the XY Table to Point geoprocessing tool created a new point feature class. The result was a feature class with seven sampling points containing concentration of 4NP in ppm (Figure 5-6).

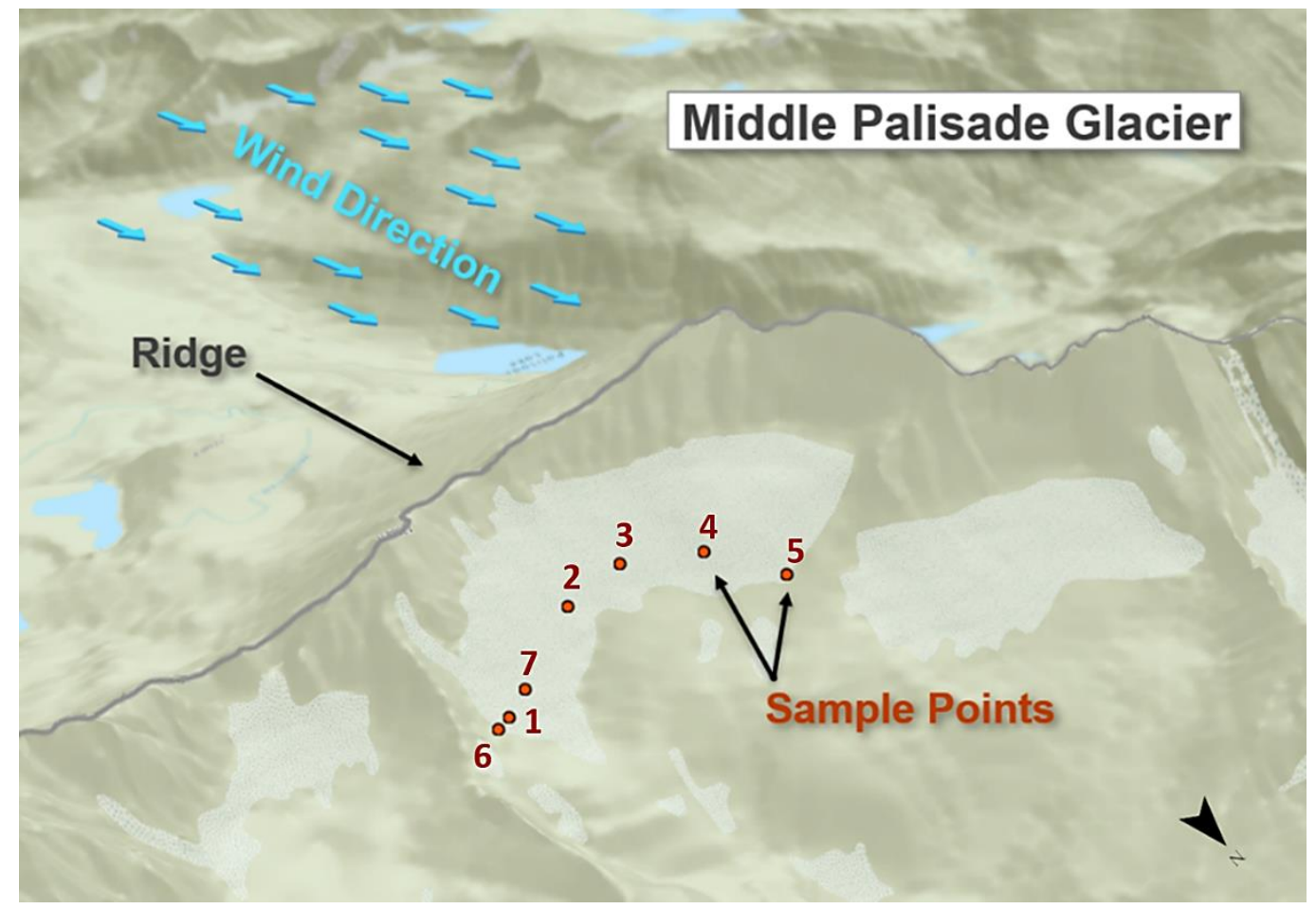

Figure 5-6: Concentration sample points in Middle Palisade Glacier 
The 4NP concentration point feature class created was spatially joined with the topographic shielding point feature class. This resulted in shielding values for each feature in the concentration feature class (Figure 5-7).

\begin{tabular}{|l|r|r|r|r|r|r|r|}
\hline Sample & AvgCon_ppm & Latitude & Longitude & RidgeDist (D) & RidgeSlope (S) & RidgeElevDif (H) & ShieldingVal (T) \\
\hline 1 & 0.0097 & 37.07149 & -118.45746 & 600.001482 & 11.14575 & 327.564 & 13.106344 \\
\hline 2 & 0.0188 & 37.07011 & -118.46034 & 386.29165 & 16.5407 & 260.429 & 15.737755 \\
\hline 3 & 0.0291 & 37.07004 & -118.46194 & 369.379597 & 16.5407 & 246.988 & 15.608879 \\
\hline 4 & 0.0115 & 37.07112 & -118.46344 & 435.046561 & 32.71792 & 315.84 & 19.879623 \\
\hline 5 & 0.012 & 37.0726 & -118.46449 & 513.135691 & 8.260968 & 367.171 & 24.346882 \\
\hline 6 & 0.077 & 37.071667 & -118.45702 & 606.03019 & 24.53818 & 299.638 & 3.917581 \\
\hline 7 & 0.0189 & 37.071111 & -118.458217 & 499.234611 & 16.5407 & 327.681 & 15.75739 \\
\hline
\end{tabular}

Figure 5-7: Attribute table of Middle Palisade Glacier 4NP concentration samples

Next, the concentration field and shielding value fields created in Section 5.3.1 were plotted as a graph in Excel (Figure 5-8) according to the sample number. A logarithmic equation was derived from a generated trendline based on the sample points (Equation 54). The function estimates each concentration given a shielding value.

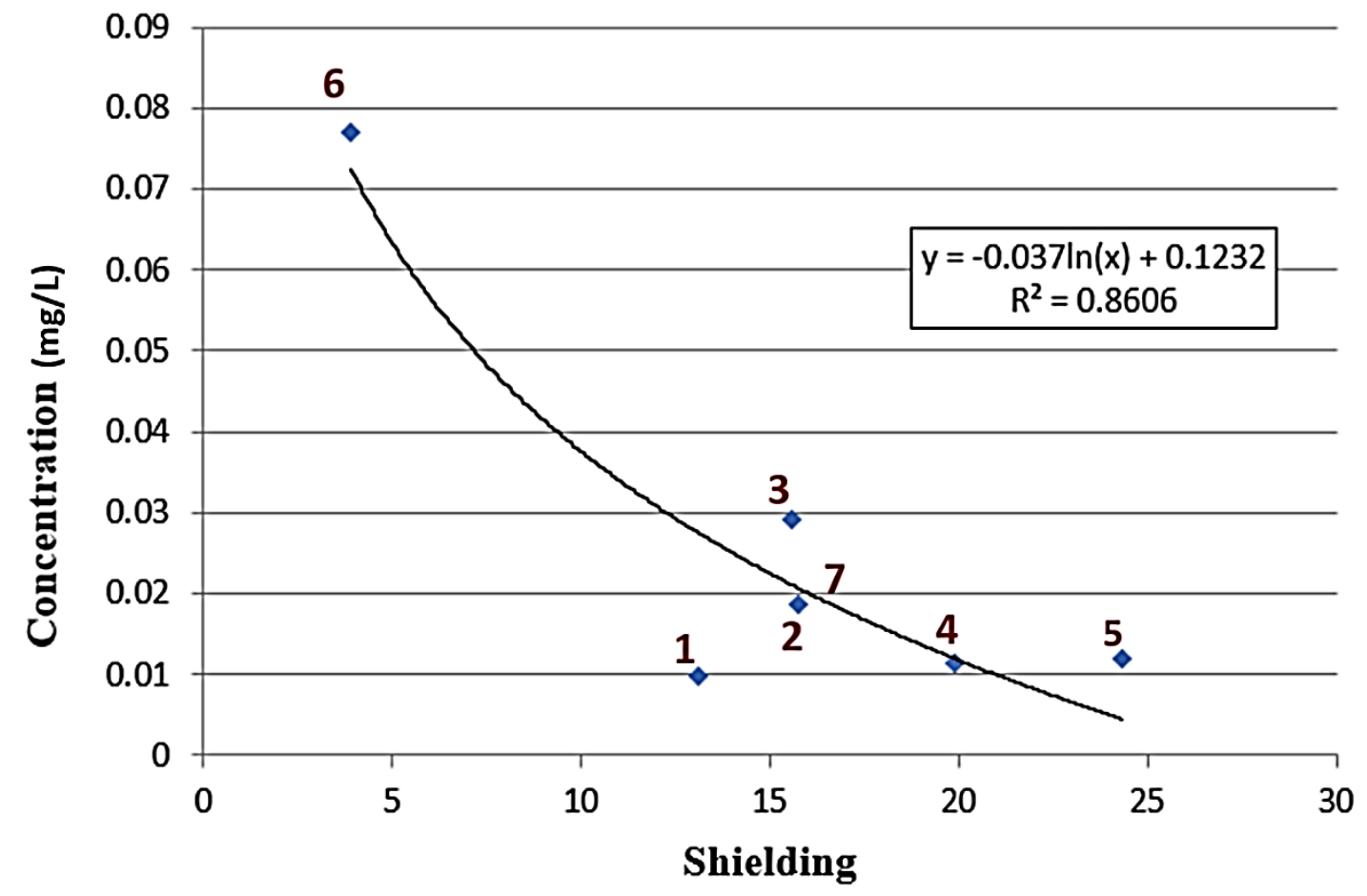

Figure 5-8: Graph of shielding values ( $x$-axis) and concentration ( $y$-axis) of samples

$$
y=-0.037 \ln (x)+0.1232
$$


The coefficient of determination, r-squared denoted by $r^{2}$, interprets how well the regression line fits the observations in the $\mathrm{X}$ and $\mathrm{Y}$ scatterplot. More specifically, the $\mathrm{r}$ squared is an indicator of the proportion of the total variation in $Y$ accounted for by the regression relationship (Burt, Barber, \& Rigby, 2009). $R^{2}$ is calculated by dividing the regression of the sum of squares by the total sum of squares. When $r^{2}=1$, the scatterplot's line has passed through all the points and the regression has explained 100\% of the total variation in the variable $Y$. Thus, the high r-squared of 0.86 reported in this study is an indication that there is a strong association between the predicted $Y$ concentration estimation and the $X$ shielding index. The r-squared value of 0.86 states that topographic shielding explains or accounts for $86 \%$ of the variation of concentration.

\subsubsection{Concentration Estimation}

The implementation of the concentration function allowed for the prediction of concentration values at locations in space where sampling had yet to take place. A concentration raster needed to be created that would be used for the final mass calculation. This required a simple but necessary series of steps outlined in Figure 5-9.

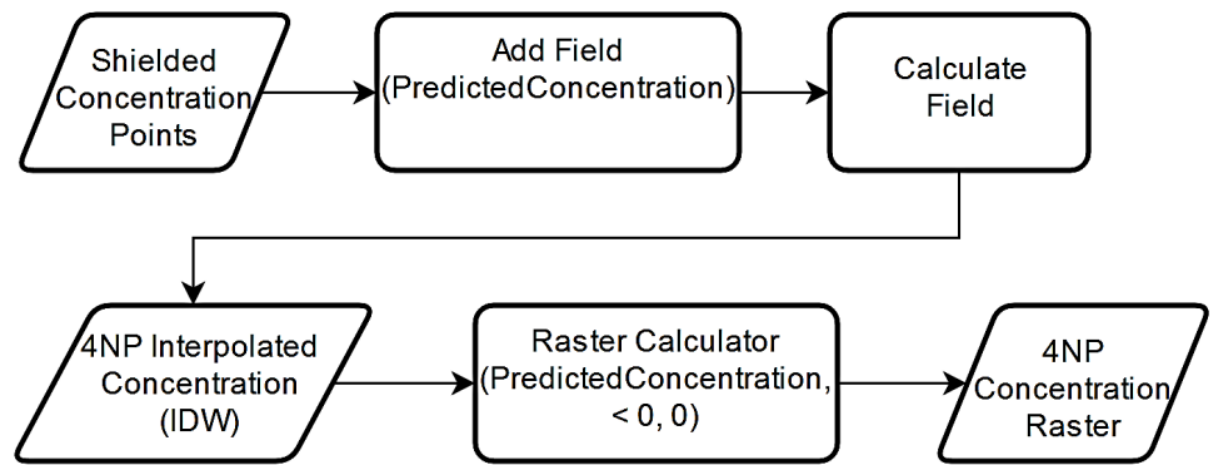

Figure 5-9: Concentration estimation raster workflow.

Once shielding values were determined for Middle Palisade Glacier's northern glacier, a predicted concentration field was added to the feature class. The Calculate Field tool was used to populate the field with the predicted value determined by the logarithmic equation which was written in Python 3 (Equation 5-5). This process estimated concentration values in ppm for each shielding point.

$$
\text { PredictedConcentration }=-0.037 * \text { math. } \log (! \text { ShieldingVal! })+0.1232
$$

Eq. 5-5

Following the creation of the estimated concentration point feature class, an interpolated raster surface was generated using the inverse distance weighted (IDW) method. This method gives measured values nearest to the predicted location more 
influence than measured values further away. The IDW method interpolated the predicted concentration values to the area extent, thus adding estimation values at surface locations within the glacier (Figure 5-10). The output cell size was determined by the snow volume raster created in Section 5.1.2. This output raster would serve as the density factor for the total 4NP mass calculation. Additionally, similar concentration prediction rasters in other glaciers were generated following the previous approach.

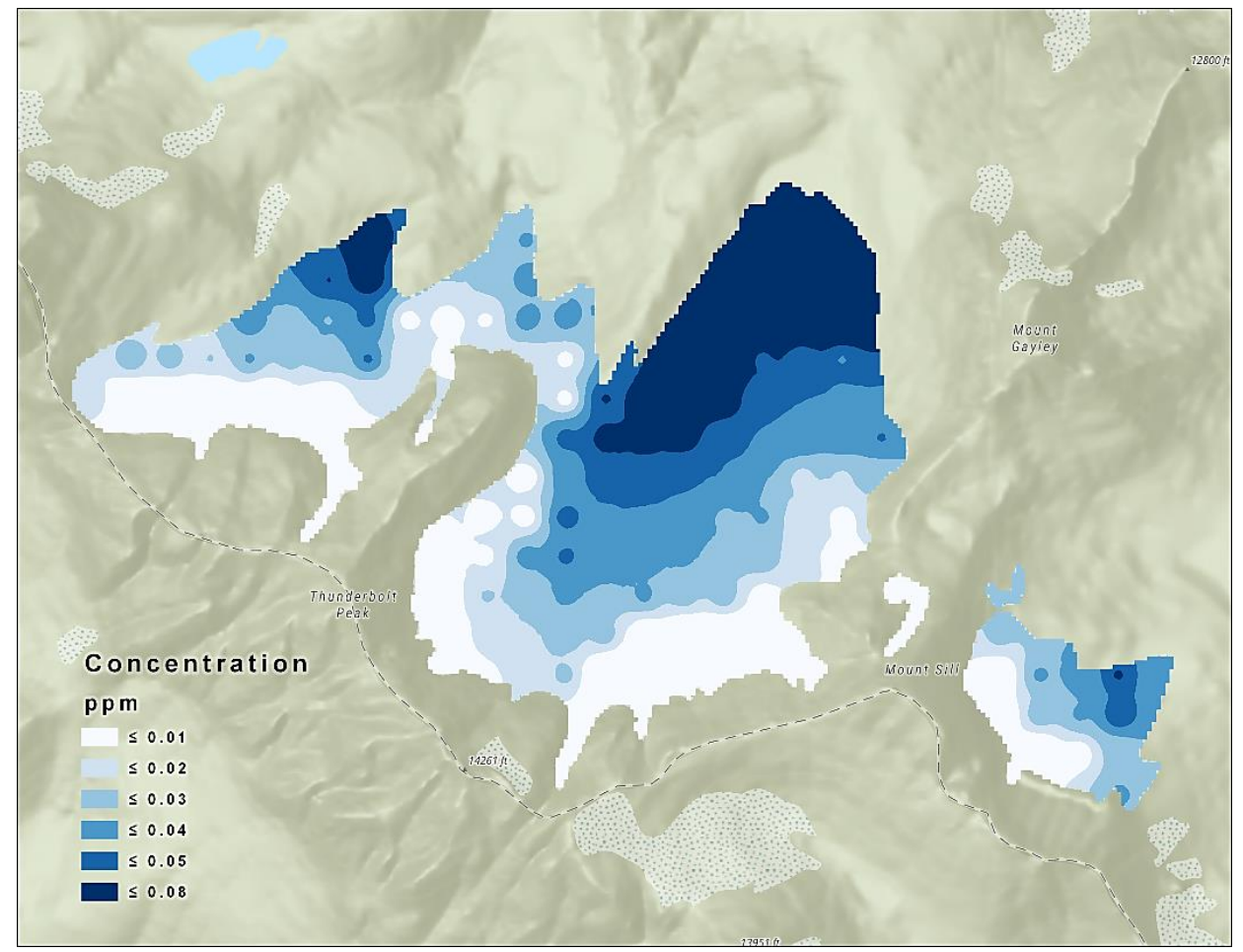

Figure 5-10: Palisade Glacier interpolated concentration estimations.

\subsection{Total Mass}

Once a snow volume raster and 4-nonylphenol density raster were created, the mass of 4NP was calculated by using the mass equation presented in Equation 5-1. Additionally, 4NP mass required estimates of density which was included in the density raster. The general workflow for calculating total 4NP mass consisted of three rasters (Figure 5-11). An additional multiplication was applied to the snow volume raster to account for snow and water density. Finally, the snow volume raster was multiplied with the 4NP density raster to produce a mass raster. 


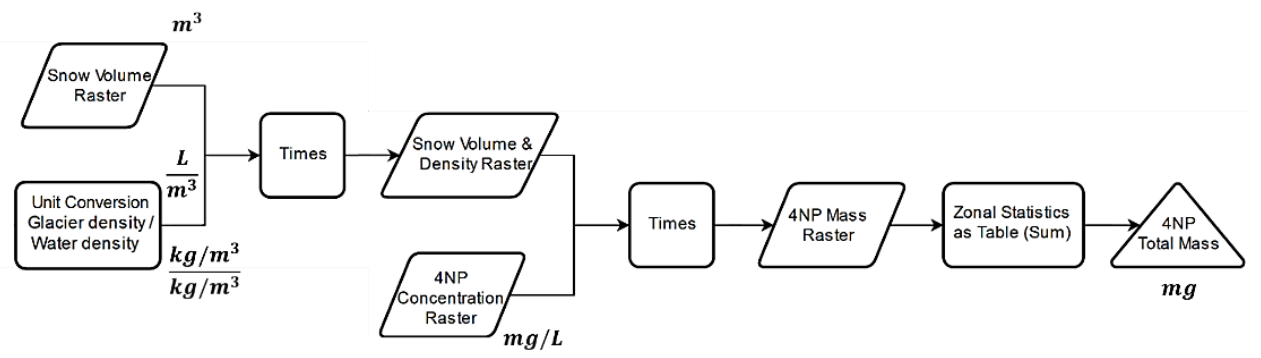

Figure 5-11: Total Mass Workflow

Snow density was estimated to be $625 \mathrm{~kg} / \mathrm{m}^{3}$ based on field data (Lyons, unpublished data, 2018). A water density of $1000 \mathrm{~kg} / \mathrm{m}^{3}$ was likewise important in ensuring the appropriate reported mass units. These values were assigned to both Palisade Glacier and Middle Palisade Glacier and were included in the calculation for total mass. The Multiply geoprocessing tool created a third output raster from the snow volume raster made up of cells that contained a product of the density of glacial snow and calculated snow volume. The total mass of 4NP in the glacier was calculated by multiplying the snow volume raster, with consideration of glacial snow and water density, with the 4NP concentration raster. Finally, running the Zonal Statistics as Table tool to find the sum of all the cell values outputted a table containing the total $4 \mathrm{NP}$ mass.

\subsection{Workflow Models}

After the workflows described in each section were implemented, it was advantageous to construct models in ModelBuilder that would automate and simplify the process. Two models were designed for producing the snow volume and 4NP concentration rasters respectively. The topographic shielding model previously created was integrated in the 4NP concentration model. Lastly, the two models were combined into a single mass model that would seamlessly calculate the 4NP mass in a glacier. A model had the additional benefit of illustrating the different components and factors needed to determine total 4NP mass in a single form. The mass calculator custom tool in Figure 5-12 prompts the user for five inputs: the snow-on and snow-off datasets, the glacial snow area polygon, spatial resolution, and snow and water densities. An image of the models and the exported Python script can be found in Appendix B. 


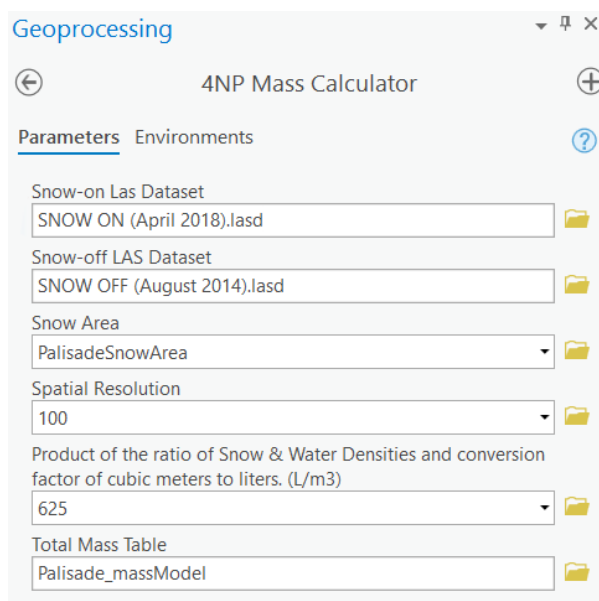

\section{Figure 5-12: 4NP Mass Calculator tool prompt.}

\subsection{Summary}

The implementation stage of the project addressed in this chapter examines the processes and analytical steps taken to reach the objective of the determination of snow volume from a digital height model and the integration of topographic shielding as an input in a function to determine 4NP concentration. The series of data processing and analyses derived and implemented were intended to explore the use of LiDAR to determine glacial snow volume and total 4NP concentration. These components were necessary to achieve the research objective of creating raster analysis workflows that would calculate the total 4NP mass. Additionally, the implementation of these workflows was designed to provide a structure for modeling 4NP presence in other unsampled glaciers. This served as a demonstration of topographic shielding as a predictor of unknown 4NP concentrations.

The various procedures conducted were intended to experiment and explore the methodologies created. A single model, consisting of all the analyses, was constructed to automate the calculations and procedures and provide a client deliverable upon project completion. This approach was helpful in providing a comprehensive understanding of the components involved and to allow for potential adaptation based on future client needs. The implementation phase achieved tested analyses that generated results that are discussed and evaluated in the following chapter. 



\section{Chapter 6 - Results and Analysis}

The results generated from the implementation phase are discussed in this chapter. To meet the research objectives, analytical outcomes were examined, analyzed, and interpreted. The results accomplished by the analyses in this study are valid under several major assumptions. The assumptions associated with each component of the analysis are discussed in each section. Section 6.1 addresses snow volume results from the LiDAR point clouds. The topographic shielding index calculations used to predict 4NP concentration are discussed in Section 6.2. The regression analysis results to determine the relationship between concentration and shielding is examined in Section 6.3. The analytical components in the previous sections are combined to determine 4NP mass in Section 6.4. Lastly, Section 6.5 contains an overview of the challenges addressed in the process of reaching project objectives.

\subsection{Seasonal Snow Volume}

Though not explicitly stated in research articles on LiDAR measurements of snow depth, the LiDAR method for mapping snow coverage was specifically limited to assessing seasonal snow volume. Total glacial volume could not be estimated from LiDAR alone since the point clouds could only measure the difference between seasonal snow and the permanent glacier surface. Thus, 4NP mass reports are only applied to a glacier's seasonal snow accumulation. Determining total glacial volume would have required a different approach, consisting of the sum of the volume of seasonal snow and the volume of permanent glacier. Though estimating 4NP mass did not require reporting snow volume measurements from the raster analysis, quantitative volumes were extracted from the snow volume rasters. The quantitative volumes were part of the project objectives since they would be essential in supporting field reports for future research work.

\subsubsection{Research and Data Assumptions}

There were several major assumptions regarding the use of LiDAR to measure snow volume. First, LiDAR would be able to capture snow elevation surfaces despite snow's high albedo compared to the albedo of bare earth or trees. This was an inherent understanding that was built on the NASA ASO's own work in relying on accurate snow coverage measurements for determining snow depths. Differencing point cloud generated surfaces from two dates was anticipated to allow for the calculation of snow depths at horizontal spatial resolutions at approximately 1 meter (Deems \& Painter, 2006). Second, any returns classified as medium vegetation in the glacier would be reclassified as ground. Third, the assumption in implementing the LiDAR method for estimating snow depth was that snow-on coverage would have greater elevation than snow-off coverage. The last assumption was that the elevation change between snow-off and snow-on specifically accounts for snow accumulation in a single period. 


\subsubsection{Volume Measurement Results}

To validate the digital height elevation (DHM) method of determining the surface difference between snow-on and snow-off coverages, it was advisable to compare its results with the results from the built-in Surface Difference ArcGIS Pro geoprocessing tool. The Surface Difference tool examines the displacement between two surfaces by performing a comparison between triangles generated by the surfaces. The tool, running with snow-on and snow-off datasets as the input and reference surfaces respectively, classified elevations. Classifications were based on generated triangles that would differentiate between areas above, below, and coplanar to the other surface (Figure 6-1). Positive height $(\mathrm{z})$ values denoted areas where the input surface was above the reference, negative $\mathrm{z}$ values illustrate areas where the input surface was below the reference surface to the reference surface. This classification was written and outputted into a polygon feature class.

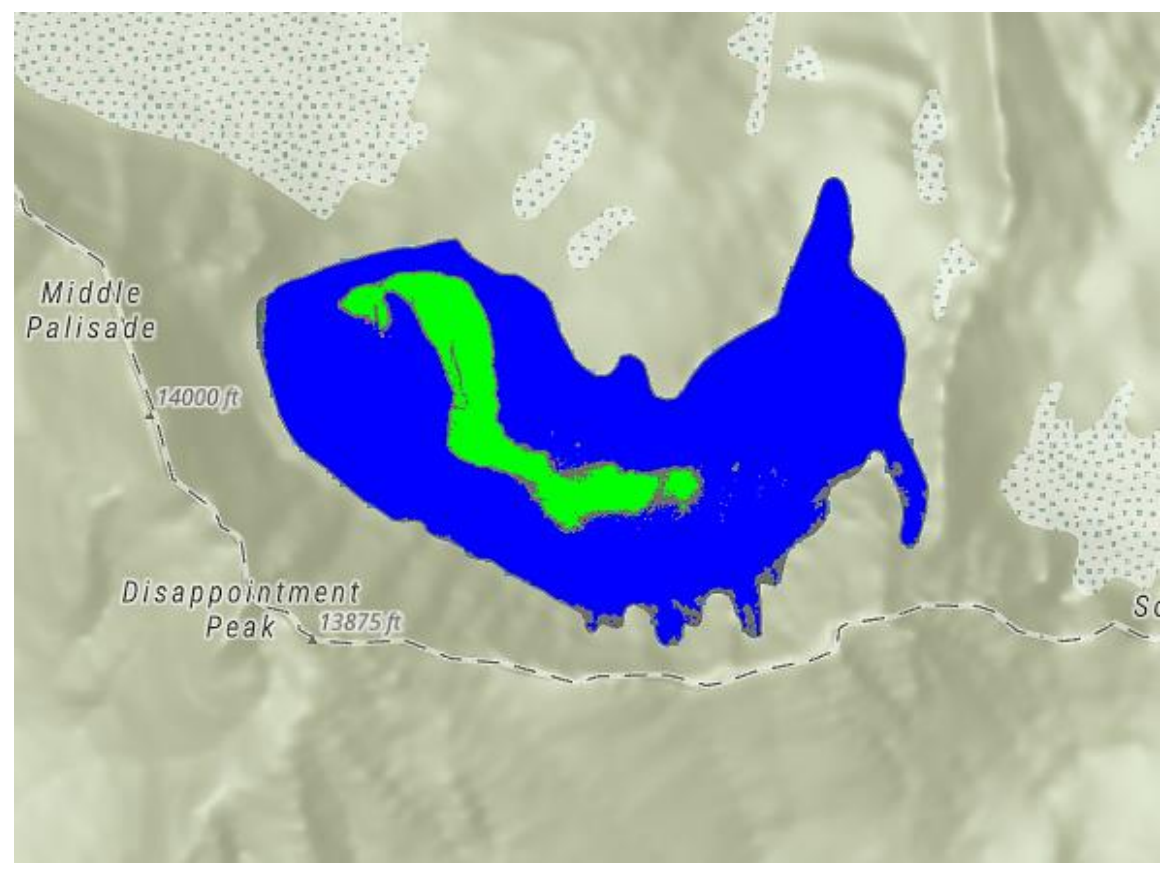

Figure 6-1: Surface Difference calculations for areas above (blue), below, (green), and the same (grey).

After examining the measurements between the two calculation procedures, the total volumes were found to be comparable, thus adding to the validity of the DHM as a highly accurate method of calculating snow volume (Table 5). The DHM method was validated as an accurate approach because it consisted of systematic, analytical steps that could be sequentially understood. The series of raster analyses was logical and consistent with the understanding of data storage and processing in cells. 
Table 5. Comparison of DHM and Surface Difference Results

\author{
Method Palisade Glacier Middle Palisade Glacier
}

\begin{tabular}{l|ll}
\hline Digital Height Model & $3,810,317.38 \mathrm{~m}^{3}$ & $2,785,786.91 \mathrm{~m}^{3}$ \\
Surface Difference & $3,864,200.90 \mathrm{~m}^{3}$ & $2,680,343.05 \mathrm{~m}^{3}$
\end{tabular}

In addition to the snow volume raster, research needs required that the quantitative snow volume results of Palisade Glacier and Middle Palisade Glacier be reported and documented (Table 6). Since Middle Palisade Glacier consisted of two glaciers, results are reported separately. Since the snow coverage reported by the NASA Airborne Snow Observatory was used to determine the area's variation of seasonal snow, this implies that the calculation for glacier snow volume accounts for the total volume of seasonal snow. Glacier seasonal snow volume was calculated using 2014 summer snow-off and 2018 spring snow-on data. Thus, this measurement does not report the total glacial volume in its entirety because glacial ice change was not captured by ASO. This demonstrates that seasonal snow changes could be captured in high accuracy but determining total glacial ice volume would necessitate another approach.

\title{
Table 6. Total Seasonal Snow Volume Results
}

\begin{tabular}{|l|c|c|}
\hline LiDAR Study Area & Surface Area & Seasonal Snow Volume \\
\hline Palisade Glacier & $1,293,988.14 \mathrm{~m}^{2}$ & $3,810,317.38 \mathrm{~m}^{3}$ \\
\hline North Middle Palisade Glacier & $200,721.74 \mathrm{~m}^{2}$ & $1,005,543.29 \mathrm{~m}^{3}$ \\
\hline South Middle Palisade Glacier & $342,298.44 \mathrm{~m}^{2}$ & $1,780,243.63 \mathrm{~m}^{3}$ \\
\hline Total Middle Palisade Glacier & $543,020.18 \mathrm{~m}^{2}$ & $2,785,786.92 \mathrm{~m}^{3}$ \\
\hline
\end{tabular}

The reported total seasonal snow volume values in Table 6 consists of LiDAR capture of fresh spring snow. Based on data from previous studies, fresh or uncompacted snow was measured at its lowest density of $330 \mathrm{~kg} / \mathrm{m}^{3}$ while compacted summer snow had an average density of $625 \mathrm{~kg} / \mathrm{m}^{3}$ (Lyons, unpublished data, 2018). Due to the compaction process of snow over time, total snow volume needed to be adjusted to accurately report snow volume at the time of 4NP sample collection. Since 4NP samples were collected in July 2018 when snow was compacted, the density of compacted snow was applied to the results.

Since total snow mass remained the same, Equation 6-2 could be derived from the mass equation where $V_{c}$ and $V_{u}$ denote volumes of compacted and uncompacted snow respectively, and $D_{c}$ and $D_{u}$ denote the densities of compacted and uncompacted snow respectively.

$$
V_{c} * D_{c}=V_{u} * D_{u}
$$

The compacted seasonal snow volume $\left(V_{c}\right)$ was calculated using Equation 6-2.

$$
V_{c}=\frac{V_{u} * D_{u}}{D_{c}}
$$


This compaction variation in snow volume was adjusted and reported in Table 7. Average depth of compacted snow $(H)$ was calculated by

$$
H=\frac{V_{c}}{S}
$$

where $V_{c}$ is compacted snow volume and $S$ is the glacier surface area.

Table 7. Adjusted Total Seasonal Snow Volume Results

\begin{tabular}{|l|c|c|c|c|}
\hline $\begin{array}{c}\text { LiDAR Study } \\
\text { Area }\end{array}$ & Surface Area & $\begin{array}{c}\text { Seasonal Snow } \\
\text { Volume (fresh) }\end{array}$ & $\begin{array}{c}\text { Seasonal Snow } \\
\text { Volume } \\
\text { (compacted) }\end{array}$ & $\begin{array}{c}\text { Seasonal } \\
\text { Snow Depth } \\
\text { (m) (2018) }\end{array}$ \\
\hline $\begin{array}{l}\text { Palisade } \\
\text { Glacier }\end{array}$ & $1,293,988.14 \mathrm{~m}^{2}$ & $3,810,317.38 \mathrm{~m}^{3}$ & $2,011,847.58 \mathrm{~m}^{3}$ & 1.55 \\
\hline $\begin{array}{l}\text { North Middle } \\
\text { Palisade } \\
\text { Glacier }\end{array}$ & $200,721.74 \mathrm{~m}^{2}$ & $1,005,543.29 \mathrm{~m}^{3}$ & $530,926.86 \mathrm{~m}^{3}$ & 2.65 \\
\hline $\begin{array}{l}\text { South Middle } \\
\text { Palisade } \\
\text { Glacier }\end{array}$ & $342,298.44 \mathrm{~m}^{2}$ & $1,780,243.63 \mathrm{~m}^{3}$ & $939,968.64 \mathrm{~m}^{3}$ & 2.75 \\
\hline $\begin{array}{l}\text { Total Middle } \\
\text { Palisade } \\
\text { Glacier }\end{array}$ & $543,020.18 \mathrm{~m}^{2}$ & $2,785,786.92 \mathrm{~m}^{3}$ & $1,470,895.49 \mathrm{~m}^{3}$ & 2.71 \\
\hline
\end{tabular}

\subsection{Calculating Topographic Shielding}

Topographic shielding was calculated at sample points with 90 -meter spacing throughout the glacier using the custom geoprocessing tool developed in ModelBuilder by the Center for Spatial Studies at the University of Redlands. This process generated a shielding index for each point (Figure 6-2). Red points indicate highest shielding values while yellow points indicate lowest shielding values. 


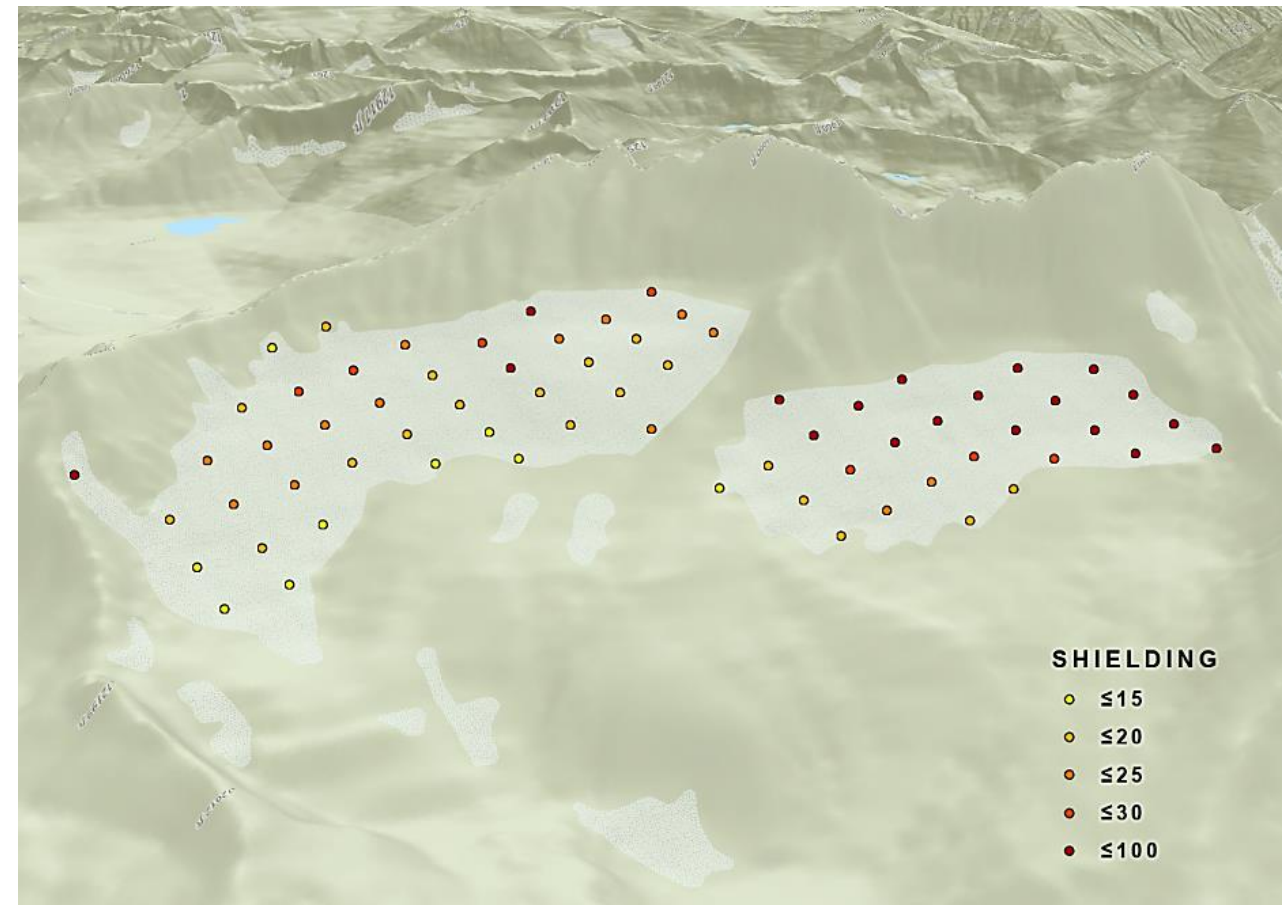

Figure 6-2: Middle Palisade Glacier with topographic shielding points.

\subsection{Concentration and Shielding Regression Analysis}

Defining the relationship between topographic shielding and 4NP concentration was a key component of the entire study. Regression analysis was utilized as a statistical method of both testing past research concepts and predicting future outcomes. Thus, the research objective of determining $4 \mathrm{NP}$ presence across a glacial space was contingent on determining a statistical model that would mathematically interpret and establish the relationship between concentration and shielding. According to Lyons (2014), there is an inverse relationship between shielding and concentration. The conceptual understanding was that concentration would decrease as shielding increased. Once the sample concentrations and their shielding values from the Middle Palisade Glacier's southern glacier were plotted as an Excel graph, this inverse relationship was supported with a logarithmic regression analysis. The regression line clearly shows an inverse or negative relationship between shielding and concentration (Figure 5-7). The calculated regression equation (Equation 5-4) was used to estimate the 4NP concentration in the glaciers. Figure 6-3 illustrates the estimated 4NP concentration throughout Middle Palisade Glacier. Two circular spots are visible in the estimated concentration raster. The cause of this pattern was unknown at the time of the study. An investigation into this observation was beyond the scope of this project but would be worthwhile in future studies. 


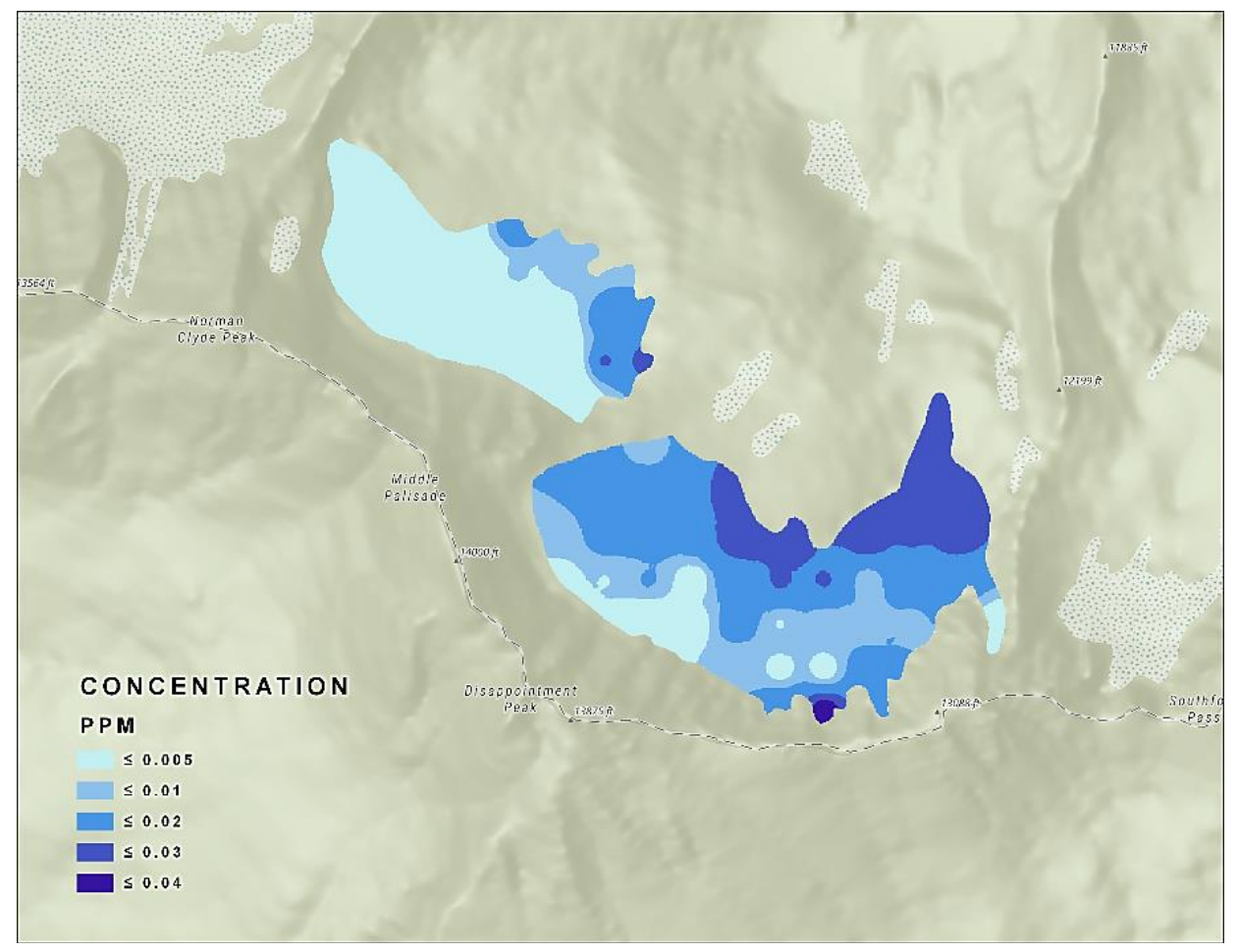

Figure 6-3: Middle Palisade 4NP concentration estimations

The results of the regression analysis were necessary before implementing the topographic shielding coefficient as a reasonable predictor of concentration estimations. Based on the equation, 4NP concentrations become undetectable at a topographic shielding value of approximately 28 . This result was comparable to the previous suggestion of undetectable 4NP levels at approximately 25 in a 2014 study (Lyons, et al., 2014).

Additionally, the regression analysis not only supported the research inference of the inverse relationship between concentration and shielding, but it also aligned with other research assumptions. For example, affirming the inverse relationship between topographic shielding and concentration likewise infers that concentration values would decrease away from a ridge in the direction of prevailing winds. This conceptualized the suggestion of a horizontal concentration gradient only interrupted by variations in headwall barriers and wind direction. Since topography is rarely uniform, a gap or Vshaped notch in a ridge may funnel the path of airborne 4NP to a snow area leading to higher concentrations in the glacier patch (Figure 6-4). 


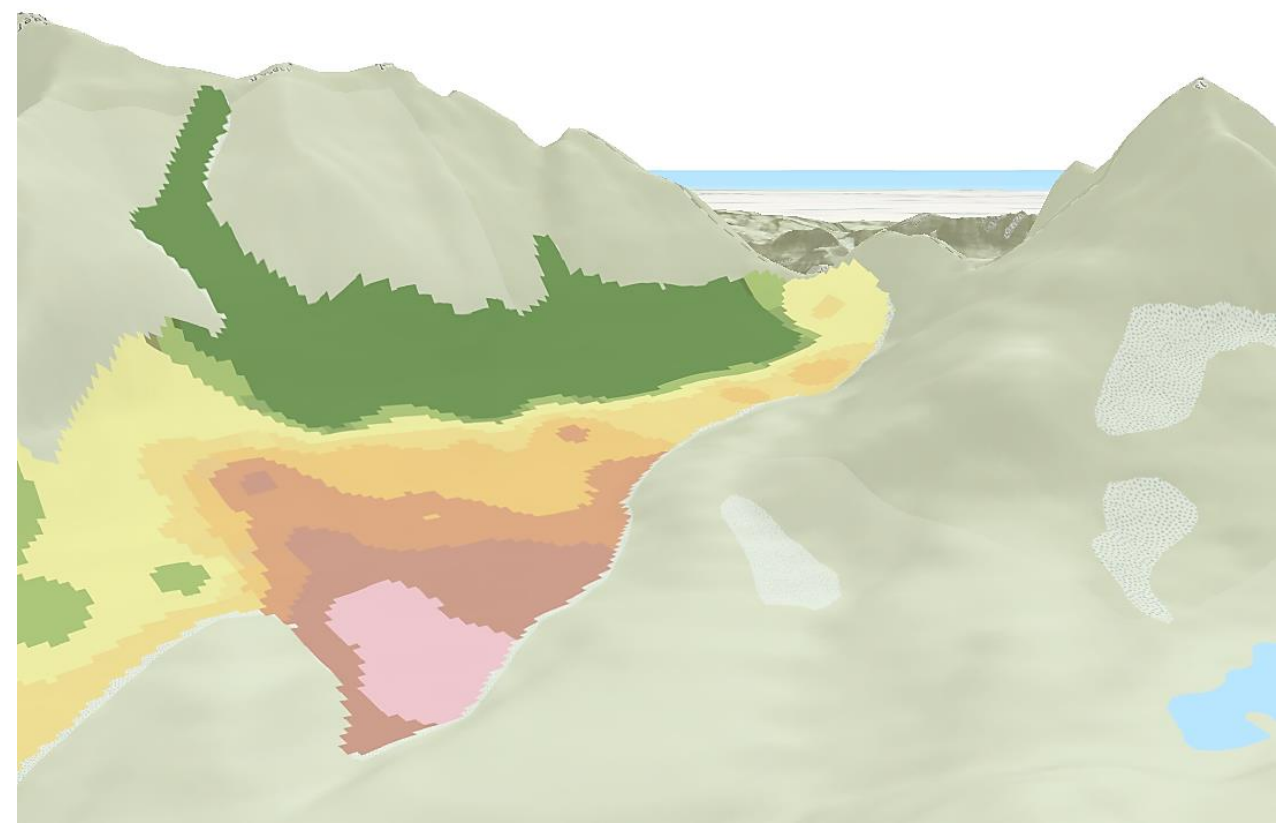

Figure 6-4: V-notch in Palisade Glacier ridge

Ridge fluctuations explain why shielding may not necessarily be greater for points closer to the ridge. Thus, points closer to the ridge may not necessarily lead to lower $4 \mathrm{NP}$ concentrations.

\subsection{4-Nonylphenol Mass Estimation}

Once snow volume and 4NP concentration estimation rasters were created, the 4NP mass could be determined. The formula for determining mass of 4NP in the glacier was further expounded into an equation that would include the factors of glacial and water density (Equation 5-1). This was necessary to ensure that the equation could be appropriately applied given the components of the research. Since mass measurements were conducted in a glacial space, density of snow and water had to be factored into the equation and a conversion factor was applied.

4NP mass was calculated using a model in ModelBuilder to automate geoprocessing steps for both Palisade Glacier and Middle Palisade Glacier. The output was a raster containing a mass value for each cell (Figure 6-5). Areas with negative elevation differences were removed from the snow volume raster and are absent from the mass raster since mass cannot be calculated from negative volumes. Table 8 reports the mass of the 4NP in seasonal glacier snow between August 2014 and April 2018. Parts per million ( $\mathrm{ppm})$ is equivalent to milligrams per liter $(\mathrm{mg} / \mathrm{L})$. Thus, results are reported in $\mathrm{mg} / \mathrm{L}$ since the conversion factor between cubic meters and liters were applied in the calculations for mass. 


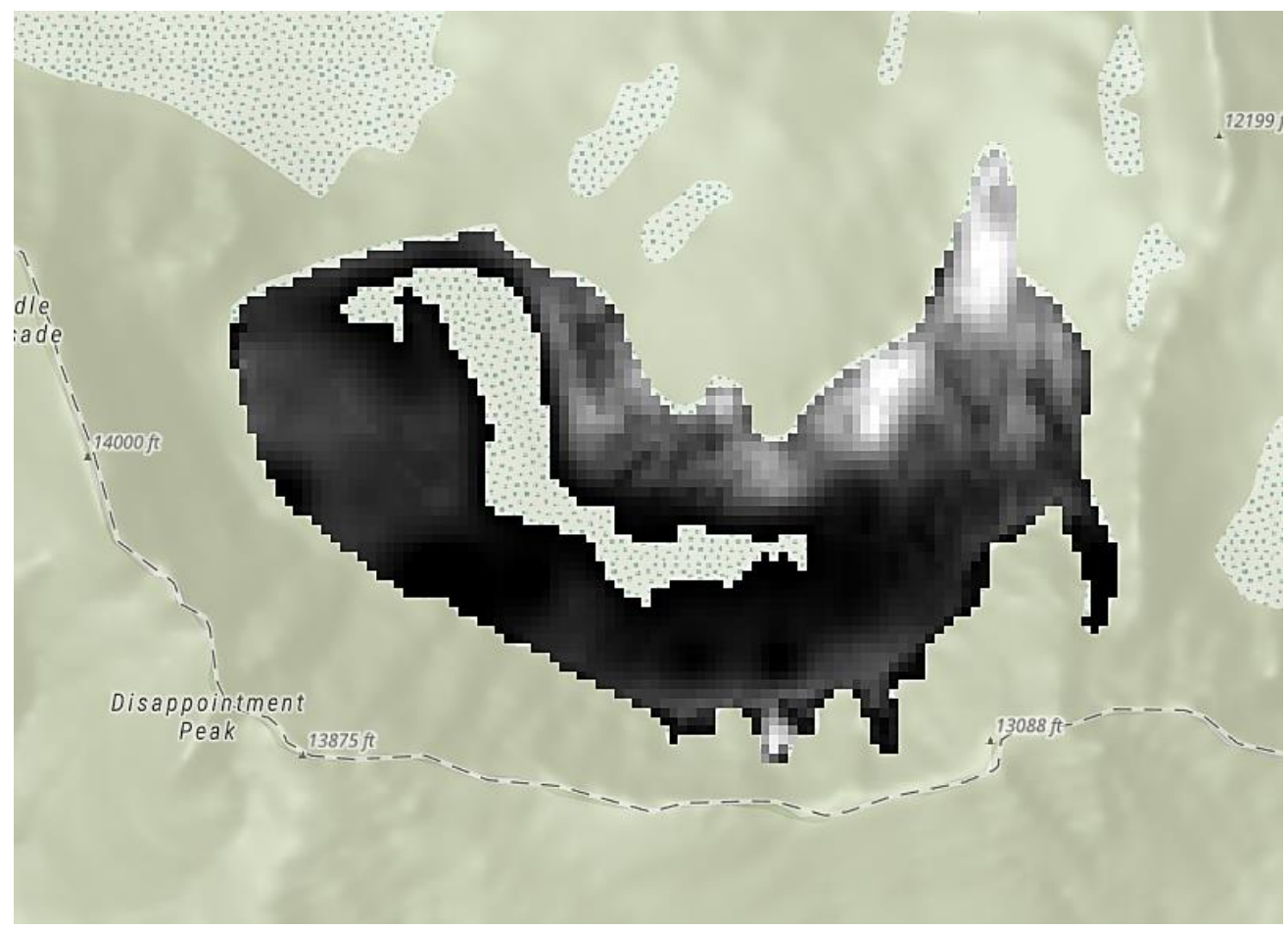

Figure 6-5: Middle Palisade Mass Raster

Table 8. 4NP Mass

\begin{tabular}{|l|c|}
\hline \multicolumn{1}{|c|}{ LiDAR Study Area } & 4NP Mass \\
\hline Palisade Glacier & $\begin{array}{c}41,031,353.23 \mathrm{mg} \\
(41 \mathrm{~kg})\end{array}$ \\
\hline North Middle Palisade Glacier & $\begin{array}{c}1,864,795.65 \mathrm{mg} \\
(1.9 \mathrm{~kg})\end{array}$ \\
\hline South Middle Palisade Glacier & $\begin{array}{c}15,555,041.59 \mathrm{mg} \\
(16 \mathrm{~kg})\end{array}$ \\
\hline Total Middle Palisade Glacier & $17,419,837.24 \mathrm{mg}$ \\
& $(17 \mathrm{~kg})$ \\
\hline
\end{tabular}

\subsection{Discussion on Study Challenges}

Several research challenges arose throughout the duration of the project. While most issues involving Esri software were solved without much difficulty, major research challenges required more attention and explanation. Some challenges, once identified, necessitated significant research and deliberations with Dr. Rebecca Lyons. These challenges are documented in the following sections. 


\subsubsection{Unexpected Snow Elevation}

The first problematic issue involved the data assumption discussed in Section 6.1.2 that snow-on elevations would be greater than snow-off elevations. Examining the data revealed that the assumption was not true. The DHM created from the two DEMs resulted in cells with unexpected negative values. A closer inspection of the point cloud of both datasets revealed that there were snow-off points that existed above the snow-on surface in both Palisade Glacier (Figure 6-6) and Middle Palisade Glacier (Figure 6-7). Since LiDAR points clouds are more accurate the basemaps provided in ArcGIS Pro, a cartographic offset was set to ensure that all points would appear above the basemap surface.

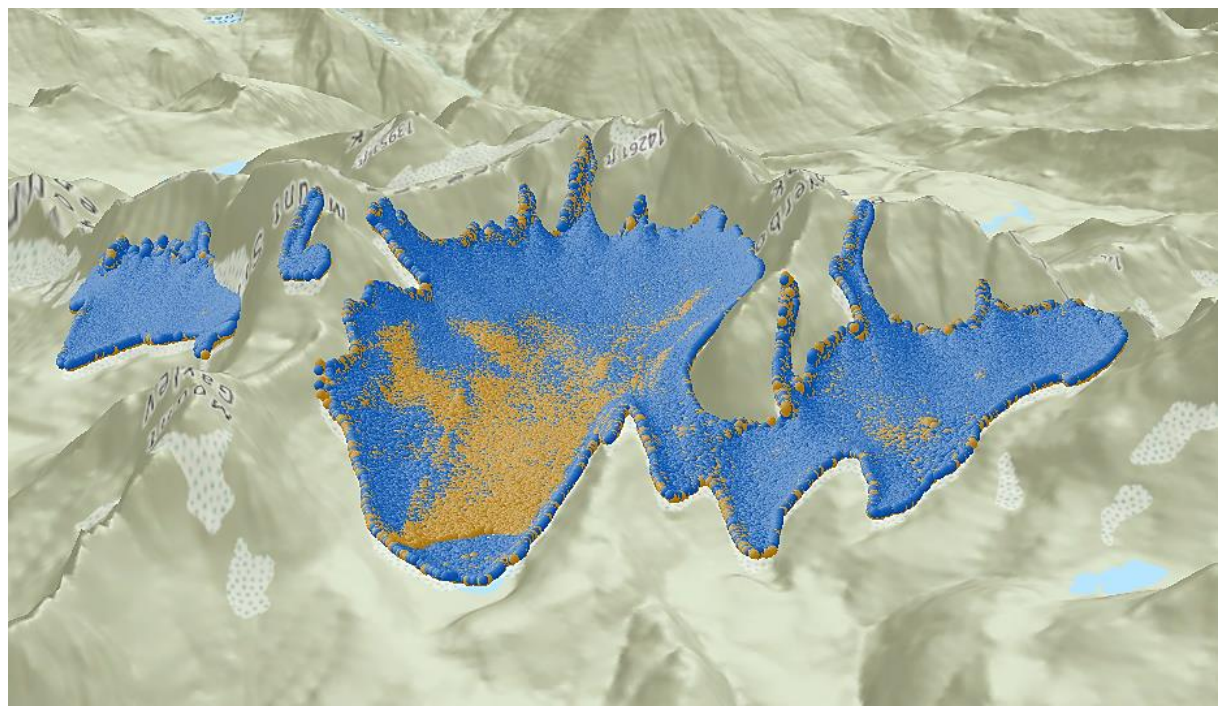

Figure 6-6: Palisade Glacier snow-off (yellow) above snow-on (blue) 


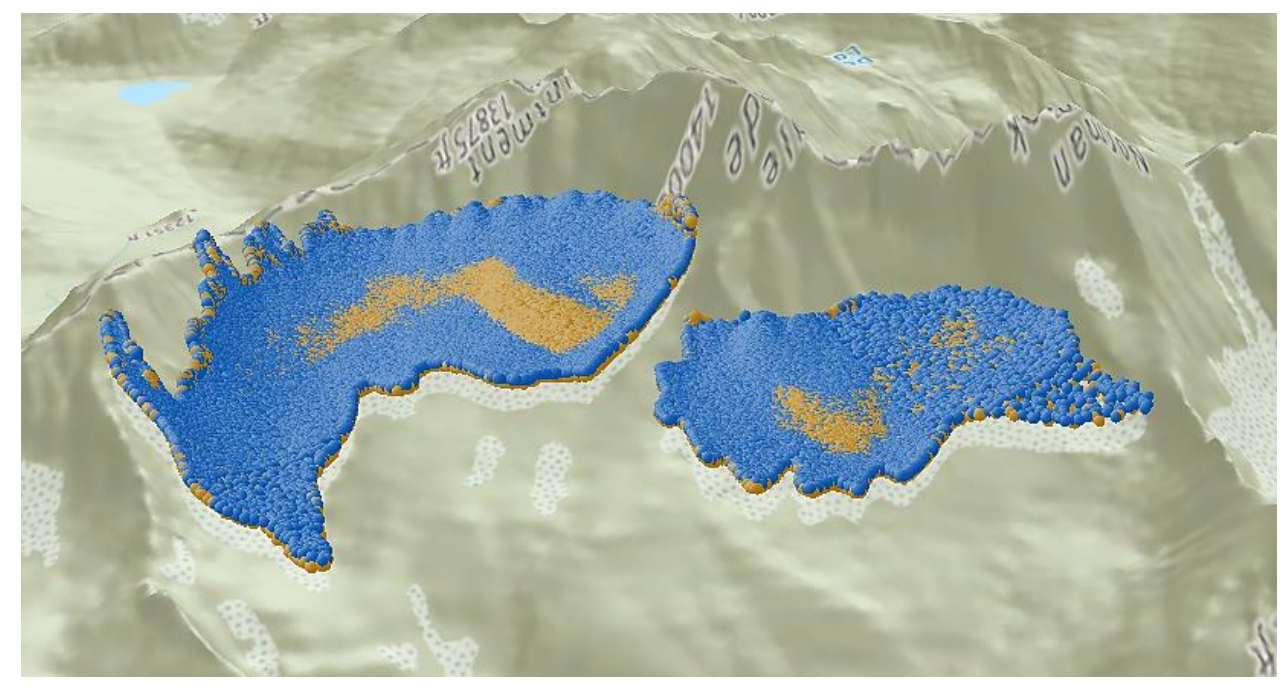

Figure 6-7: Middle Palisade Glacier snow-off (yellow) above snow-on (blue)

The elevation of snow-off in some areas was significantly greater (in some areas as great as 22 meters) than the elevation of snow-on. This was a direct contradiction to the assumption that the peak snow coverage in the snow-on dataset would lead to higher elevations. There were several explanations for this unexpected snow elevation in the data, all of which centered around the four-year difference of the 2014 snow-off and 2018 snow-on datasets. It is advisable that future snow volume analysis be conducted with snow-on and snow-off coverages from the same year.

Initially, changes in landforms was proposed as a plausible explanation for the significant elevation differences in the glacier. The landform changes, such as earthquakes or avalanches were speculated to have played a role in shifts in elevations. However, after investigating satellite and digital imagery, no significant landform changes could be discovered. Additionally, there were no reports found on significant earthquakes in the area which would have caused changes in topography. Thus, it was concluded that negative values in the digital height model could be attributed to a net loss of glacial volume during the time period captured in snow-on and snow-off. Since the Palisade and Middle Palisade glaciers exist as temperate glaciers in the Sierra Nevada, subglacial meltwater channels or flow may be responsible for changes in surface snow elevation from season to season. Seasonal snow may accumulate on the surface while melt occurring below glacial ice may lower surface elevations. This would account for negative net mass balance even while seasonal snow accumulation occurs, denoted by positive values in the raster.

Additionally, LiDAR errors could be another explanation for some of the unexpected snow elevation differences. LiDAR sources of error can include GPS positioning, IMU (attitude), scan angle, timing (range), and the co-registration between laser and IMU system (boresight). These errors can affect the horizontal and vertical accuracy of LiDAR returns (Tedesco, 2015). For LiDAR sensors, vertical accuracies are typically reported on the magnitude of 15 centimeters with average ground point spacings of 1.5 meters (Deems \& Painter, 2006). As the differences contained in the DHM were significant (up to -22 meters in Palisade Glacier), the likelihood of LiDAR errors being responsible for 
the majority of the unexpected measurements is minimal. Additionally, it is important to note that since the creation of the DEMs involves interpolation, some error is introduced. However, owing to the high spatial resolution of point cloud data, IDW or other simple interpolation schemes can be utilized while minimally introducing errors (Deems \& Painter, 2006).

Lastly, elevation changes could be attributed to movement and fluctuations of moraine. If snow and ice dislodge rocks, regolith, and other glacial debris, the changes in these surfaces are captured by LiDAR sensors. These changes will affect snow volume measurements. Thus, snow melt behavior and the movement of snow over the four-year time period was a more reasonable explanation for instances where snow-off elevations were greater than snow-on.

\subsubsection{Variations in Snow Coverage and Glacial Boundaries}

The results discussed in this chapter are valid only under the assumption that they are reported as estimations for snow volume and 4NP presence in a limited period as determined by seasonal snow fluctuations. Any rasters generated in this study included cell values extended to the polygon determined as the glacier area. This glacial area was digitally traced and inferred from Esri's topographic basemaps as well as the client's own field knowledge. In reality, snow may not be covered for the entire area, instead changing from season to season. In addition to providing an account for the unexpected snow elevation difference discussed in the previous section, this fluctuation is an explanation for why determining the precise boundary of a glacier presents a challenge even for glaciologists experienced in the field (Tedesco, 2015). The difficulties are further compounded in temperate glaciers where small changes in temperature can mean significant changes in glacial melt, volume, and area. Satellite imagery confirmed that this was a relevant variable for both the Palisade and Middle Palisade Glaciers where snow coverage dramatically changed from year to year. This change is most evident in the terminus of the glacier which is constantly advancing and retreating. This snow coverage fluctuation is seen in the LiDAR 2014 and 2018 coverages in the Palisade Glacier's tarn or lake at the basin of the glacier (Figure 6-8). A comparison between an image of the glacier terminus and the LiDAR snow-on and snow-off point cloud illustrates the different stages of snow coverage captured by LiDAR (Figure 6-9). 


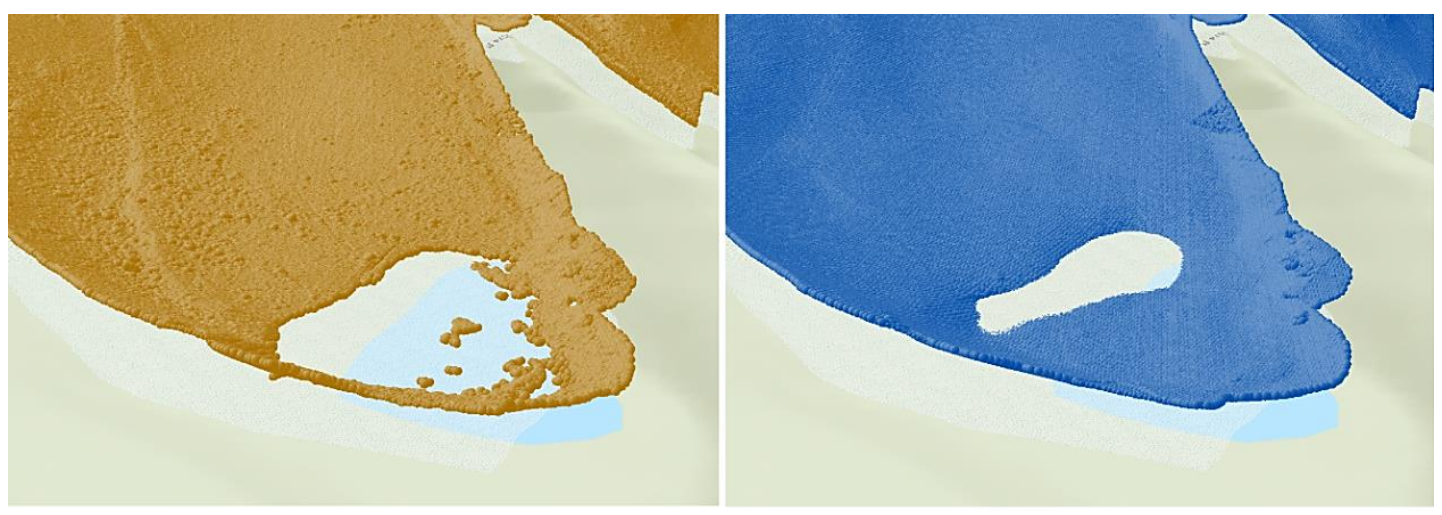

Figure 6-8: Palisade Glacier terminus point clouds: Snow-Off (left) and Snow-On (right).

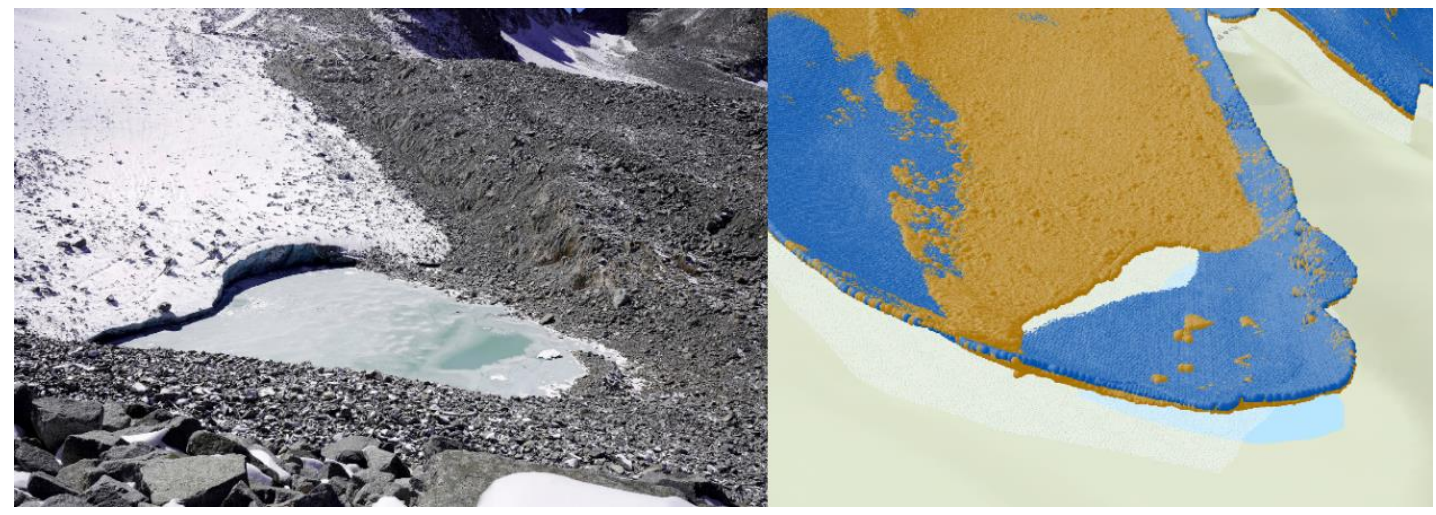

Figure 6-9: Palisade Glacier in October 2018 (left) and LiDAR point cloud datasets 2014 (brown) and 2018 (blue). Image reproduced with permission, Dale Matson.

Since the time period examined in this study occurred during the height of California's drought in 2014 and its transitional end from 2017 to 2019, glacial area changed dramatically during the snow-off and snow-on data periods. Since LiDAR returns from waterbodies are usually scattered, points did not capture the surface of the Palisade Glacier terminus lake.

\subsection{Summary}

The design and implementation phases of the project were oriented to produce results that aligned with the research objectives. This chapter discussed the measurements of glacial seasonal snow volume, 4NP concentrations based on topographic shielding calculations, and total 4NP mass estimations. Analyses were based on methodologies that would provide information on the presence of 4NP in glaciers in California's Sierra Nevada mountain range. 


\section{Chapter 7 - Conclusions and Future Work}

Since this document captures only a segment of the research continuum, its content was purposefully constrained to embody the scope limited by time and the availability of resources. Each component of the investigation of 4NP presence in glaciers was captured in the previous chapters. The project aligned with the study's research process and was described according to the progress and direction of the research. The conclusion of this report, found in Section 7.1, details the accomplishments and objectives achieved. Since this project laid the foundation for the GIS application to the scientific study, future work to improve and expand the project was envisioned throughout the project and discussed in Section 7.2.

\subsection{Conclusions}

The client's needs and the research objectives of her study were the driving force behind the implementation, analyses, and results of the project. By outlining, testing, and generating procedures that produced snow volume results, a raster analysis workflow was constructed to use LiDAR point cloud data to map snow depth. The concept of the topographic shielding index as an indicator of 4NP presence given a prevailing wind direction was implemented in GIS analysis to estimate concentration gradients. The research objective of determining a 4NP mass in a glacier was achieved by estimating 4NP concentrations using topographic shielding and snow volume through the implementation of LiDAR snow coverage data.

The practical application of the project consisted in the predictions of $4 \mathrm{NP}$ concentrations across unsampled glacial spaces. This proved to be valuable to the client who based her sampling expedition plans on the raster analysis work. Predicting optimal sites saved research teams both time and cost by providing a map of concentration estimations. This significantly reduced guesswork and improved overall research productivity.

Overall, the GIS application of this project proved to be highly effective in bringing together all the data, concepts, and research in existence at the time of this study. GIS was an important contribution to the research because it organized and gave direction to the study. Results from GIS analyses supported research concepts while simultaneously opening avenues for discussion and the formulation of new research questions, an important aspect of useful science.

Integrating the various components of the research achieved at the time of the study allowed for a more cohesive understanding of the work while simultaneously enabling further exploration of related research ideas and concepts. Conducting GIS work in this study provided a fruitful arena for the expansion of productive investigation into glacial space, the movement of mass, and the behavior of glacial material. Throughout the project's lifespan, greater appreciation for the research work of glaciers was achieved. 


\subsection{Future Work}

The methods detailed in this document provide the foundation for the continuation of GIS work in mapping chemical transport and presence in glacial space based on wind and topography. The project's results and analyses are a culmination of an approach for determining a chemical mass in a glacier body. Future work falls in two categories. The first is to test and refine the methodologies and models described in this study. Since NASA ASO's work is ongoing, it would be worthwhile to revisit the seasonal snow volume measurements by using snow-off and snow-on datasets from the same year. At the time of writing, a research team embarked on an expedition to collect samples from Palisade Glacier which had previously been unsampled for 4NP concentrations. Ice core samples, once processed in the laboratory, will yield 4NP concentration values at new locations in the glacier. These values can be compared to the predicted concentrations from the estimation map discussed in Section 6.6. Comparing the actual values to the estimated values generated from the logarithmic equation will indicate how well the GIS methods reflected field work. Shielding values can be calculated following the methods described in previous chapters and a similar 4NP function can be derived from a regression analysis from Palisade Glacier. This function can be compared with the Middle Palisade Glacier 4NP function from this study. Additionally, the topographic shielding model could also be improved to insure the processing of feature classes containing more input points. This would improve shielding value calculations throughout the glacial surface.

The second category of future GIS work applies to the exploration of concepts and questions raised throughout the lifespan of this project. These concepts are listed in Table 9. 


\section{Table 9. Future Research GIS Work}

\begin{tabular}{|l|l|}
\hline \multicolumn{1}{|c|}{ Concept } & \multicolumn{1}{|c|}{ Description } \\
\hline Permanent glacial snow volume & $\begin{array}{l}\text { Derive methods to measure } \\
\text { permanent glacial snow and add } \\
\text { seasonal snow results to calculate } \\
\text { total glacial volume }\end{array}$ \\
\hline Snow compaction factor & $\begin{array}{l}\text { Investigate whether snow } \\
\text { compaction over time influences } \\
\text { 4NP concentration }\end{array}$ \\
\hline $\begin{array}{l}\text { 4NP vertical concentration } \\
\text { gradient }\end{array}$ & $\begin{array}{l}\text { Measure 4NP concentration } \\
\text { gradients at various depths in the } \\
\text { glacier }\end{array}$ \\
\hline Glacier melt rate & $\begin{array}{l}\text { Calculate glacier melt rate given } \\
\text { albedo and temperature }\end{array}$ \\
\hline 4NP downstream deposition & $\begin{array}{l}\text { Determine location and presence of } \\
\text { 4NP in glacier runoff }\end{array}$ \\
\hline $\begin{array}{l}\text { Mass and extent of re-released } \\
\text { 4NP }\end{array}$ & $\begin{array}{l}\text { Calculate the total mass of 4NP } \\
\text { released if glaciers completely melt } \\
\text { and model areas affected }\end{array}$ \\
\hline Exposure risk of 4NP & $\begin{array}{l}\text { Conduct analysis on 4NP exposure } \\
\text { threat to human and wildlife health }\end{array}$ \\
\hline
\end{tabular}

\subsection{Summary}

The Pacific Ocean coast, the highly agricultural productive Central Valley, and the formidable Sierra Nevada mountain range makes California's landscape a scientific rich space for study. Dr. Rebecca Lyons, a University of Redlands professor and researcher, embarked on studies that have begun to trace concentrations of 4-nonylphenol in waterbodies to the presence of the endocrine disruptor stored in these glaciers. These temperate glaciers release 4NP into waterbodies each year. Thus, it became important to investigate the storage of 4NP in glaciers. After collecting and organizing research to formulate an environmental narrative, raster analysis methodologies were designed to explain 4NP deposition and presence. GIS analyses were designed and applied to address the spatial aspects of the topographic shielding equation and its application to 4NP concentrations.

The power of GIS is in its ability to cross disciplines. While the research of 4NP has specifically fallen under the framework of the natural sciences, GIS can broaden the study into other disciplines. The goal of the 4NP research in glaciers should be to 
ultimately apply it to public health. The potential health risks associated with 4NP and other endocrine disruptors will continue to increase if studies are discontinued and public health warning signs are ignored. The known links between 4NP bodily intake and health consequences should be the driving force for continual investigation into the health effects and extent of 4NP spread in the natural environment. Exposure risks of 4NP should be investigated, and GIS scientists should collaborate with environmental scientists, public health experts, resource managers, and industry leaders to minimize risks to human and wildlife health. 


\section{Works Cited}

Aronoff, S. (2005). Remote sensing for GIS managers. Redlands, California: ESRI Press.

Bahr, D. B., Meier, M. F., \& Peckham, S. D. (1997, September 10). The physical basis of glacier volume-area scaling. Journal of Geophysical Research, 102(B9), 20,35520,362 .

Blais, M. J., Schindler, W. D., Muir, C. D., Sharp, M., Donald, D., Lafrenière, M., . . . Strachan, M. W. (2001, November). Melting glaciers: A major source of persistent organochlorines to Subalpine Bow Lake in Banff National Park, Canada. Ambio, 30(7), 410-415.

Bolstad, P. (2016). GIS Fundamentals: A First Text on Geographic Information Systems (Fifth ed.). White Bear Lake, Minnesota, United States: Eider Press.

Brooks, A. N. (2012). Modeling the Impact of Terrain on Wind Speed and Dry Particle Deposition Using WindNinja and ArcGIS Spatial Analyst (Master's thesis, University of Redlands). Retrieved from https://inspire.redlands.edu/gis_gradproj/162

Bugshan, O. A. (2016). Analyzing 4-nonylphenol Deposition in the Sierra Mountain Area Using GIS (Master's thesis, University of Redlands). Retrieved from https://inspire.redlands.edu/gis_gradproj/256

Burt, J. E., Barber, G. M., \& Rigby, D. L. (2009). Elementary Statistics for Geographers (Third ed.). New York: The Guilford Press.

Campbell, J. B. (2002). Introduction to remote sensing (Third ed.). New York, NY: The Guilford Press.

Davidson, C., \& Knapp, R. A. (2007). Multiple stressors and amphibian declines: dual impacts of pesticides and fish on yellow-legged frogs. Ecological Applications, 17(2), 587-597.

Davis, M. L., \& Masten, S. J. (2016). Principles of Environmental Engineering and Science (Third ed.). McGraw Hill Education.

Deems, J. S., \& Painter, T. H. (2006). LiDAR measurement of snow depth: accuracy and error sources.

Deems, J. S., Painter, T. H., \& Finnegan, D. C. (2013). Lidar measurement of snow depth: a review. Journal of Glaciology, 59(215), 467-479. doi:10.3189/2013JoG12J154

Forte, M., Di Lorenzo, M., Carrizzo, A., Valiante, S., Vecchinoe, C., Laforgia, V., \& De Falco, M. (2016). Nonylphenol effects on human prostate non tumorigenic cells. Toxicology, 357-358, 21-32.

Guyton, B. (1998). Glaciers of California. (A. C. Smith, Ed.) University of California Press.

Hambrey, M., \& Alean, J. (2004). Glaciers (Second ed.). Cambridge University Press.

Huss, M. (2013). Density assumptions for converting geodetic glacier volume change to mass change. The Cryosphere, 7, 877-887. Retrieved from https://doi.org/10.5194/tc-7-877-2013

Keranen, K., \& Kolvoord, R. (2016). Making spatial decisions using GIS and lidar: a workbook. Redlands, California: ESRI Press.

Kim, Y.-S., Hwang, K.-A., Hyun, S.-H., Nam, K.-H., Lee, C.-K., \& Choi, K.-C. (2015). Bishenol A and Nonylphenol Have the Potential to Stimulate the Migration of 
Ovarian Cancer Cells by Inducing Epithelial-Mesenchymal Transition via an Estrogen Receptor Dependent Pathway. Chemical Research in Toxicology, 28, 662-671.

Kirchner, P. B., Bales, R. C., Molotch, N. P., Flanagan, J., \& Guo, Q. (2014). LiDAR measurement of seasonal snow accumulation along an. Hydrology and Earth System Sciences, 4261-4275.

Lyons, R. A., \& Benvenuti, L. (2016). Deposition and distribution factors for the endocrine disruptor, 4-nonylphenol, in the Sierra Nevada Mountains, California, USA. Journal of Environmental \& Analytical Toxicology, 6(4). doi:10.4172/21610525.1000388

Lyons, R., Togashi, T., \& Bowyer, C. (2019). Environmental conditions affecting rerelease from particulate matter of 4-Nonylphenol into an aqueous medium. Environmental Toxicology and Chemistry, 38(2), 350-360.

Lyons, R., Van de Bittner, K., \& Morgan-Jones, S. (2014). Deposition patterns and transport mechanisms for the endocrine disruptor 4-nonylphenol across the Sierra Nevada Mountains, California. Environmental Pollution, 123-132. doi:10.1016/j.envpol.2014.08.006

Manente, L., Sellitti, A., Lucariello, A., Laforgia, V., De Falco, M., \& De Luca, A. (2011). Effects of 4-nonylphenol on proliferation of AGS gastric cells. Cell Proliferation, 44, 477-485. doi:10.1111/j.1365-2184.2011.00774.x

Painter, T. H., Berisford, D. F., Boardman, J. W., Bormann, K. J., Deems, J. S., Gehrke, F., ... Winstral, A. (2016). The Airborne Snow Observatory; FUsion of scanning lidar, imaging spectrometer, and physically-based modeling for mapping snow water equivalent and snow albedo. Remote Sensing of Environment, 139-152.

Raub, W., Brown, C., \& Post, A. (2006). Inventory of Glaciers in the Sierra Nevada, California. U.S. Geological Survey Open-File Report.

Schwarzenbach, R. P., Gschwend, P. M., \& Imboden, D. M. (2003). Environmental Organic Chemistry (Second ed.). Hoboken, New Jersey: John Wiley \& Sons, Inc.

Sugden, D. E., \& John, B. S. (1976). Glaciers and Landscape. Edward Arnold Ltd.

Tedesco, M. (2015). Remote sensing in the cryosphere. John Wiley \& Sons, Ltd.

U.S. Environmental Protection Agency. (2002). Long-range atmospheric transport of persistent bioaccumulative toxics from Central America. Chicago, Illinois.

U.S. Fish \& Wildlife Service. (2016). National Conservation Training Center. Retrieved from https://nctc.fws.gov/courses/references/tutorials/geospatial/CSP7304/2016docume nts/HandsOn_Afternoon/LiDAR/LidarExercise.pdf

Vazquez-Duhalt, R., Marquez-Rocha, F., Ponce, E., Licea, A. F., \& Viana, M. T. (2005, January). Nonylphenol, an integrated vision of a pollutant. Applied Ecology and Environmental Research, 1-25. 


\section{Appendix A. Topographic Shielding Calculator}

Even though the topographic shielding model consisted of a series of steps, three components to prepare the shielding calculation can be visualized in Figure 5-7. First, a copy of the input feature points was made and given $\mathrm{X}$ and $\mathrm{Y}$ coordinates in UTM. A minimum bounding geometry (MBG) was created to encircle all the points in the input feature class. The diameter of the MBG was calculated and reported as the "extend distance."

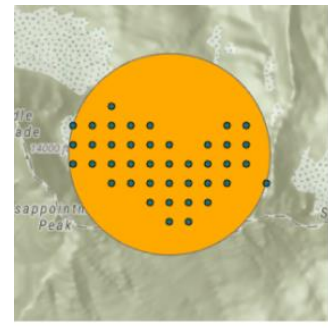

1.

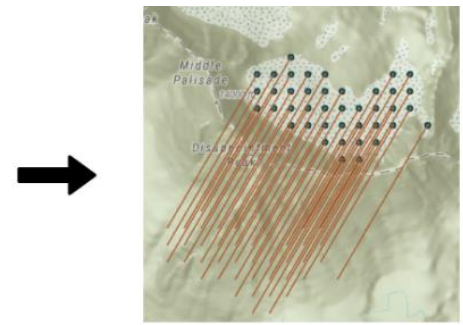

2.

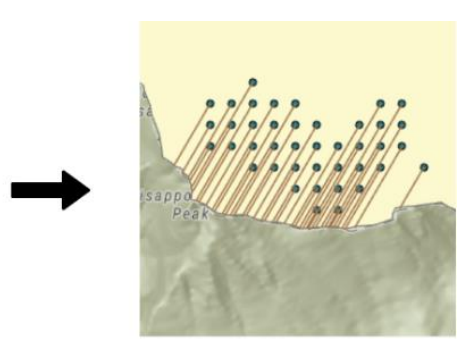

3.

Figure A-1: Model Workflow

Next, using the wind direction field as a parameter, a new feature class containing the shortest line connecting two points was generated using the Bearing Distance To Line tool. These line features, known as geodetic lines, were based on the values reported in the $\mathrm{X}$ and $\mathrm{Y}$ coordinate, distance, and the newly introduced bearing or wind direction field.

Finally, these geodetic lines were clipped to the ridgeline polygon, provided as an input parameter. A ridge distance field was added to the line feature class and populated by the geodesic length of each line feature calculated using the Calculate Geometry Attribute tool. The input parameter ridgeline line feature class containing elevation and slope for each feature segment was spatially joined to the geodetic line features. Fields were joined so that the result was a point feature class containing the variables needed to calculate topographic shielding values. Lastly, the shielding value was calculated by dividing the product of slope and the ridge elevation difference by the horizontal distance to the ridge.

The topographic shielding value is reported without units as a scalar number for each input point. Concentration point target features closest to the shielding point features were joined one to one. The resulting product was a feature class of the concentration points containing shielding attributes. The image of the model and the Python script is available in Appendix B. 


\section{Appendix B. Models and Scripts}

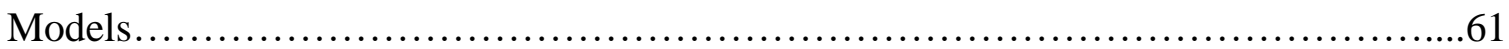

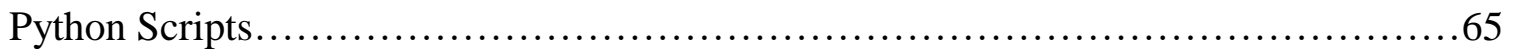




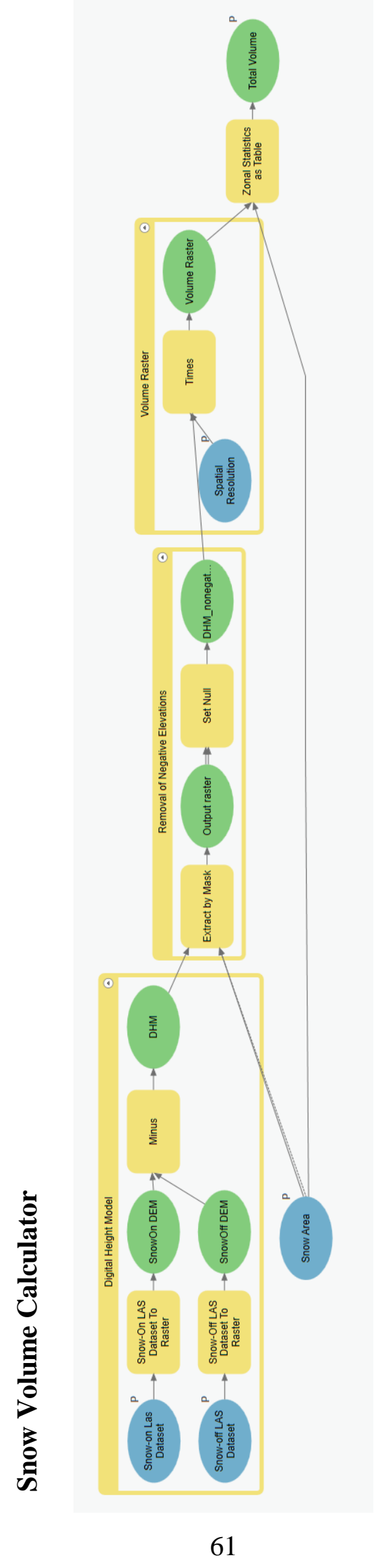




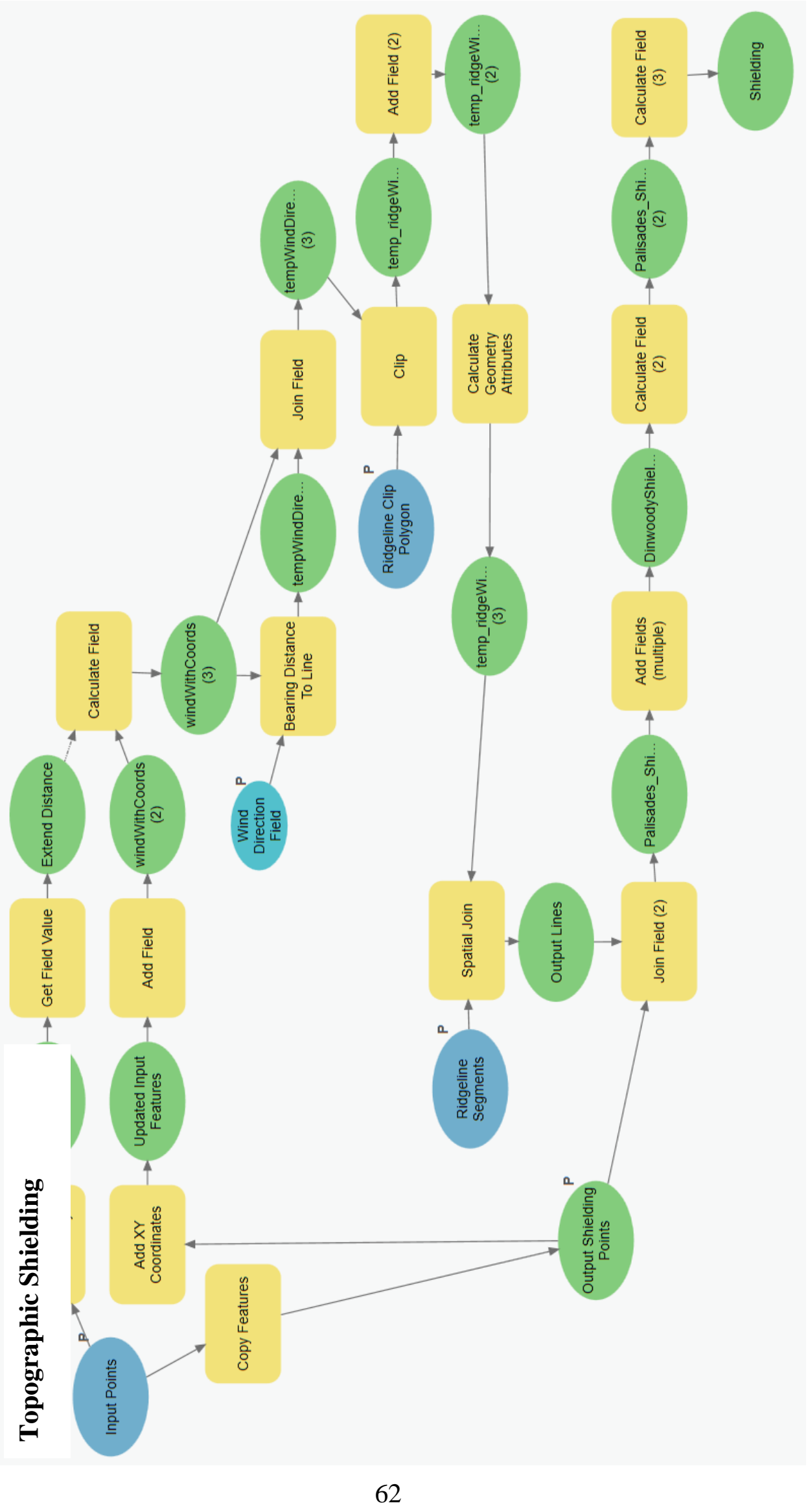




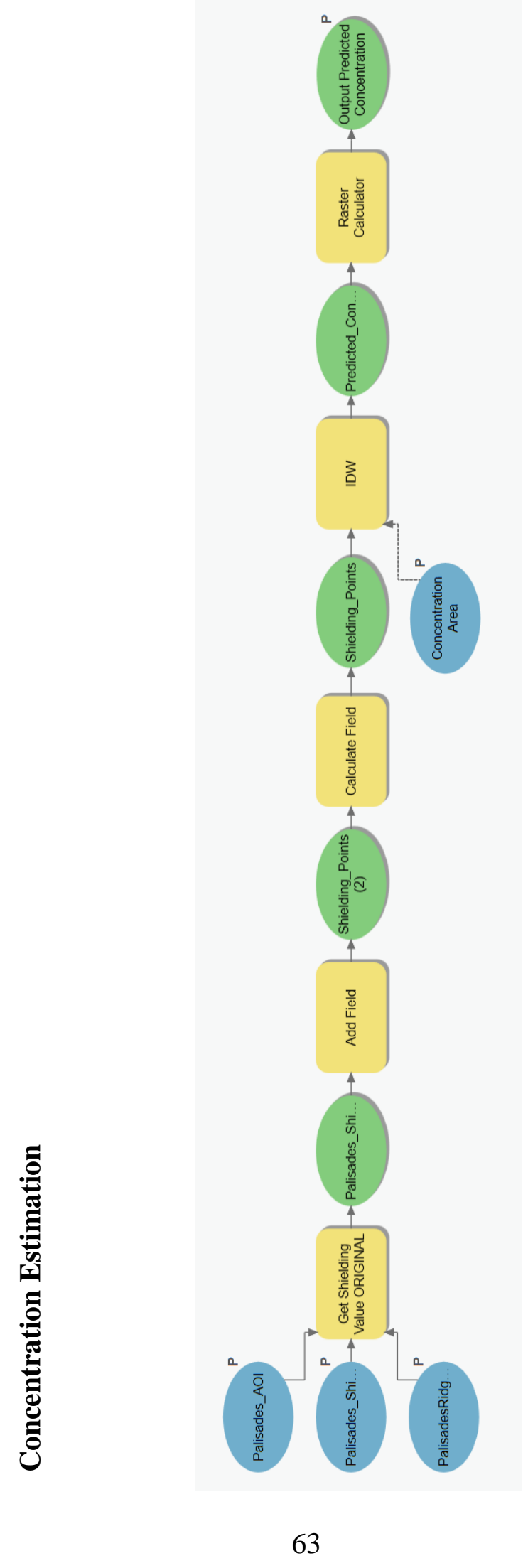




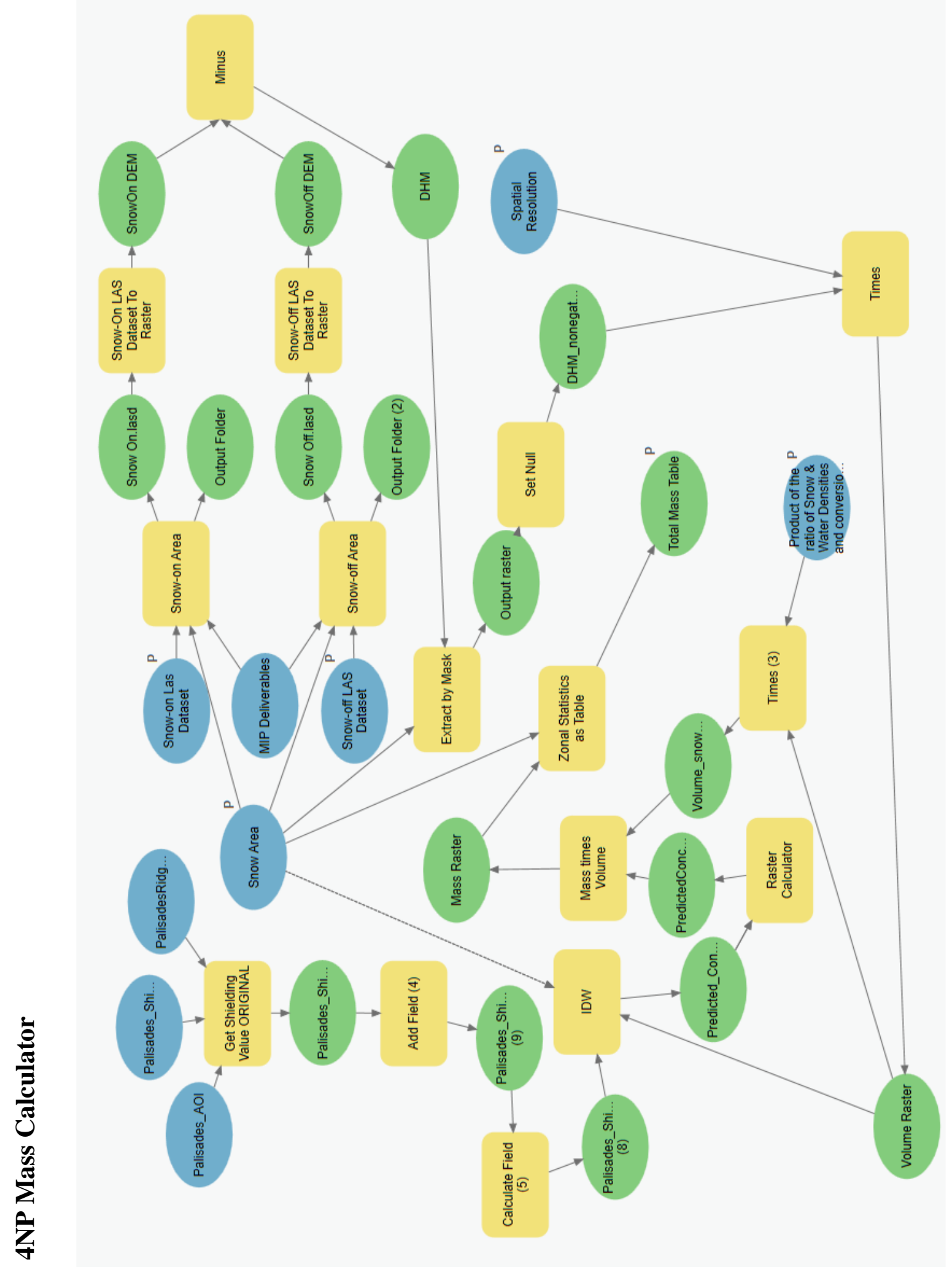




\section{Topographic Shielding Calculator}

\# -*- coding: utf-8 -*-

"" "Generated by ArcGIS ModelBuilder on: 2019-08-05 18:25:53

All ModelBuilder functionality may not be exported. Edits may be required for equivalency with the original model."""

import arcpy

\# To allow overwriting the outputs change the overwrite option to true.

arcpy.env.overwriteOutput $=$ False

\# Load required toolboxes

arcpy.ImportToolbox("Model Tools")

\# Script parameters

Input_Points $=$ arcpy.GetParameterAsText $(\theta)$ or

r"Palisades $\backslash$ Palisades_ShieldingInputPoints"

Wind_Direction_Field = arcpy.GetParameterAsText(1) or

"winddirection"

Ridgeline_Segments = arcpy.GetParameterAsText(2) or

r"Palisades $\backslash \mathrm{PalisadesRidgeline \_ Intersect"}$

Ridgeline_Clip_Polygon = arcpy.GetParameterAsText(3) or

"Palisades_AOI"

Output_Shielding_Points = arcpy.GetParameterAsText(4) or

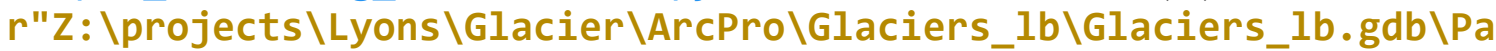

lisades_Shielding"

\# Local variables:

Updated_Input_Features $=$ Output_Shielding_Points

Palisades_Shielding = Output_Shielding_Points

windWithCoords_2_ = Updated_Input_Features

windWithCoords _ $3_{-}=$windWithCoords 2 
temp_WindMBR =

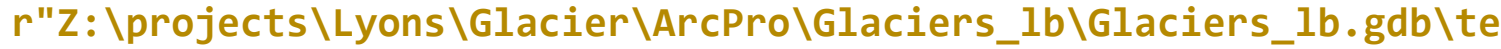
mp_WindMBR"

Extend_Distance $=$ temp_WindMBR

tempWindDirection_BearingDistanc_3 3 = windWithCoords_3_

tempWindDirection_BearingDistanc $=$

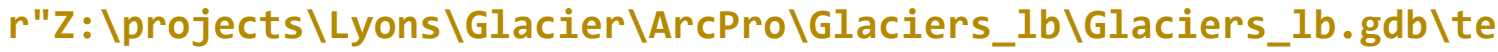
mpWindDirection_BearingDistanc"

temp_ridgeWindVect $=$

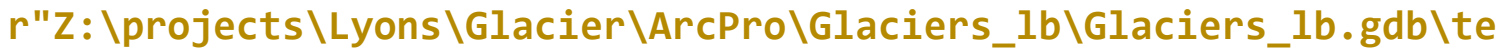
mp_ridgeWindVect"

temp_ridgeWindVect__2_ = temp_ridgeWindVect

temp_ridgeWindVect__3_ = temp_ridgeWindVect__2

Output_Lines =

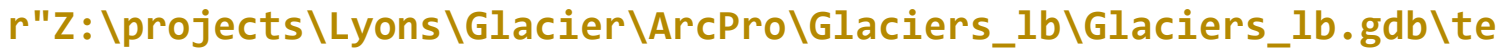
mpRidgeInfoLines"

DinwoodyShielding = Palisades_Shielding

Palisades_Shielding__ ${ }_{-}=$DinwoodyShielding

Shielding = Palisades_Shielding__2

\section{\# Process: Copy Features}

arcpy.CopyFeatures_management(in_features=Input_Points, out_feature_class=Output_Shielding_Points, config_keyword="", spatial_grid_1="", spatial_grid_2="", spatial_grid_3="")

\# Process: Add XY Coordinates

arcpy.AddXY_management(in_features=0utput_Shielding_Points)

\# Process: Add Field

arcpy.AddField_management(in_table=Updated_Input_Features, field_name="lineDist", field_type="DOUBLE", field_precision="", field_scale="", field_length="", field_alias="", field_is_nullable="NULLABLE", field_is_required="NON_REQUIRED", field_domain="")

\section{\# Process: Minimum Bounding Geometry}

arcpy.MinimumBoundingGeometry_management(in_features=Input_Points , out_feature_class=temp_WindMBR, geometry_type="CIRCLE", 
group_option="ALL", group_field="", mbg_fields_option="MBG_FIELDS")

\# Process: Get Field Value

arcpy.GetFieldValue_mb(in_table=temp_WindMBR, field="MBG_Diameter", data_type="Double", null_value="0")

\# Process: Calculate Field

arcpy.CalculateField_management(in_table=windWithCoords_2_, field="lineDist", expression="\%Extend Distance\%", expression_type="PYTHON3", code_block="")

\# Process: Bearing Distance To Line

arcpy.BearingDistanceToLine_management(in_table=windWithCoords_ 3 _, out_featureclass=tempWindDirection_BearingDistanc, $\bar{x}$ field $=$ =POINT_X", y field="POINT_Y", distance_field="lineDist", distance_units="METERS", bearing_field=Wind_Direction_Field, bearing_units="DEGREES", line_type="GEODESIC", id_field="ORIG_FID", spatial_reference="PROJCS[ 'NAD_1927_UTM_Zone_11N ", GEOGCS[ 'GCS_Nor th_American_1927 ' , DATUM[ 'D_North_American_1927' , SPHEROID[ 'Clarke_ 1866 ' , 6378206.4, 294.9786982] ], PRIMEM [ ' Greenwich ' , 0.0] , UNIT [ 'Degre e' , 0.0174532925199433] ], PROJECTION [ 'Transverse_Mercator' ], PARAMET ER [ 'False_Easting ' , 500000.0] , PARAMETER [ 'False_Northing ' , 0.0 ] , PARA METER ['Central_Meridian' , -

$117.0]$, PARAMETER [ 'Scale_Factor' ', 0.9996 ] , PARAMETER [ 'Latitude_Of_Or igin' , 0.0], UNIT['Meter' , 1.0] ];-5121000 -9998000

450450052.747599;-100000 10000;-100000

$10000 ; 0.001 ; 0.001 ; 0.001 ;$ IsHighPrecision")

\# Process: Join Field

arcpy.JoinField_management(in_data=tempWindDirection_BearingDista nc, in_field="ORIG_FID", join_table=windWithCoords_3_, join_field="ORIG_FID", fields="Elev_m;Slope;ppt;tmean;Aspect")

\# Process: Clip 
arcpy.Clip_analysis(in_features=tempWindDirection_BearingDistanc_ _3_, clip_features=Ridgeline_Clip_Polygon,

out_feature_class=temp_ridgeWindVect, cluster_tolerance="")

\# Process: Add Field (2)

arcpy.AddField_management(in_table=temp_ridgeWindVect, field_name="RidgeDist", field_type="DOUBLE", field_precision="", field_scale="", field_length="", field_alias="", field_is_nullable="NULLABLE", field_is_required="NON_REQUIRED", field_domain="")

\# Process: Calculate Geometry Attributes

arcpy.CalculateGeometryAttributes_management(in_features=temp_rid geWindVect_2_, geometry_property="RidgeDist LENGTH_GEODESIC", length_unit="METERS", area_unit="", coordinate_system="")

\# Process: Spatial Join

arcpy.SpatialJoin_analysis(target_features=temp_ridgeWindVect_3 , join_features=Ridgeline_Segments, out_feature_class=Output_Lines, join_operation="JOIN_ONE_TO_ONE", join_type="KEEP_ALL", field_mapping=r"POINT_X "POINT_X" true true false $\theta$ Double $\theta$

0,First,\#,Z: \projects\Lyons\Glacier\ArcPro\Glaciers_lb\Glaciers_1 b.gdb ttemp_ridgeWindVect,POINT_X,-1,-1;POINT_Y "POINT_Y" true true false $\theta$ Double $\theta$

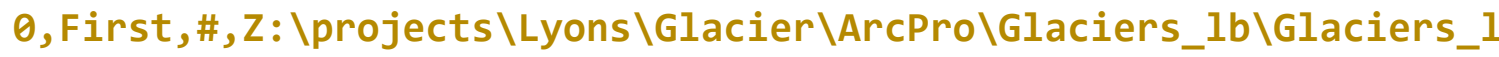
b.gdb temp_ridgeWindVect,POINT_Y,-1,-1;lineDist "lineDist" true true false $\theta$ Double $\theta$

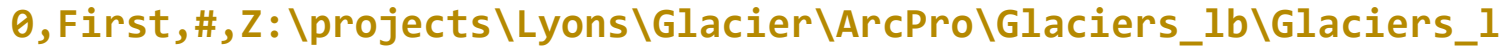
b.gdb \temp_ridgeWindVect, lineDist, -1, -1; winddirection

"winddirection" true true false $\theta$ Double $\theta$

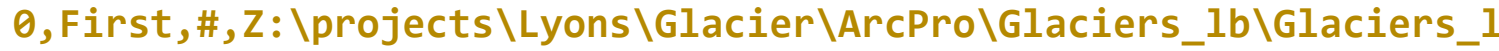
b.gdb temp_ridgeWindVect,winddirection,-1,-1;ORIG_FID "ORIG_FID" true true false $\theta$ Double $\theta$

0, First,\#,Z: \projects\Lyons\Glacier \ArcPro\Glaciers_lb\Glaciers_l b.gdb \temp_ridgeWindVect,ORIG_FID,-1,-1;Slope "Slope" true true false 8 Double $\theta$

0, First, \#,Z: \projects\Lyons\Glacier \ArcPro\Glaciers_lb\Glaciers_1 b.gdb\temp_ridgeWindVect,Slope,-1,-1;ppt "ppt" true true false 8 Double 0 
0,First, \#,Z: \projects\Lyons\Glacier\ArcPro\Glaciers_lb\Glaciers_l b.gdb \temp_ridgeWindVect,ppt,-1,-1; tmean "tmean" true true false 8 Double $\theta$

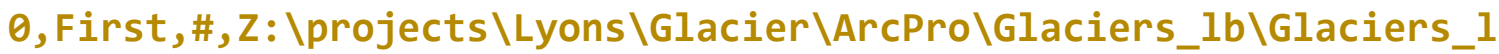
b.gdb\temp_ridgeWindVect,tmean,-1,-1; Shape_length "Shape_length" true true false $\theta$ Double $\theta$

0,First,\#,Z: \projects\Lyons\Glacier\ArcPro\Glaciers_lb\Glaciers_l b.gdb \temp_ridgeWindVect,Shape_Length, -1, -1; RidgeDist "RidgeDist" true true false $\theta$ Double $\theta$

0,First,\#,Z: \projects\Lyons\Glacier\ArcPro\Glaciers_lb\Glaciers_l b.gdb\temp_ridgeWindVect, RidgeDist, $-1,-1$; RidgeElev_m

"RidgeElev_m" true true false 4 Float $\theta$

0 , First, \#, Palisades $\backslash$ PalisadesRidgeline_Intersect, Elevation, -1, 1 ; RidgeSlope "RidgeSlope" true true false 4 Float $\theta$ 0 , First, \#, Palisades $\backslash$ PalisadesRidgeline_Intersect, Slope, -1, 1;RidgeAspect "RidgeAspect" true true false 4 Float $\theta$ 0 , First, \#, Palisades \PalisadesRidgeline_Intersect, Aspect, -1, 1;RidgeTemp "RidgeTemp" true true false 8 Double $\theta$ 0 , First, \#, Palisades\PalisadesRidgeline_Intersect, Temperature, -1, 1;RidgePrecip "RidgePrecip" true true false 8 Double $\theta$ 0, First, \#, Palisades $\backslash$ PalisadesRidgeline_Intersect, Precipitation, 1,-1;RidgeWindspeed "RidgeWindspeed" true true false 8 Double 0 0 , First, \#, Palisades $\backslash$ PalisadesRidgeline_Intersect, windspeed, -1, 1 ; RidgeWindDir "RidgeWindDir" true true false 8 Double $\theta$ 0 , First, \#, Palisades $\backslash$ PalisadesRidgeline_Intersect, winddirection, $1,-1 "$, match_option="INTERSECT", search_radius="", distance_field_name=" ")

\# Process: Join Field (2)

arcpy.Joinfield_management(in_data=Output_Shielding_Points, in_field="ORIG_FID", join_table=0utput_Lines, join_field="ORIG_FID", fields="RidgeElev_m;RidgeSlope;RidgeWindspeed;RidgeDist" )

\# Process: Add Fields (multiple)

arcpy.AddFields_management(in_table=Palisades_Shielding, field_description="RidgeElevDif DOUBLE \# \# \# \#;ShieldingVal DOUBLE \# \# \# \#")

\# Process: Calculate Field (2) 
arcpy.CalculateField_management(in_table=DinwoodyShielding, field="RidgeElevDif", expression="!RidgeElev_m!-!Elevation!", expression_type="PYTHON3", code_block="")

\# Process: Calculate Field (3)

arcpy.CalculateField_management(in_table=Palisades_Shielding_2_, field="ShieldingVal", expression="(!Slope! * !RidgeElevDif!) / !RidgeDist!", expression_type="PYTHON3", code_block="") 


\section{NP Mass Calculator}

\# - *- coding: utf-8 -*_

"""Generated by ArcGIS ModelBuilder on: 2019-08-05 17:59:41

All ModelBuilder functionality may not be exported. Edits may be required for equivalency with the original model."""

import arcpy

\# To allow overwriting the outputs change the overwrite option to true.

arcpy.env.overwriteOutput = False

\# Load required toolboxes

arcpy.ImportToolbox ("C:/Users/Jonah/Documents/ArcGIS/Projects/Mid dle Palisade/Middle Palisade.tbx")

\# Script parameters

Snow_on_Las_Dataset = arcpy.GetParameterAsText $(\theta)$ or "SNOW ON (April 2018).lasd"

Snow_off_LAS_Dataset = arcpy.GetParameterAsText(1) or "SNOW OFF (August 2014).lasd"

Snow_Area = arcpy.GetParameterAsText(2) or

$r " C: \backslash U s e r s \backslash J o n a h \backslash D o c u m e n t s \backslash A r c G I S \backslash P r o j e c t s \backslash M I P$

Deliverables\Middle Palisade Deliverables.gdb\PalisadeSnowArea"

Spatial_Resolution = arcpy.GetParameterAsText(3) or "100"

\# The value entered in the following parameter should be the ratio of snow density and water density multiplied by the conversion factor between cubic meters and Liters. Example: snow density / water density $=\left(625 \mathrm{~kg} / \mathrm{m}^{\wedge} 3\right) /\left(1000 \mathrm{~kg} / \mathrm{m}^{\wedge} 3\right) *(1000 \mathrm{~L}$ / $\left.1 \mathrm{~m}^{\wedge} 3\right)$. Since snow volume is reported in $\mathrm{m}^{\wedge} 3$, mass will be reported in $\mathrm{mg}$.

Product_of_the_ratio_of_Snow_Water_Densities_and_conversion_fac tor_of_cubic_meters_to_liters_L_m3_- = arcpy.GetParameterAsText(4) or "625" 
Total_Mass_Table $=$ arcpy.GetParameterAsText(5) or

$r " C: \backslash U s e r s \backslash J o n a h \backslash D o c u m e n t s \backslash A r c G I S \backslash P r o j e c t s \backslash M I P$

Deliverables \Middle Palisade Deliverables.gdb\Palisade_massModel"

\section{\# Local variables:}

Palisades_ShieldingInputPoints = "Palisade_inputpoints"

PalisadesRidgeline_Intersect = "PalisadesRidgeline_Intersect"

Palisades_AOI = "Palisades_AOI"

Palisades_Shielding $=$

$r " C: \backslash$ Users $\backslash$ Jonah \Documents \ArcGIS \Projects \MIP

Deliverables \Middle Palisade

Deliverables.gdb\Palisades_Shielding"

Palisades_Shielding_9_ = Palisades_Shielding

Palisades_Shielding_8_ = Palisades_Shielding_9

MIP_Deliverables $=r " C: \backslash$ Users $\backslash$ Jonah $\backslash$ Documents $\backslash$ ArcGIS $\backslash$ Projects $\backslash$ MIP

Deliverables"

Output_Folder = MIP_Deliverables

Output_Folder_2 $2_{-}$MIP_Deliverables

Snow_On_lasd $=r " C$ : \Users $\backslash$ Jonah \Documents $\backslash$ ArcGIS $\backslash$ Projects $\backslash M I P$

Deliverables\Middle Palisade Deliverables.gdb\Snow On.lasd"

SnowOn_DEM = r"C: $\backslash$ Users $\backslash$ Jonah $\backslash$ Documents $\backslash A r C G I S \backslash P r o j e c t s \backslash M I P$

Deliverables\Middle Palisade Deliverables.gdb\SnowOnraster"

Snow_Off_lasd $=r " C: \backslash$ Users $\backslash$ Jonah \Documents $\backslash$ ArcGIS $\backslash$ Projects $\backslash M I P$

Deliverables\Middle Palisade Deliverables.gdb\Snow Off.lasd"

SnowOff_DEM $=r " C: \backslash$ Users $\backslash$ Jonah \Documents $\backslash A r c G I S \backslash P r o j e c t s \backslash M I P$

Deliverables\Middle Palisade Deliverables.gdb\SnowOffraster"

$\mathrm{DHM}=r$ "C: $\backslash$ Users $\backslash$ Jonah \Documents $\backslash$ ArcGIS $\backslash P$ rojects $\backslash M I P$

Deliverables\Middle Palisade Deliverables.gdb\DHM"

Output_raster $=r " \mathrm{C}: \backslash$ Users $\backslash$ Jonah $\backslash$ Documents $\backslash A r c G I S \backslash P r o j e c t s \backslash M I P$

Deliverables\Middle Palisade Deliverables.gdb\Extract_DHM"

DHM nonegatives $=r " C$ : \Users $\backslash$ Jonah \Documents $\backslash$ ArcGIS $\backslash P r o j e c t s \backslash M I P$

Deliverables\Middle Palisade Deliverables.gdb\DHM_nonegatives"

Volume_Raster $=r " C: \backslash$ Users $\backslash$ Jonah $\backslash$ Documents $\backslash$ ArcGIS $\backslash$ Projects $\backslash M I P$

Deliverables \Middle Palisade Deliverables.gdb\VolumeRaster"

Predicted_Concentration =

$r " C: \backslash$ Users $\backslash$ Jonah \Documents \ArcGIS \Projects \MIP

Deliverables \Middle Palisade

Deliverables.gdb\Predicted_Concentration_IDW"

PredictedConcentration_negativestozero =

$r " C: \backslash$ Users $\backslash$ Jonah \Documents \ArcGIS \Projects \MIP

Deliverables\Middle Palisade

Deliverables.gdb\PredictedConcentration_negativestozero" 
Volume_snowandwaterdensities =

$r " C: \backslash U s e r s \backslash J o n a h \backslash D o c u m e n t s \backslash A r c G I S \backslash P r o j e c t s \backslash M I P$

Deliverables \Middle Palisade

Deliverables.gdb\Volume_snowandwaterdensities"

Mass_Raster $=r " C: \backslash U$ sers $\backslash$ Jonah $\backslash$ Documents $\backslash$ ArcGIS $\backslash$ Projects $\backslash$ MIP

Deliverables\Middle Palisade Deliverables.gdb\MassRaster"

\# Process: Get Shielding Value ORIGINAL

arcpy.Model4_MiddlePalisade(Input_Points=Palisades_ShieldingInput Points, Wind_Direction_Field="winddirection", Ridgeline_Segments=PalisadesRidgeline_Intersect, Ridgeline_Clip_Polygon=Palisades_AOI, Output_Shielding_Points=Palisades_Shielding)

\# Process: Add Field (4)

arcpy.AddField_management(in_table=Palisades_Shielding, field_name="PredictedConcentration", field_type="DOUBLE", field_precision="", field_scale="", field_length="", field_alias="PredictedConcentration", field_is_nullable="NULLABLE", field_is_required="NON_REQUIRED", field_domain="")

\# Process: Calculate Field (5)

arcpy.CalculateField_management(in_table=Palisades_Shielding_9_, field="PredictedConcentration", expression=" -

$0.037 *$ math. $\log ($ !ShieldingVal!)+0.1232",

expression_type="PYTHON3", code_block="")

\# Process: Snow-on Area

arcpy.ExtractLas_3d(in_las_dataset=Snow_on_Las_Dataset, target_folder=MIP_Deliverables, extent=r"Palisade\PSnowArea", boundary=Snow_Area, process_entire_files="PROCESS_EXTENT", name_suffix="", remove_vlr="MAINTAIN_VLR", rearrange_points="REARRANGE_POINTS", compute_stats="COMPUTE_STATS", out_las_dataset=Snow_On_lasd, compression="SAME_AS_INPUT") 


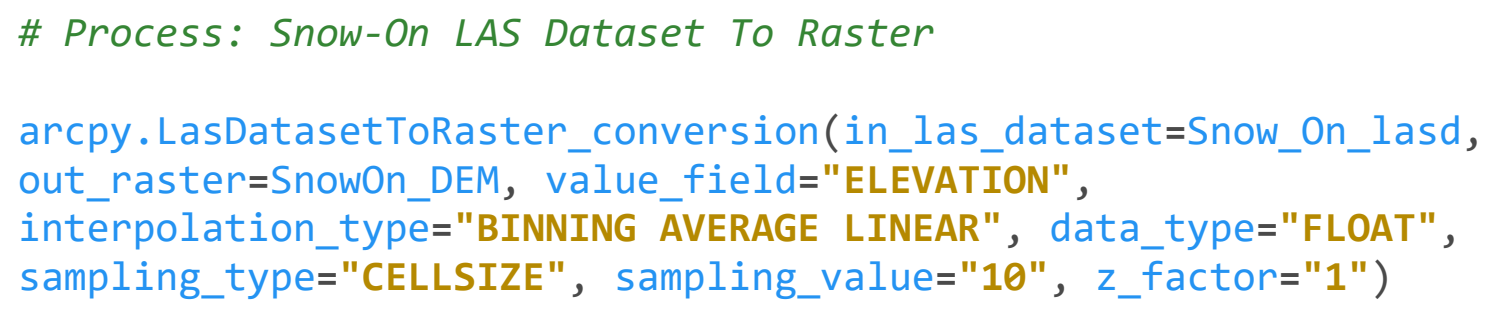

\section{\# Process: Minus}

arcpy.Minus_3d(in_raster_or_constant1=SnowOn_DEM, in_raster_or_constant2=SnowOff_DEM, out_raster=DHM)

\# Process: Extract by Mask

tempEnvironmento = arcpy.env. extenttempEnvironment0 = arcpy.env.extentarcpy.gp.ExtractByMask_sa(in_raster=DHM, in_mask_data=Snow_Area, out_raster=0utput_raster) arcpy.env.extent = tempEnvironmento

\section{\# Process: Set Null}

arcpy.SetNull_ia(in_conditional_raster=0utput_raster, in_false_raster_or_constant=0utput_raster, out_raster=DHM_nonegatives, where_clause="VALUE < 0 ") 
\# Process: Times

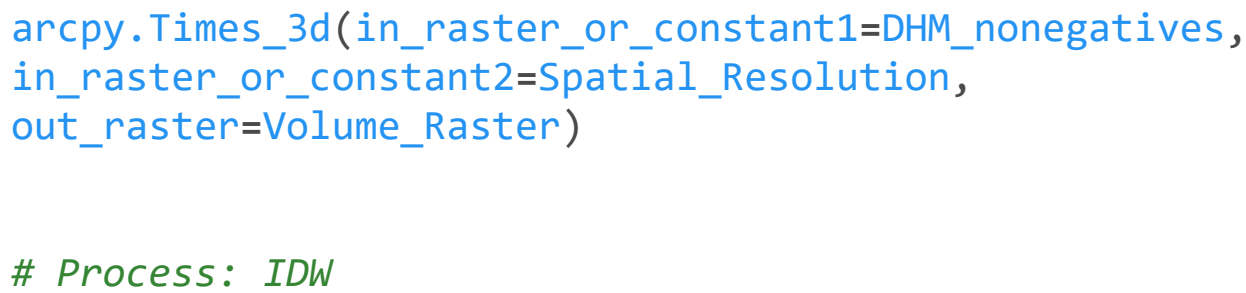

\# Process: Times (3)

arcpy.Times_3d(in_raster_or_constant1=Volume_Raster, in_raster_or_constant2=Product_of_the_ratio_of_Snow_Water_Densi ties_and_conversion_factor_of_cubic_meters_to_liters__L_m3_, out_raster=Volume_snowandwaterdensities)

\section{\# Process: Mass times Volume}

arcpy.Times_3d(in_raster_or_constant1=PredictedConcentration_nega tivestozero, in_raster_or_constant2=Volume_snowandwaterdensities, out_raster=Mass_Raster)

\# Process: Zonal Statistics as Table 
arcpy.gp.ZonalStatisticsAsTable_sa(in_zone_data=Snow_Area, zone_field="OBJECTID", in_value_raster=Mass_Raster, out_table=Total_Mass_Table, ignore_nodata="DATA", statistics_type="SUM") 